\title{
Protein modification via mild photochemical isomerization of triazenes to release aryl diazonium ions
}

\section{Supporting Information}

Garrett J. Davis, Julia A. Townsend, Madeline G. Morrow, Mohamed Hamie, Abigail J. Shepard, Chih-Chieh Hsieh, Michael T. Marty, and John C. Jewett*

Department of Chemistry and Biochemistry University of Arizona, Tucson, AZ 85721

*corresponding author. E-mail: jjewett@email.arizona.edu 


\section{Table of Contents}

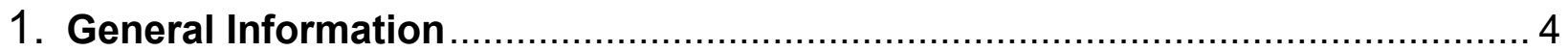

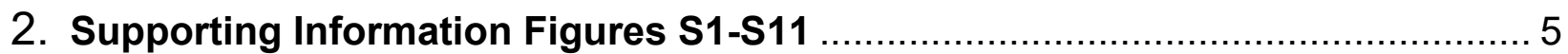

S1. Yields of various piperidine triazenes ................................................... 5

S2. Yields of $\mathbf{2} \mathbf{g}$ from triazene derived from various cyclic amines..................... 6

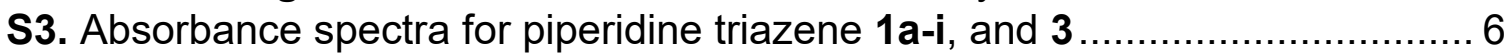

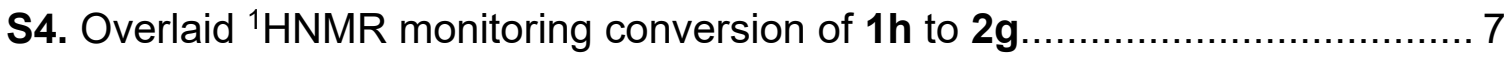

S5. Synthesis 3-ethynyl piperidine triazene (3) .......................................... 8

S6. Synthesis and characterization of ethynyl-resorcinol azo-adduct (4) ............ 8

S7. Pre-acidification of $\mathbf{3}$ for labeling of BSA ............................................... 9

S8. UV irradiation of $\mathbf{3}$ for labeling of BSA .............................................. 10

S9. Quantifying mods by 3 following increasing irradiation time ..................... 11

S10. Quantifying mods by 3 following pre-acidification................................. 12

S11. Determining optimal pH for UV initiated labeling of MSP by $3 \ldots \ldots \ldots \ldots \ldots \ldots . \ldots 12$

3. Synthetic procedures and characterization of triazene .................................. 13

General synthesis of triazene scaffold ...................................................... 13

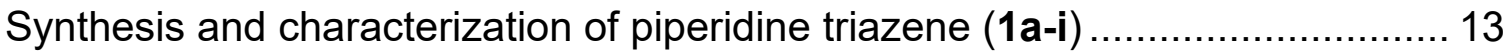

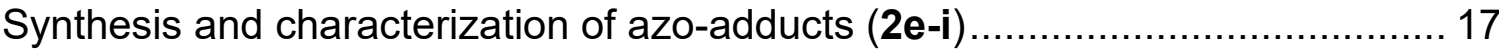

Synthetic protocol and characterization of 3-ethynyl triazene (3) ................... 22

Synthetic protocol and characterization of ethynyl-resorcinol azo-adduct (4) ....22

Synthesis of additional novel piperidine triazenes (S1-S2) .......................... 23

Synthesis \& characterization of triazenes from various cyclic amines (S3-S5)... 24

Synthesis and characterization of pyrrolidine triazenes (S7-S10)................... 26

SI Table 1. Yields of various 1-phenyl diazinyl pyrrolidine triazenes ................. 27

4. Evaluation of azo-adducts formation - Low pH \& UV irradiation ...................... 28

Protocol for triazene reactivity with resorcinol in citrate buffer $(\mathrm{pH} 4) \ldots \ldots \ldots \ldots \ldots . . .28$

Protocol for triazene reactivity with resorcinol under UV irradiation $(\mathrm{pH} 7) \ldots \ldots . .28$

Figure S12. Percent yield of azo-adduct vs. substituent Hammett Value .......... 29

5. Effect of cyclic secondary amine on diazonium ion release .............................30

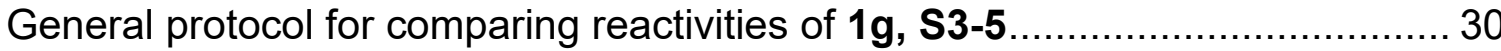

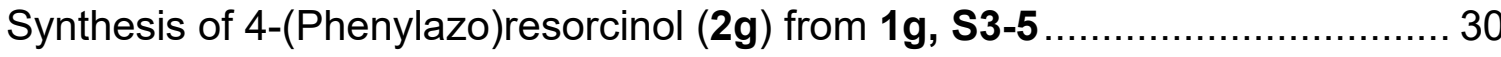

6. Determining mechanism of UV initiated diazonium ion release ...................... 31

Protocol for measuring $\Delta \mathrm{pH}$ upon irradiation of triazene water solutions ......... 31

7. Kinetic Experiments with $\boldsymbol{p}$-methyl piperidine triazene .................................. 32

Protocol for ${ }^{1} \mathrm{HNMR}$ kinetics of $\mathbf{1 h}$ upon irradiation ....................................... 32

Figure S13. Overlaid ${ }^{1} \mathrm{HNMR}$ focused on $\mathbf{1 h}$ and $\mathbf{2 h}$ methyl peaks .................. 32

Figure S14. Natural log plot of $1 \mathrm{~h}$ concentration vs. irradiation time ................ 33

Procedure for plotting natural log of $1 \mathrm{~h}$ concentration vs. irradiation time ......... 33

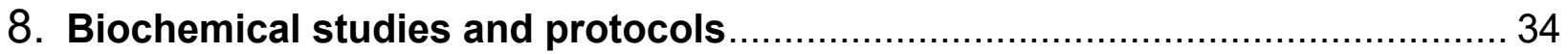

Confirmation of azo-modification by sodium dithionite reduction - (Figure 4B) . 34 
Confirmation of azo-modification by resorcinol competition during lysozyme labeling - (Figure 4C) .................................................................................... 34

Time point assessment for pre-acidification treatment of BSA with $\mathbf{3}$ - (Figure S7) 35

Reactivity of $\mathbf{3}$ with BSA upon UV irradiation - (Figure S8) ................................. 35

SDS-PAGE time point assessment of 3 labeling of MSP - (Figure 5A) ..............35 Assessment of diazonium ion stability with and without UV irradiation - (Figure 5B) 36 Native MS evaluation of MSP treatment by 3 under increasing UV irradiation times

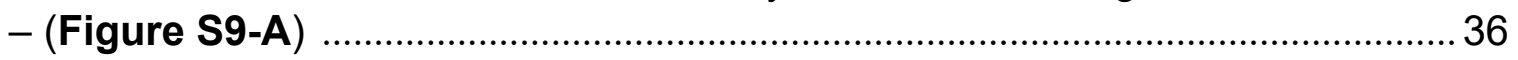

Quantification of protein band fluorescence - (Figure S9-B) ............................... 37

Labeling of MSP with pre-acidified 3 - (Figure S10) ........................................... 37

Determining optimal pH for 3 labeling of MSP via UV irradiation - (Figure S11)

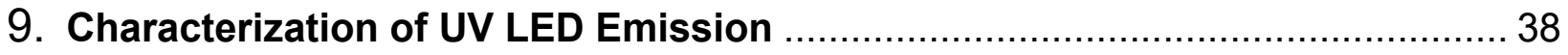

General protocol for determination of emission max.............................................38

Figure S15. Emission maximum for LED UV source.............................................38

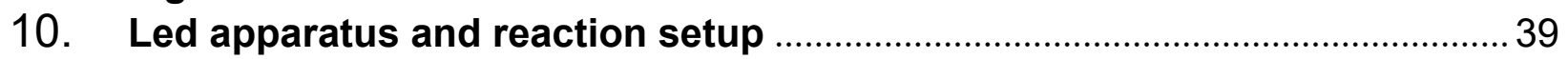

Figure S16. View of LED source and reaction progression.....................................39

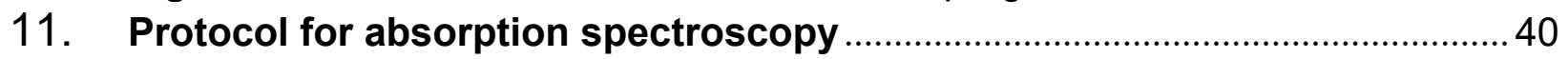

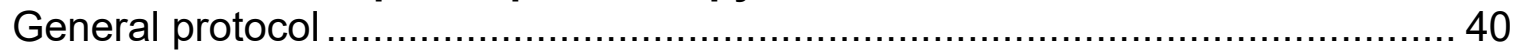

Absorbance for compounds S3-5 ……............................................... 40

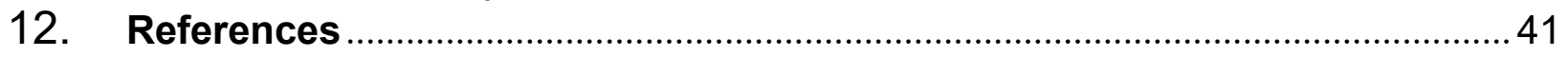

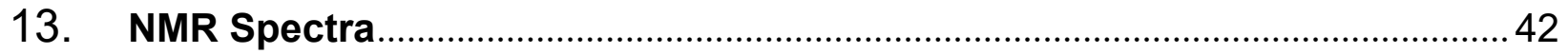

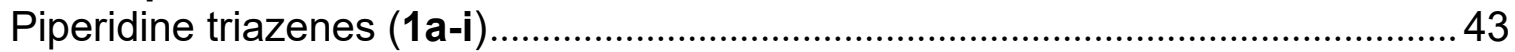

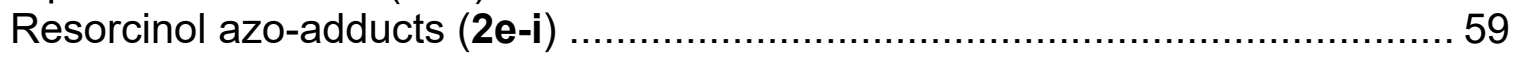

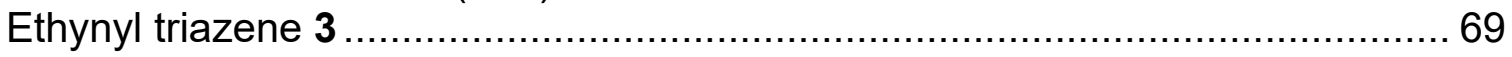

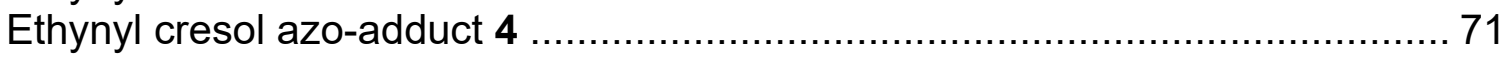

Novel piperidine triazenes (S1-2) ................................................... 73

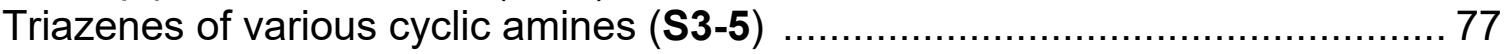

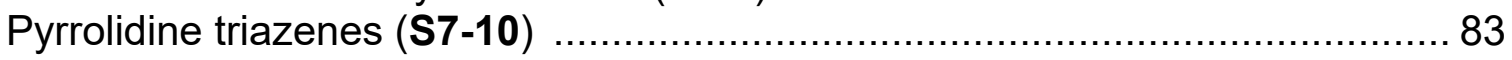




\section{General Information}

\section{Synthesis \& Characterization}

Anilines, piperidine, morpholine, pyrrolidine, acids along with all organic solvents were all commercially purchased and used as received.

NMR spectra were taken on a Bruker AVIII-400 NMR Spectrometer for ${ }^{1} \mathrm{H}$ and ${ }^{13} \mathrm{C}$ NMR and referenced with residual solvent peaks at $7.26 \mathrm{ppm}$ and $77.05 \mathrm{ppm}$ for $\mathrm{CDCl}_{3}, 2.50$ and 39.52 for DMSO. Coupling on the NMR spectra is expressed in Hertz, chemical shifts in ppm, with abbreviations for multiplicities reported as $\mathrm{s}=$ singlet, $\mathrm{bs}=$ broad singlet, $w s=$ weak singlet, $d=$ doublet,$t=$ triplet, $q=$ quartet,$m=$ multiplet. Mass spectra were obtained using a Thermo LTQ Orbitrap Velos with an ion trap mass analyzer. Absorbance spectra were obtained using an Agilent 8453 UV-visible spectroscopy system. Infrared spectra were obtained using a Thermo Fisher Scientific Nicolet IS50R FT-IR spectrometer equipped with an MCT-A detector and a germanium spectratech thunderdome ATR accessory with signals reported as $\mathrm{w}=$ weak, $\mathrm{br}=$ broad, $\mathrm{s}=$ strong. Native Mass Spectrometry was performed in positive-ion mode using borosilicate nano-electrospray ionization needles pulled using a P-1000 micropipette puller (Sutter Instrument, Novato, CA). Instrumental parameters applied include $1.1 \mathrm{kV}$ spray voltage, $50 \mathrm{~V}$ source voltage, and $50 \mathrm{~V}$ collisional voltage. The $\mathrm{pH}$ probe (Thermo Scientific Orion) was connected through an electrode amplifier (Vernier Software Technology) to a laptop. Logger Pro 3.9 was used to calibrate the $\mathrm{pH}$ probe and to record all $\mathrm{pH}$ values versus time. UV irradiation of samples was performed using a 2watt (170 v) Sunlite 365 nm A19 UV LED lamp (80114-SU). Note: actual maximum excitation was observed at $370 \mathrm{~nm}$.

\section{Biochemical}

Buffers were made appropriately using commercially purchased salts and nanopore water using recipe derived from AAT Bioquest buffer recipe tool. ${ }^{1,2,3}$ They were checked for proper $\mathrm{pH}$ prior to experimental use by a Thermo Scientific Orion $\mathrm{pH}$ probe. BSA stocks were made from commercially purchased lyophilized powder (Sigma Aldrich, CAS: 904846- 8). MSP1D1T2 protein (MSP) was supplied by the lab of Michael T. Marty following expression and purification by methods previously described. ${ }^{4}$ Modified protein samples and controls were analyzed by SDS-PAGE on a $12 \%$ acrylamide resolving gel. Samples were treated with 1:1 ratio of 2X Laemmli sample buffer from Sigma Aldrich (Item S3401) containing $4 \%$ SDS, $20 \%$ glycerol, $10 \%$ 2- mercaptoethanol, $0.004 \%$ bromophenol blue, and $0.125 \mathrm{M}$ Tris $\mathrm{HCl} \mathrm{pH}$ 6.8. Alexa fluor ${ }^{\mathrm{TM}} 488$ azide was purchased from Thermo-Fisher Scientific (Catalog number: A10266). Fluorescent imaging was performed with a

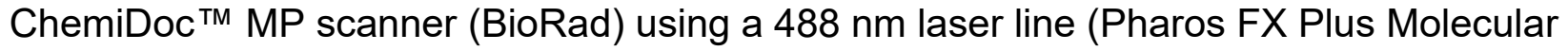
Imager) with a $535 \mathrm{~nm}$ filter. Coomassie staining was imaged using the same scanner. 


\section{Supporting Information Figures}

Yields of various piperidine triazenes

A.

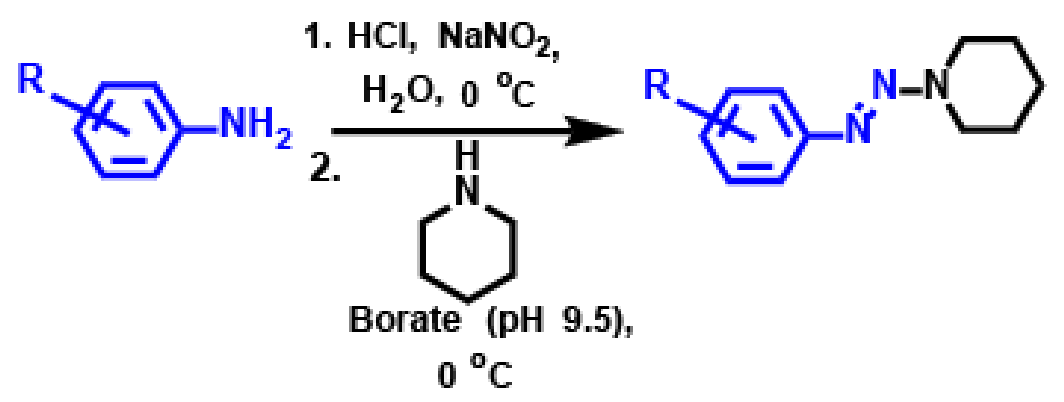

\begin{tabular}{l|l|l|l}
$\begin{array}{c}\text { Briazene } \\
\#\end{array}$ & \multicolumn{1}{|c|}{$\mathrm{R}$ Group } & $\begin{array}{c}\text { Hammett } \\
\text { Value }\end{array}$ & $\begin{array}{c}\text { Yield } \\
\%\end{array}$ \\
\hline $1 \mathrm{a}$ & $p-\mathrm{NO}_{2}$ & +0.78 & 99 \\
$\mathrm{~S} 1$ & $m-\mathrm{NO}_{2}$ & +0.71 & 99 \\
$1 \mathrm{~b}$ & $p-\mathrm{CN}$ & +0.66 & 99 \\
$1 \mathrm{c}$ & $p-\mathrm{CF}_{3}$ & +0.54 & 54 \\
$\mathrm{~S} 2$ & $p-\mathrm{COOH}$ & +0.41 & 99 \\
$1 \mathrm{~d}$ & $p-\mathrm{CONHCH}$ & +0.36 & 99 \\
$1 \mathrm{e}$ & $p-\mathrm{Br}$ & +0.23 & 83 \\
1f & $m-\mathrm{OCH}_{3}$ & +0.15 & 77 \\
$1 \mathrm{~g}$ & $\mathrm{H}$ & 0.00 & 82 \\
1h & $p-\mathrm{CH}_{3}$ & -0.17 & 31 \\
$1 \mathrm{i}$ & $p-\mathrm{OCH}_{3}$ & -0.27 & 56
\end{tabular}

Figure S1. (A) General scheme for the synthesis of phenyldiazenyl triazene scaffold via diazotization of various anilines and treatment of piperidine in alkaline solutions. (B) The respective yields of triazenes with varying aryl substituents compared to their Hammett values. 
Yields of $\mathbf{2 g}$ from triazene derived from various cyclic amines

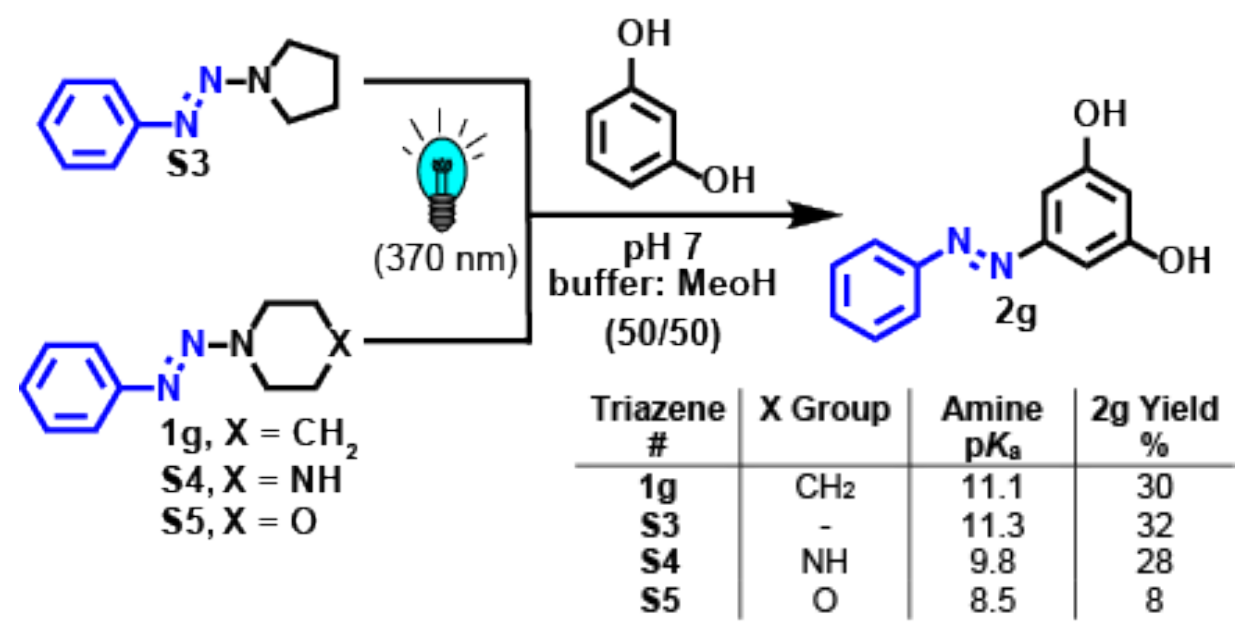

Figure S2. General scheme for the synthesis of $\mathbf{2 g}$ via irradiation of triazenes made from various cyclic amines. Yields were calculated and displayed relative to the $\mathrm{pK}_{\mathrm{a}}$ of the cyclic amine within the triazene scaffold. Overall, the lower the $\mathrm{pK}_{\mathrm{a}}$ of the cyclic amine in the scaffold, the lower the yield of $\mathbf{2 g}$, insinuating that release of the protected aryl diazonium ion can be tuned by the relative basicity of the cyclic amine in the scaffold.

\section{Absorbance spectra for piperidine triazene $\mathbf{1 a}-\mathbf{i}$, and $\mathbf{3}$}

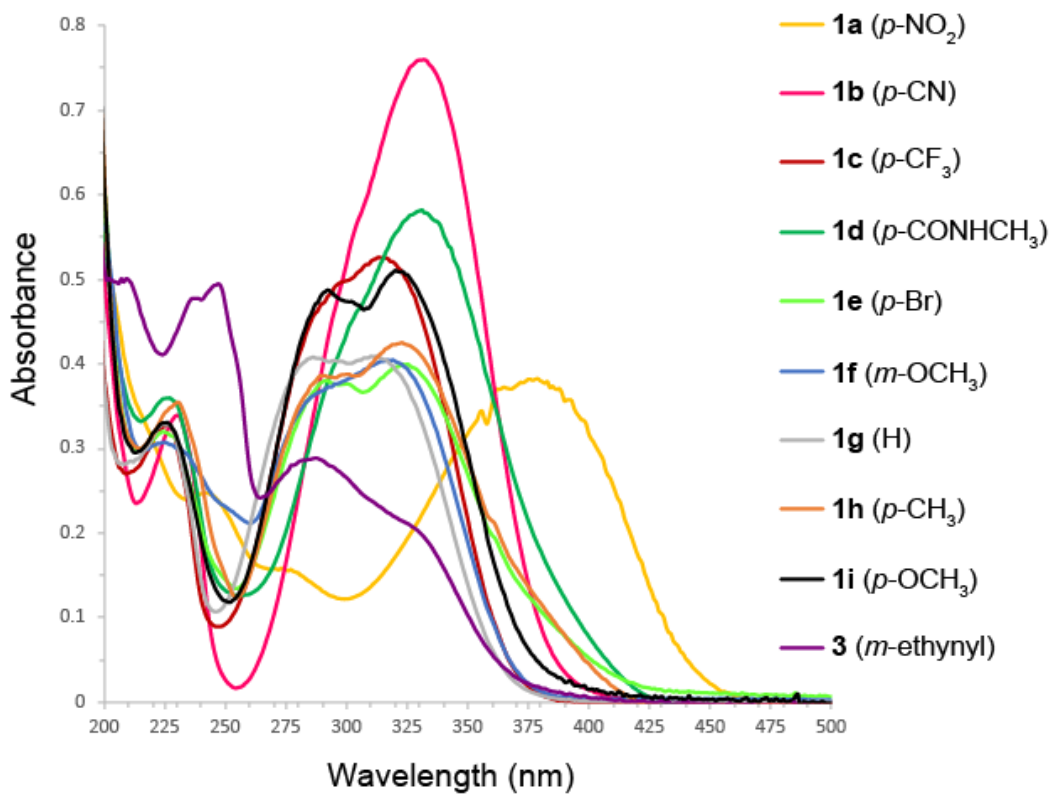

Figure S3. Overlaid absorbance profile for piperidine triazenes 1a-i, and 3.

Compounds were dissolved in stocks of $\mathrm{MeOH}$ and were diluted into a 50/50 mixture of $0.1 \mathrm{M} \mathrm{PBS} \mathrm{pH} 7$ and $\mathrm{MeOH}$. Final triazene concentration was $0.0492 \mathrm{mM}$. 
Overlaid ${ }^{1} H N M R$ monitoring conversion of $\mathbf{1 h}$ to $\mathbf{2 h}$

A.
(e) $\stackrel{\text { (i) }}{\overbrace{N}-N}$
(b) (h)
(i) 1 equiv.
(c)
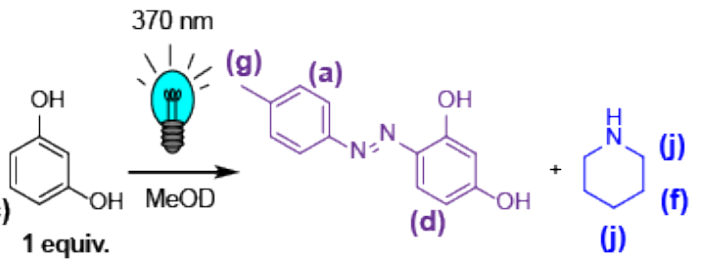

B.

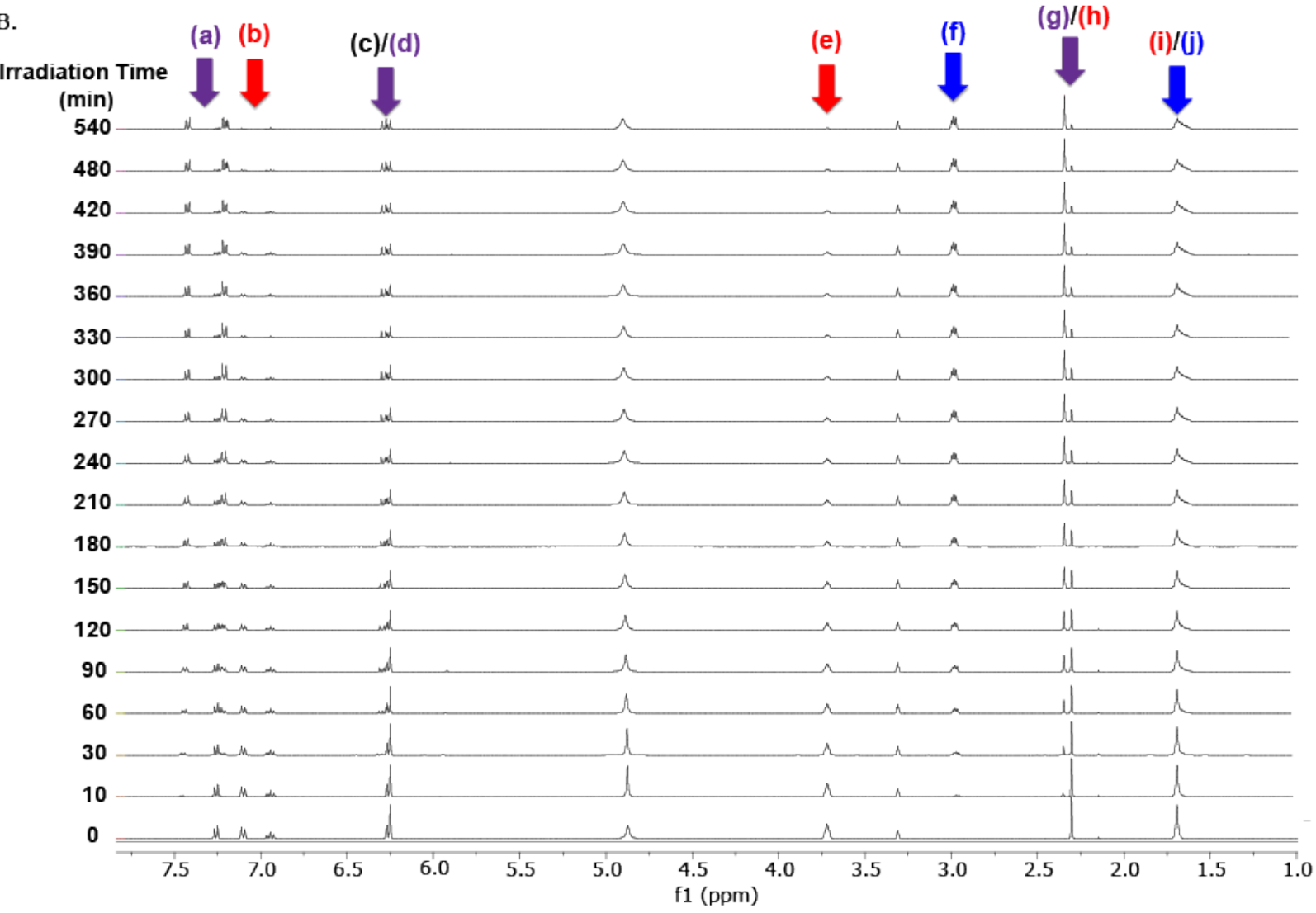

Figure S4. (A) Reaction scheme for the ${ }^{1} \mathrm{HNMR}$ Kinetics experiment using 1 equiv. of $1 \mathrm{~h}$ and 1 equiv. of resorcinol in deuterated methanol. (B) Overlaid ${ }^{1}$ HNMR scans showing product conversion from triazene $1 \mathrm{~h}$ to azo-adduct $\mathbf{2 h}$ over 540 minutes of irradiation. Proton signals are labeled and color-coded with letters associated with protons labeled within their corresponding structure. (red) 1h, (black) resorcinol, (purple) 2h, (blue) piperidine. 
Synthesis 3-ethynyl piperidine triazene (3)

1. $\mathrm{HCl}, \mathrm{NaNO}_{2}, \mathrm{H}_{2} \mathrm{O}$,

$30 \mathrm{~min}, 4{ }^{\circ} \mathrm{C}$

2. Borate buffer $(\mathrm{pH} 9.5)$

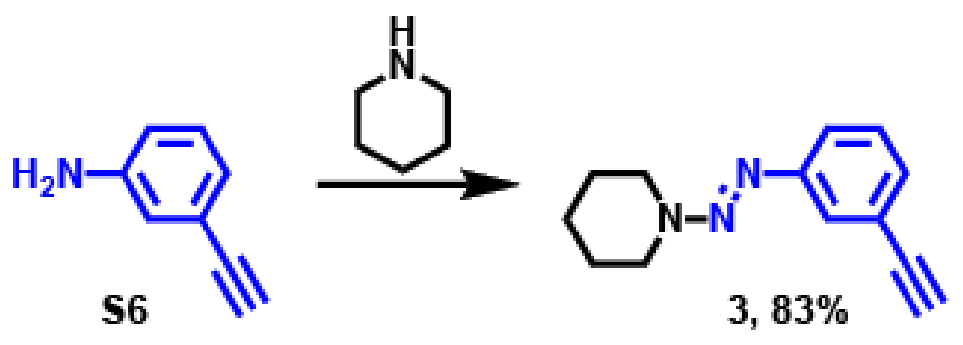

Figure S5. 3-ethynyl piperidine triazene (3) was synthesized via a two-step procedure. In the first step, 3-ethynyl aniline (S6) was diazotized by dissolving the aniline in a mixture of water and $\mathrm{HCl}$, followed by the addition of excess sodium nitrite. After 20-30 minutes of diazotization on ice $\left(4^{\circ} \mathrm{C}\right)$, the reaction mixture was added over to a borate buffer solution ( $\mathrm{pH}$ 9.5) containing excess piperidine. Following filtration of the resulting precipitate, we attained an $83 \%$ yield of 3 .

Synthesis and characterization of ethynyl-resorcinol azo-adduct (4)

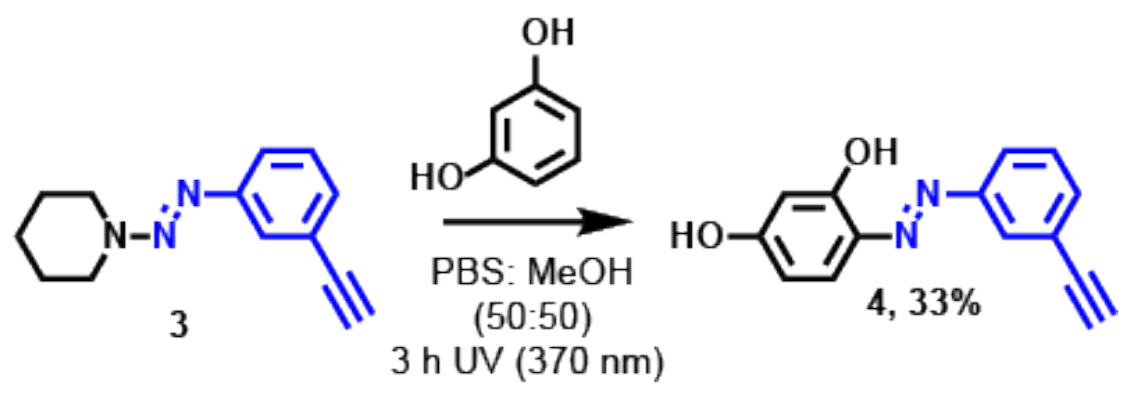

Figure S6. Treatment of 3-ethynyl triazene 3 with 1 equivalence of resorcinol in 50/50 mixture of $0.1 \mathrm{M} \mathrm{PBS}(\mathrm{pH} \mathrm{7})$ and methanol in the presence of $370 \mathrm{~nm}$ irradiation for 3 hours. Reaction yielded $33 \%$ of the desired ethynyl azo-adduct (4). 
Pre-acidification of $\mathbf{3}$ for labeling of BSA

A. Pre-acidification

Step 1<smiles>C#Cc1cccc(N=NN2CCCCC2)c1</smiles>

Step 2

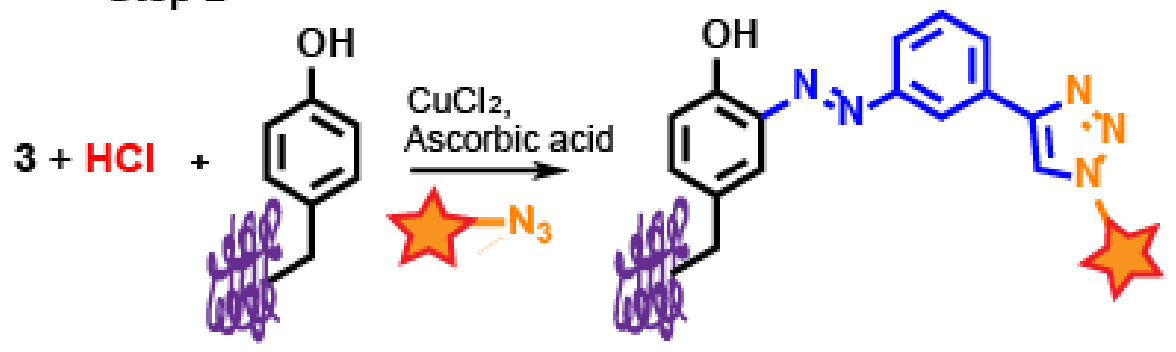

B.

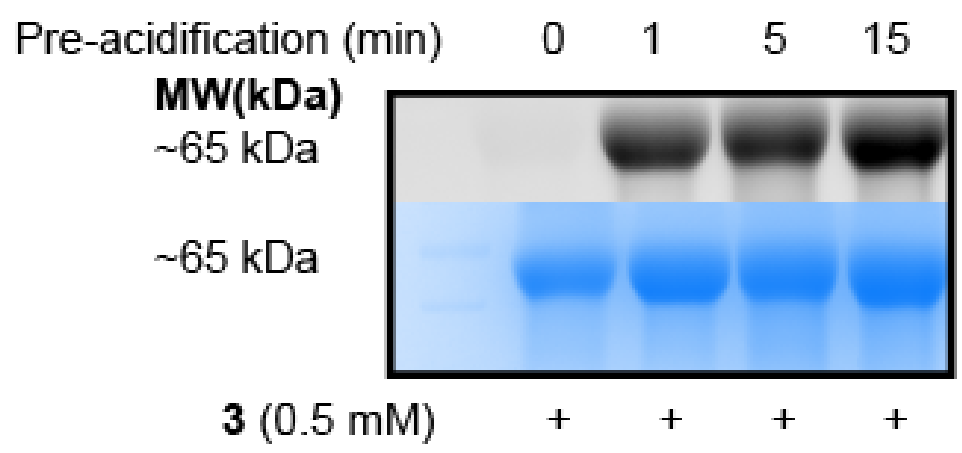

Figure S7. (A) Scheme showing pre-acidification process and subsequent treatment of protein. 3 is pre-acidified with $\mathrm{HCl}$ resulting in the liberated aryl diazonium ion. Next, the solution is transferred to a protein sample and allowed to incubate. Lastly, 'copper click' is performed resulting in covalent modification by the fluorescent azide (orange star). (B) SDS-PAGE analysis of BSA treated with $0.5 \mathrm{mM} 3$ that had been pre-treated with $\mathrm{HCl}(\sim \mathrm{pH} 1)$ for various time points (0-15 $\mathrm{min})$. 


\section{UV irradiation of 3 for labeling of BSA}

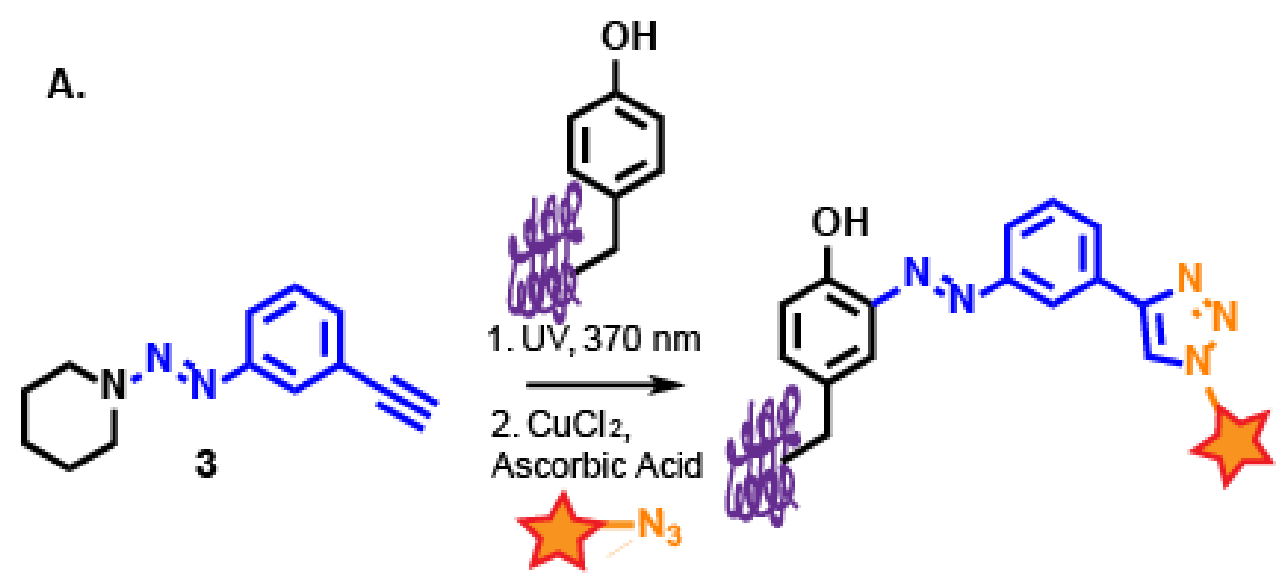

B.

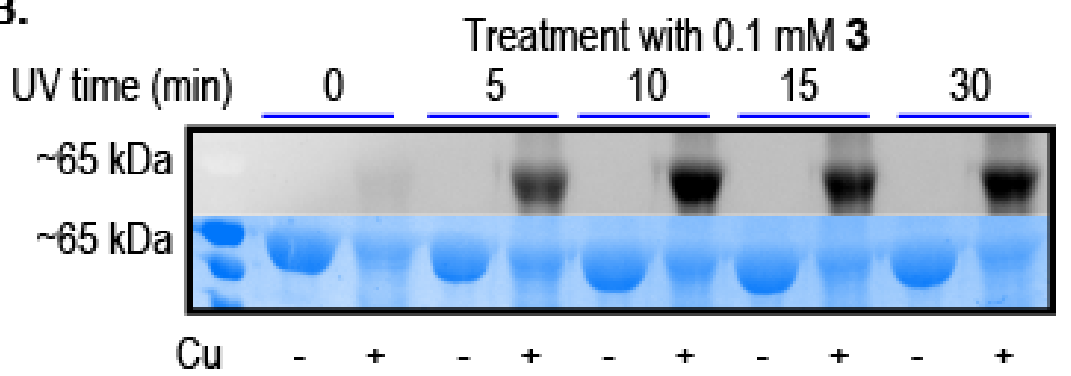

Figure S8. (A) General scheme for treatment of protein (BSA) with 3 followed by UV irradiation resulting in azo-modification. After irradiation, addition of 'copper-click' reagents copper chloride, ascorbic acid and the fluorescent azide (AlexaFluor ${ }^{\mathrm{TM}} 488$ azide) resulted in fluorescence modification of the labeled protein. (B) SDS-PAGE analysis of BSA treated with $0.1 \mathrm{mM}$ of 3 and subsequently irradiated for time points of $0,5,10,15$ and 30 minutes. Robust fluorescence was seen in as little as 5 minutes of irradiation. Coomassie stain was used to confirm the presence of BSA. 
Quantifying mods by 3 following increasing irradiation time
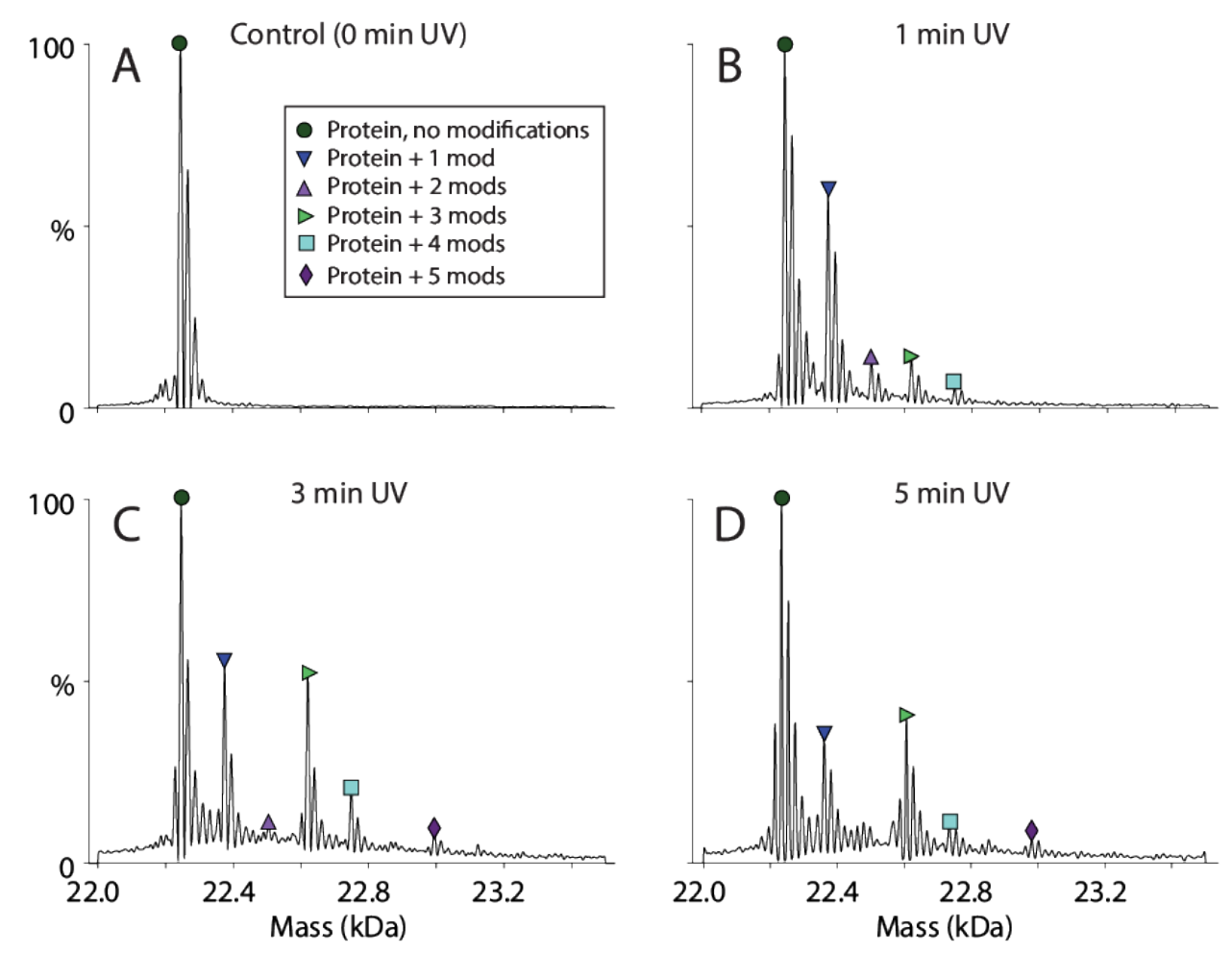

E.

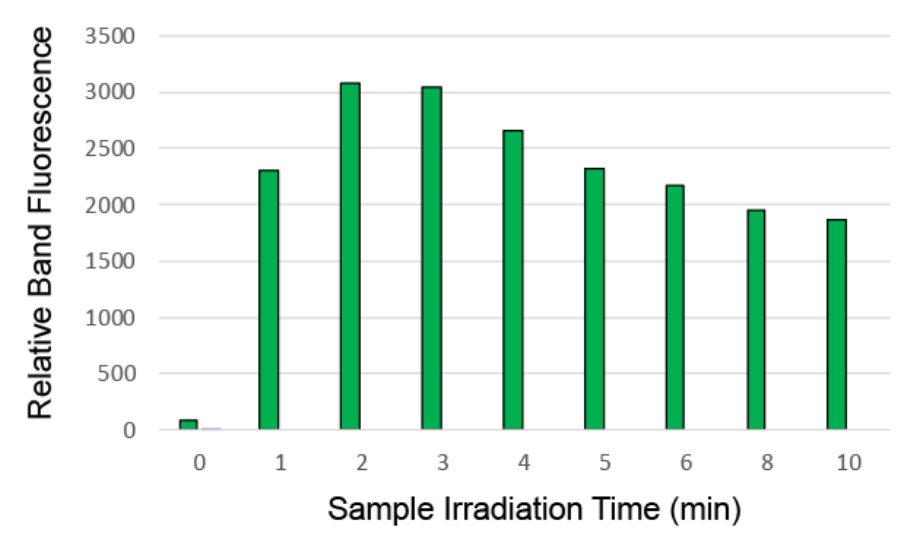

Figure S9. Spectra from native mass spec analysis of MSP treated with $0.5 \mathrm{mM} 3$ and irradiated for increasing time points. (A) Control sample of MSP with $0.5 \mathrm{mM} 3$ without irradiation. (B) MSP following 1 minute of irradiation with $0.5 \mathrm{mM}$ 3. (C) MSP following 3 minutes of irradiation with 3. (D) MSP following 5 minutes of irradiation with 3. Maximal number of modifications was observed after 3 minutes of irradiation (5-6 mods, $129 \mathrm{Da}$ each). At 5 minutes of irradiation the percent of modifications diminished noticeably for all number of mods. (E) Quantification of MSP band fluorescence following evaluation by SDS-PAGE. MSP was treated with $0.5 \mathrm{mM} 3$ and irradiated for increasing amounts of time by our $370 \mathrm{~nm}$ LED UV light.

Fluorescence quantification was performed using ImageJ software and plotted as a function of irradiation time. 
Quantifying mods by 3 following pre-acidification

A. Control Sample

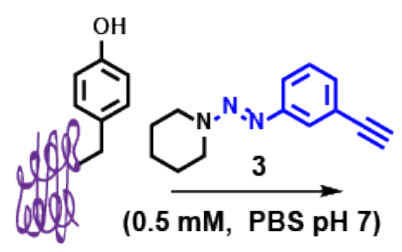

No Modifications

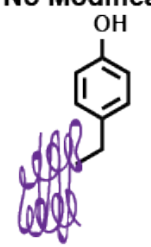

B.

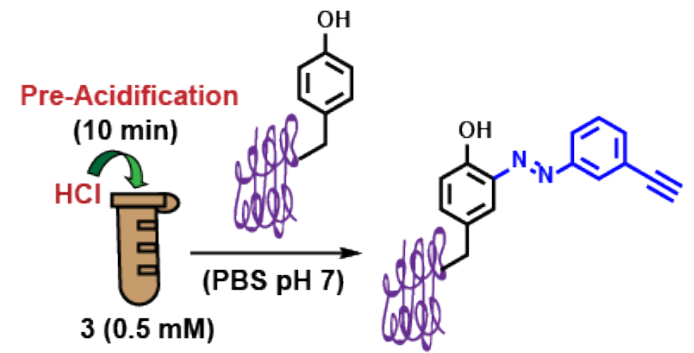

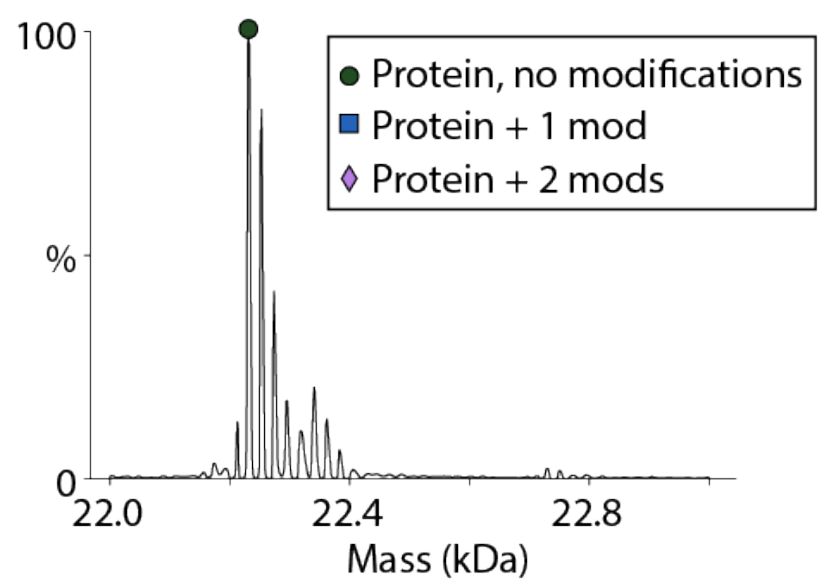

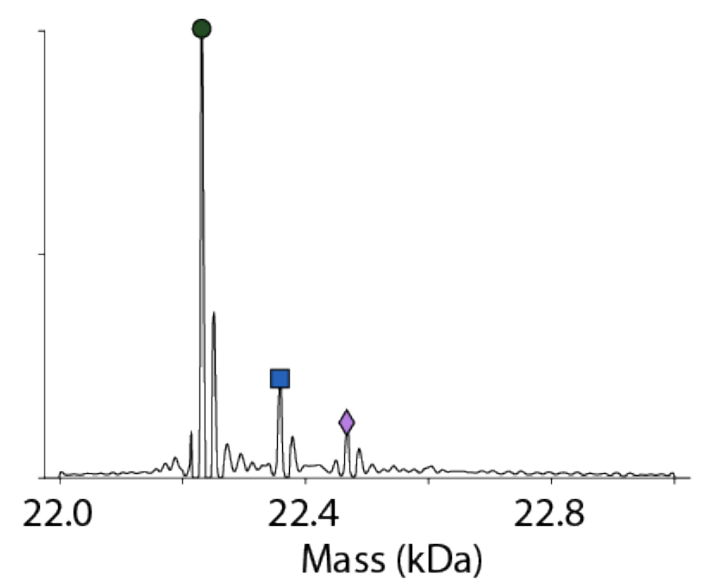

Figure S10. Spectra for MSP treated with $0.5 \mathrm{mM} 3$ with and without pre-acidification with $\mathrm{HCl}$. (A) Control sample containing MSP protein along with $0.5 \mathrm{mM}$ of intact 3 . Overnight incubation resulted in no modifications. (B) Treatment of MSP following preacidification of 3 yielded up to 2 modifications of $\sim 129 \mathrm{Da}$ each, consistent with the expected azo-modification mass. Notably, the overall number and percent of modifications by pre-acidified 3 (2-mods) was substantially lower than samples irradiated in the presence of 3 (5-6 mods) even after 10 minutes of pre-acidification, compared to 3 minutes of irradiation (Figure S9).

Determining optimal $\mathrm{pH}$ for UV initiated labeling of MSP by 3

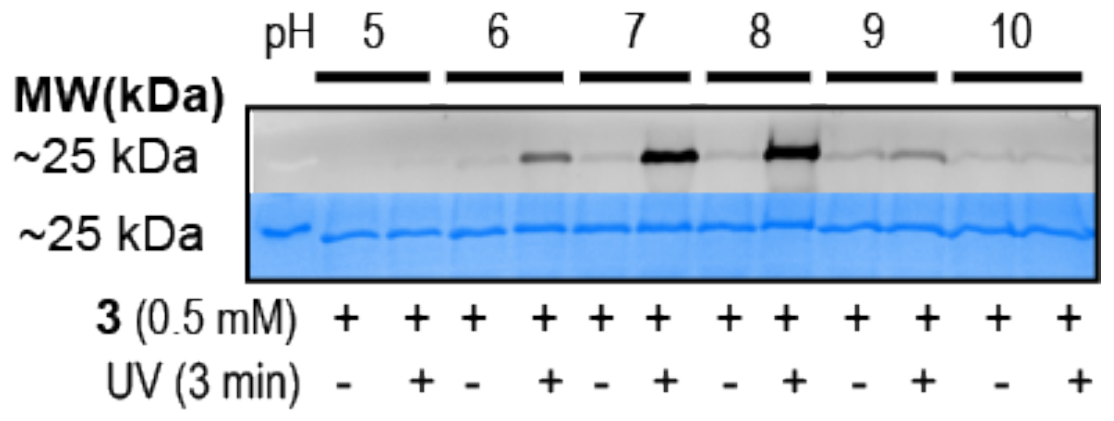

Figure S11. SDS-PAGE analysis showing a pH evaluation of 3 photo-reactivity upon 3 minutes of UV irradiation at $\mathrm{pH} 5-10$. MSP fluorescence was shown to be optimal at $\mathrm{pH}$ between 7 and 8 . 


\section{Synthetic procedures \& characterization of triazenes}

General synthesis of triazene scaffold

In a $20 \mathrm{~mL}$ glass synthetic vial, aniline (1 equiv.) was measured and subsequently placed on an ice bath $\left(0-4{ }^{\circ} \mathrm{C}\right) .4 \mathrm{~mL}$ of $10 \% \mathrm{HCl}$ solution in water was added to the reaction vessels and magnetically stirred until the solution is clear and the aniline is completely dissolved. In a $1.6 \mathrm{~mL}$ Eppendorf tube, sodium nitrite (5 equiv.) was measured out and dissolved in $1 \mathrm{~mL}$ of nanopore water and place on ice. Once cool, the sodium nitrite solution was added slowly over 5 minutes, sometimes associated with a color change. Diazotization reactions are stirred for 20-30 minutes. In separate $50 \mathrm{~mL}$ Erlenmeyer flask, 5 equivalents of secondary amine nucleophile (piperidine, pyrrolidine, piperazine, and morpholine) is added to $20 \mathrm{~mL}$ of $0.1 \mathrm{M}$ borate buffer ( $\mathrm{pH} 9.5)$ and stirred on ice. After the 30 minutes, aryl diazonium ions are slowly added to the borate solution, in $0.5 \mathrm{~mL}$ additions, noting color change and precipitation upon addition. Reaction $\mathrm{pH}$ is monitored by $\mathrm{pH}$ paper following each $0.5 \mathrm{~mL}$ addition. $10 \% \mathrm{NaOH}$ is added as needed to keep reaction solution basic when needed. Upon final addition, the reaction is let stir for 30 minutes on ice. Precipitate was then isolated by gravity filtration and washed with nanopore water. Extraction with DCM should be performed to remove excess salts. Products were characterized by ${ }^{1} \mathrm{HNMR}$ using $\mathrm{CDCl}_{3}$.

Synthesis and characterization of piperidine triazene - (1a-i)

Piperidine, 1-[2-(4-nitrophenyl)diazenyl] - (1a)

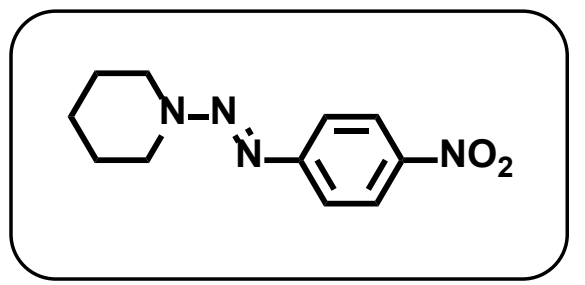

General synthesis starting with diazotization of 4nitroaniline $(0.100 \mathrm{~g}, 0.724$ mmoles) in $4 \mathrm{~mL}$ of $10 \% \mathrm{HCl}$ via addition of sodium nitrite $(0.25 \mathrm{~g}, 3.62$ mmoles). Solution was added to piperidine $(0.3 \mathrm{~g}, 3.62 \mathrm{mmoles}$, $0.362 \mathrm{~mL}$ ) in borate $\mathrm{pH} 9.5$ to yield dark brown solid $(0.168 \mathrm{~g}, 99 \%)$. The compound's spectra matched the literature values. ${ }^{5}$

${ }^{1} \mathrm{H}$ NMR $\left(400 \mathrm{MHz}, \mathrm{CDCl}_{3}\right) \delta 8.23-8.16(\mathrm{~m}, 2 \mathrm{H}), 7.54-7.46(\mathrm{~m}, 2 \mathrm{H}), 3.90(\mathrm{~s}, 4 \mathrm{H}), 1.76$ (s, 6H).

${ }^{13} \mathrm{C}$ NMR $\left(100 \mathrm{MHz}, \mathrm{CDCl}_{3}\right) \delta$ 156.2, 144.8, 124.97, 120.6, 53.5 (ws), 43.5 (ws), 24.3. 
Benzonitrile, 4-[2-(1-piperidinyl)diazenyl] - (1b)

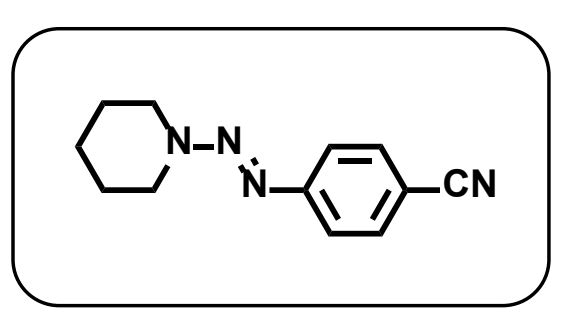

General synthesis starting with diazotization of 4aminobenzonitrile $(0.100 \mathrm{~g}, 0.847$ mmoles $)$ in $4 \mathrm{~mL}$ of $10 \%$ $\mathrm{HCl}$ via addition of sodium nitrite $(0.292 \mathrm{~g}, 4.24$ mmoles $)$. Solution was added to piperidine $(0.36 \mathrm{~g}, 4.24 \mathrm{mmoles}$, $0.420 \mathrm{~mL})$ in borate $\mathrm{pH} 9.5$ to yield brown solid $(0.180 \mathrm{~g}$, $99 \%)$.

${ }^{1} \mathrm{H}$ NMR $\left(400 \mathrm{MHz}, \mathrm{CDCl}_{3}\right) \delta 7.62-7.56(\mathrm{~m}, 2 \mathrm{H}), 7.50-7.45(\mathrm{~m}, 2 \mathrm{H}), 3.86(\mathrm{~s}, 4 \mathrm{H}), 1.74$ (s, 6H).

${ }^{13} \mathrm{C}$ NMR (100 MHz, $\left.\mathrm{CDCl}_{3}\right) \delta 154.4,133.1,120.0,119.7,107.9,52.9$ (ws), 43.6 (ws), 24.3.

IR (ATR) $1637(\mathrm{~m}), 1426(\mathrm{w}), 1189(\mathrm{w}), 1106(\mathrm{w}), 836(\mathrm{~m}), 800(\mathrm{~m}), 763(\mathrm{~m}), 731(\mathrm{~s})$, 705 (s), 695 (s).

HRMS (ESI) m/z: [M+Na] Calculated for $\mathrm{C}_{12} \mathrm{H}_{14} \mathrm{~N}_{4} \mathrm{Na} 237.1116$; Found 237.1113.

1-[2-[4-(Trifluoromethyl)phenyl]diazinyl]piperidine - (1c)

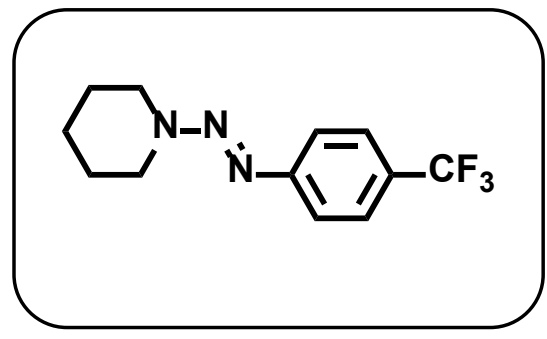

General synthesis starting with diazotization of 4(trifluoromethyl)aniline $(0.100 \mathrm{~g}, 0.621 \mathrm{mmoles})$ in $4 \mathrm{~mL}$ of $10 \% \mathrm{HCl}$ via addition of sodium nitrite $(0.214 \mathrm{~g}, 3.11$ mmoles). Solution was added to piperidine $(0.261 \mathrm{~g}, 3.11$ mmoles, $0.302 \mathrm{~mL}$ ) in borate $\mathrm{pH} 9.5$ to yield an orangebrown oil $(0.87 \mathrm{~g}, 54 \%)$. The compound's spectra matched the literature values. ${ }^{6}$

${ }^{1} \mathrm{H}$ NMR $\left(400 \mathrm{MHz}, \mathrm{CDCl}_{3}\right) \delta 7.59(\mathrm{~d}, J=8.4 \mathrm{~Hz}, 2 \mathrm{H}), 7.51(\mathrm{~d}, J=8.4 \mathrm{~Hz}, 2 \mathrm{H}), 3.84(\mathrm{~s}$, $4 \mathrm{H}), 1.73(\mathrm{~s}, 6 \mathrm{H})$.

${ }^{13} \mathrm{C}$ NMR $\left(100 \mathrm{MHz}, \mathrm{CDCl}_{3}\right) \delta 153.7,128.7,126.9$ (q, $\left.J=32.3 \mathrm{~Hz}\right), 126.0$ (q, $\left.J=3.8 \mathrm{~Hz}\right)$, 123.2, 120.5, 25.3, 24.3. 
$\mathrm{N}$-methyl benzamide, 4-[2-(1-piperidinyl)diazenyl] - (1d)

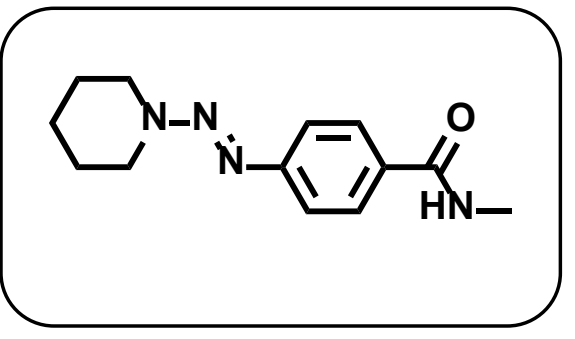

General synthesis starting with diazotization of 4-amino$\mathrm{N}$-methylbenzamide $(0.100 \mathrm{~g}, 0.666 \mathrm{mmoles})$ in $4 \mathrm{~mL}$ of $10 \% \mathrm{HCl}$ via addition of sodium nitrite $(0.230 \mathrm{~g}, 3.33$ mmoles). Solution was added to piperidine $(0.283 \mathrm{~g}$, 3.33 mmoles, $0.329 \mathrm{~mL}$ ) in borate $\mathrm{pH} 9.5$ to yield brown solid $(0.186 \mathrm{~g}, 99 \%)$.

${ }^{1} \mathrm{H}$ NMR $\left(400 \mathrm{MHz}, \mathrm{CDCl}_{3}\right) \delta 7.74(\mathrm{~d}, J=8.5 \mathrm{~Hz}, 2 \mathrm{H}), 7.45(\mathrm{~d}, J=8.5 \mathrm{~Hz}, 2 \mathrm{H}), 6.20(\mathrm{~s}$, 1H), $3.82(\mathrm{~s}, 4 \mathrm{H}), 2.99(\mathrm{~d}, 3 \mathrm{H}), 1.72(\mathrm{~s}, 6 \mathrm{H})$.

${ }^{13} \mathrm{C}$ NMR $\left(100 \mathrm{MHz}, \mathrm{CDCl}_{3}\right) \delta 168.2,153.5,131.2,127.8,120.5,26.9,24.4$.

IR (ATR) 3316 (br), 2968 (w), 1631 (s), 1551 (s), 1427 (m), $1288(\mathrm{~m}), 1187(\mathrm{~m}), 1105$ (m), $1002(w), 762(w)$.

HRMS (ESI) m/z: [M+H] Calculated for $\mathrm{C}_{13} \mathrm{H}_{18} \mathrm{~N}_{4} \mathrm{ONa} 247.1560$; Found 247.1553.

1-[2-(4-Bromophenyl)diazinyl]piperidine - (1e)

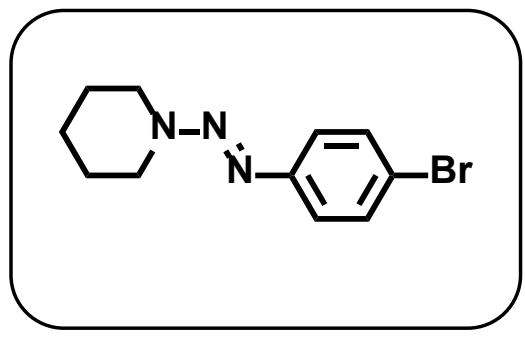

General synthesis starting with diazotization of 4bromoaniline $(0.100 \mathrm{~g}, 0.581 \mathrm{mmoles})$ in $4 \mathrm{~mL}$ of $10 \% \mathrm{HCl}$ via addition of sodium nitrite $(0.201 \mathrm{~g}, 2.91 \mathrm{mmoles})$. Solution was added to piperidine $(0.248 \mathrm{~g}, 2.91 \mathrm{mmoles}$, $0.287 \mathrm{~mL}$ ) in borate $\mathrm{pH} 9.5$ to yield an orange-brown solid $(0.131 \mathrm{~g}, 83 \%)$. The compound's spectra matched the literature values. ${ }^{5}$

${ }^{1} \mathrm{H}$ NMR $\left(400 \mathrm{MHz}, \mathrm{CDCl}_{3}\right) \delta 7.44(\mathrm{~d}, J=8.7 \mathrm{~Hz}, 2 \mathrm{H}), 7.31(\mathrm{~d}, J=8.7 \mathrm{~Hz}, 2 \mathrm{H}), 3.78(\mathrm{~s}$, $4 \mathrm{H}), 1.71(\mathrm{~s}, 6 \mathrm{H})$.

${ }^{13} \mathrm{C}$ NMR (100 MHz, $\left.\mathrm{CDCl}_{3}\right) \delta 150.0,131.9,122.2,118.7,48.9$ (ws), 25.4, 24.5. 
Piperidine, 1-[2-(3-methoxyphenyl)diazenyl] - (1f)

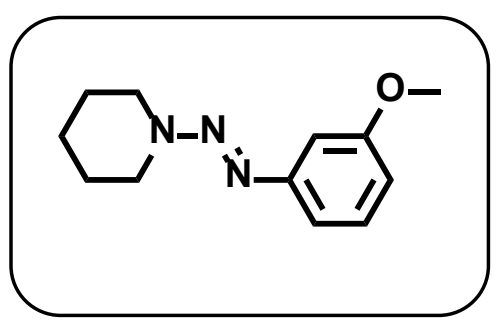

General synthesis starting with diazotization of 3methoxyaniline $(0.100 \mathrm{~g}, 0.812 \mathrm{mmoles}, 0.091 \mathrm{~mL})$ in $4 \mathrm{~mL}$ of $10 \% \mathrm{HCl}$ via addition of sodium nitrite $(0.280 \mathrm{~g}, 4.06$ mmoles). Solution was added to piperidine $(0.345 \mathrm{~g}, 4.06$ mmoles, $0.40 \mathrm{~mL}$ ) in borate $\mathrm{pH} 9.5$ to yield a dark brown oil $(0.137 .2 \mathrm{~g}, 77 \%)$. The compound's spectra matched the literature values. ${ }^{7}$

${ }^{1} \mathrm{H}$ NMR $\left(400 \mathrm{MHz}, \mathrm{CDCl}_{3}\right) \delta 7.23(\mathrm{t}, J=8.0 \mathrm{~Hz}, 1 \mathrm{H}), 7.14-6.98(\mathrm{~m}, 2 \mathrm{H}), 6.71$ (dd, $J=$ 8.0, $2.0 \mathrm{~Hz}, 1 \mathrm{H}), 3.81(\mathrm{~s}, 3 \mathrm{H}), 3.79-3.72(\mathrm{~m}, 4 \mathrm{H}), 1.68(\mathrm{~s}, 6 \mathrm{H})$.

${ }^{13} \mathrm{C}$ NMR $\left(100 \mathrm{MHz}, \mathrm{CDCl}_{3}\right) \delta 160.3,152.2,129.5,113.5,111.9,105.3,55.3,48.2,25.3$, 24.4 .

Piperidine, 1-(2-phenyldiazenyl) - (19)

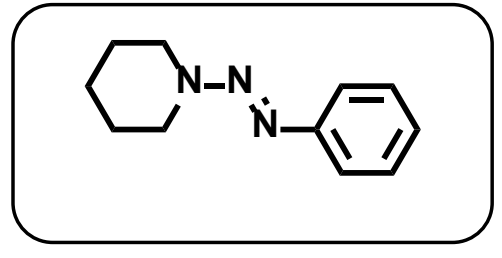

General synthesis starting with diazotization of aniline $(0.100 \mathrm{~g}, 1.07 \mathrm{mmoles})$ in $4 \mathrm{~mL}$ of $10 \% \mathrm{HCl}$ via addition of sodium nitrite $(0.370 \mathrm{~g}, 5.35 \mathrm{mmoles})$. Solution was added to piperidine $(0.454 \mathrm{~g}, 5.35 \mathrm{mmoles}, 0.528 \mathrm{~mL})$ in borate $\mathrm{pH} 9.5$ to yield a light-brown solid $(0.167 \mathrm{~g}, 82 \%)$. The compound's spectra matched the literature values. ${ }^{5}$

${ }^{1} \mathrm{H}$ NMR $\left(400 \mathrm{MHz}, \mathrm{CDCl}_{3}\right) \delta 7.49(\mathrm{~d}, J=8.2 \mathrm{~Hz}, 2 \mathrm{H}), 7.38(\mathrm{t}, J=7.8 \mathrm{~Hz}, 2 \mathrm{H}), 7.19(\mathrm{t}, J$ $=7.3 \mathrm{~Hz}, 1 \mathrm{H}), 3.81(\mathrm{~s}, 4 \mathrm{H}), 1.73(\mathrm{~s}, 6 \mathrm{H})$.

${ }^{13} \mathrm{C}$ NMR $\left(100 \mathrm{MHz}, \mathrm{CDCl}_{3}\right) \delta 150.9,128.9,125.7,120.6,48.2$ (ws), 25.4, 24.5.

Piperidine, 1-[2-(4-methylphenyl)diazenyl] - (1h)

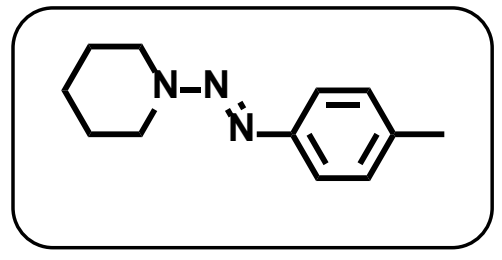

General synthesis starting with diazotization of 4methylaniline $(0.100 \mathrm{~g}, 0.933 \mathrm{mmoles})$ in $4 \mathrm{~mL}$ of $10 \% \mathrm{HCl}$ via addition of sodium nitrite $(0.370 \mathrm{~g}, 5.35 \mathrm{mmoles})$. Solution was added to piperidine $(0.454 \mathrm{~g}, 5.35 \mathrm{mmoles}, 0.528 \mathrm{~mL})$ in borate $\mathrm{pH} 9.5$ to yield brownish-red, oil $(0.059 \mathrm{~g}, 31 \%)$. The compound's spectra matched the literature values. ${ }^{8}$

${ }^{1} \mathrm{H}$ NMR $\left(400 \mathrm{MHz}, \mathrm{CDCl}_{3}\right) \delta 7.33(\mathrm{~d}, J=8.3 \mathrm{~Hz}, 2 \mathrm{H}), 7.14(\mathrm{~d}, J=8.0 \mathrm{~Hz}, 2 \mathrm{H}), 3.75(\mathrm{~s}$, $4 \mathrm{H}), 2.34(\mathrm{~s}, 3 \mathrm{H}), 1.70(\mathrm{~s}, 6 \mathrm{H})$.

${ }^{13} \mathrm{C}$ NMR (100 MHz, $\left.\mathrm{CDCl}_{3}\right) \delta$ 148.7, 135.4, 129.5, 120.5, 48.3 (ws), 25.4, 25.0, 21.2. 
Piperidine, 1-[2-(4-methylphenyl)diazenyl] - (1i)

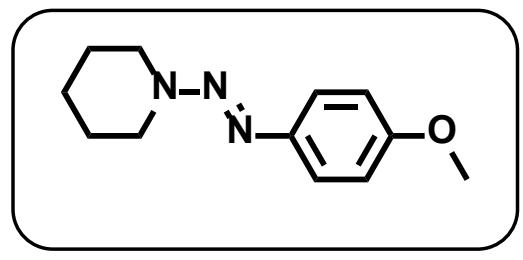

General synthesis starting with diazotization of 4methoxyaniline $(0.064 \mathrm{~g}, 0.520 \mathrm{mmoles})$ in $4 \mathrm{~mL}$ of $10 \% \mathrm{HCl}$ via addition of sodium nitrite $(0.179 \mathrm{~g}, 2.59 \mathrm{mmoles})$. Solution was added to piperidine $(0.454 \mathrm{~g}, 5.35 \mathrm{mmoles}$, $0.528 \mathrm{~mL})$ in borate $\mathrm{pH} 9.5$ to yield brown oil $(0.063 \mathrm{~g}, 56 \%)$. The compound's spectra matched the literature values. ${ }^{9}$

${ }^{1} \mathrm{H}$ NMR (400 MHz, $\left.\mathrm{CDCl}_{3}\right) \delta 7.46-7.37(\mathrm{~m}, 2 \mathrm{H}), 6.92-6.86(\mathrm{~m}, 2 \mathrm{H}), 3.81(\mathrm{~s}, 3 \mathrm{H}), 3.77$ $-3.67(\mathrm{~m}, 4 \mathrm{H}), 1.71$ (dd, $J=9.9,4.0 \mathrm{~Hz}, 6 \mathrm{H})$.

${ }^{13} \mathrm{C}$ NMR (100 MHz, $\left.\mathrm{CDCl}_{3}\right) \delta 158.0,144.8,121.6,114.1,55.5,53.5,48.2$ (ws), 25.3, 24.6.

Synthesis and characterization of azo-adducts (2a-i)

*Azo-products were not isolated for $1 \mathrm{a}-\mathbf{d}$ when treated with citrate $\mathrm{pH} 4$. Additionally, products were not isolated for 1a-d irradiated with $370 \mathrm{~nm}$ UV light at $\mathrm{pH} 7$.

4-(4-Bromophenylazo) resorcinol - (2e)

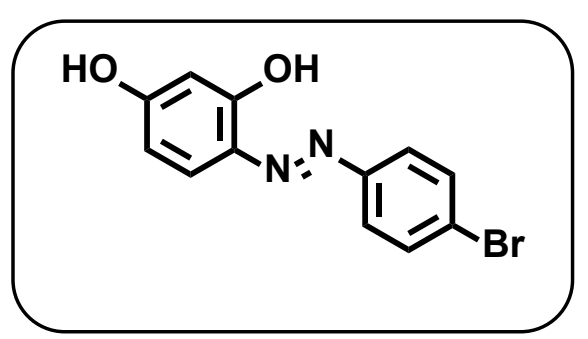

\section{pH $7+$ UV}

In $20 \mathrm{~mL}$ glass vial $10 \mathrm{mg}$ of $1 \mathrm{e}(0.037 \mathrm{mmoles})$ was dissolved with resorcinol (4.1 $\mathrm{mg}, 0.037 \mathrm{mmoles})$ in a $4 \mathrm{~mL}, 50: 50$ solution of $\mathrm{MeOH}$ and PBS pH 7. Sample was stirred and irradiated for 3 hours. DCM extraction was followed by purification by silica gel column chromatography (MeOH: DCM, 0\%-100\% MeOH). Product was an orange solid (3.2 mg, 30\%).

\section{pH 4}

Sample was stirred void of light in citrate buffer, $\mathrm{pH} 4$ for 3 hours. DCM extraction was followed by purification by silica gel column chromatography (MeOH: DCM, 0\%-100\% $\mathrm{MeOH})$. Product was an orange solid (0.5 mg, 5\%).

${ }^{1} \mathrm{H}$ NMR (400 MHz, DMSO) $\delta 7.80$ (d, J = 8.7 Hz, 2H), 7.72 (d, J = 8.7 Hz, 2H), 7.65 (d, $J=8.9 \mathrm{~Hz}, 1 \mathrm{H}), 6.49(\mathrm{dd}, J=8.9,2.5 \mathrm{~Hz}, 1 \mathrm{H}), 6.36(\mathrm{~d}, J=2.5 \mathrm{~Hz}, 1 \mathrm{H})$.

${ }^{13} \mathrm{C}$ NMR (100 MHz, DMSO) $\delta$ 163.8. 156.9, 149.9, 132.4, 132.3, 128.8, 124.0, 122.9, 109.5, 103.0.

IR (ATR) 3196 (br), 1624 (m), 1486 (m), 1415 (w), 1247 (s), 1123 (w), 1070 (w), 1005 $(\mathrm{m}), 824(\mathrm{~m}), 779(\mathrm{~m})$.

HRMS (ESI) m/z: [M+H] Calculated for $\mathrm{C}_{12} \mathrm{H}_{9} \mathrm{BrN}_{2} \mathrm{O}_{2} \mathrm{H}$ 292.9926; Found 292.9920. 


\section{4-(3-methoxyphenylazo) resorcinol - (2f)}

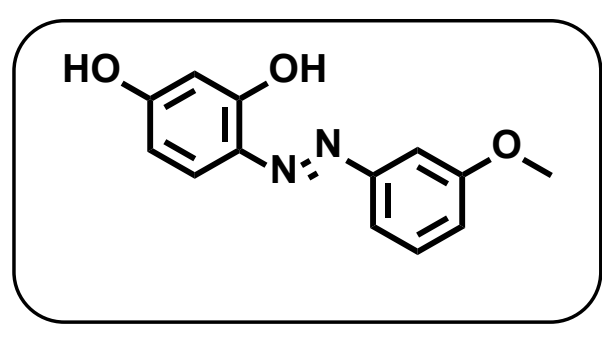

$\mathrm{pH} 7+\mathrm{UV}$

In $20 \mathrm{~mL}$ glass vial $10 \mathrm{mg}$ of $1 \mathrm{f}(0.046$ mmoles $)$ was dissolved with resorcinol $(4.9 \mathrm{mg}, 0.046 \mathrm{mmoles})$ in a $4 \mathrm{~mL}, 50: 50$ solution of $\mathrm{MeOH}$ and PBS $\mathrm{pH} 7$. Sample was stirred and irradiated for 3 hours. DCM extraction was followed by purification by silica gel column chromatography (MeOH: DCM, 0\%-100\% $\mathrm{MeOH})$. Product provided was an orange-red solid (4.0 mg, 36\%).

\section{pH 4}

Sample was stirred void of light in citrate buffer, $\mathrm{pH} 4$ for 3 hours. DCM extraction was followed by purification by silica gel column chromatography (MeOH: DCM, 0\%-100\% $\mathrm{MeOH})$. Product provided was an orange-red solid (1.4 mg, 13\%).

${ }^{1} \mathrm{H}$ NMR (500 MHz, DMSO) $\delta 12.30(\mathrm{~s}, 1 \mathrm{H}), 10.55(\mathrm{~s}, 1 \mathrm{H}), 7.68(\mathrm{~d}, \mathrm{~J}=8.8 \mathrm{~Hz}, 1 \mathrm{H}), 7.43$ (dd, $J=6.4,3.3 \mathrm{~Hz}, 3 \mathrm{H}), 7.04(\mathrm{dd}, J=8.2,3.4 \mathrm{~Hz}, 1 \mathrm{H}), 6.49(\mathrm{dd}, J=8.8,2.5 \mathrm{~Hz}, 1 \mathrm{H}$ ), $6.35(\mathrm{~d}, J=2.4 \mathrm{~Hz}, 1 \mathrm{H}), 3.84(\mathrm{~s}, 3 \mathrm{H})$.

${ }^{13} \mathrm{C}$ NMR (100 MHz, DMSO) $\delta 163.1,160.4,156.5,152.0,132.2,130.1,129.7,116.4$, 115.3, 109.1, 105.4, 103.0, 55.4.

IR (ATR) 2919 (w), 1603 (s), 1484 (s), 1319 (w), 1263 (s), 1138 (m), 1038 (w), 868 (m), $826(w), 726(w)$.

HRMS (ESI) m/z: [M+H] Calculated for $\mathrm{C}_{13} \mathrm{H}_{12} \mathrm{~N}_{2} \mathrm{O}_{3} \mathrm{H} 245.0927$; Found 245.0921. 
4-(Phenylazo) resorcinol $-\mathbf{( 2 g})$

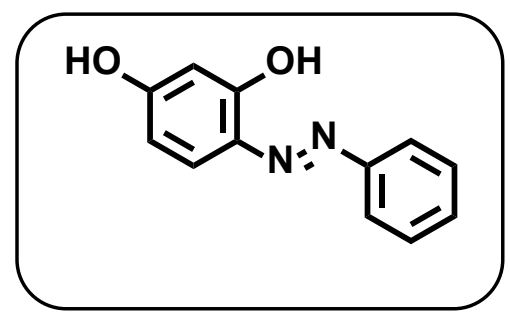

$\mathrm{pH} 7+\mathrm{UV}$

In $20 \mathrm{~mL}$ glass vial $10 \mathrm{mg} \mathbf{1 g}(0.053 \mathrm{mmoles})$ was dissolved with resorcinol ( $5.8 \mathrm{mg}, 0.053 \mathrm{mmoles}$ ) in a $4 \mathrm{~mL}, 50: 50$ solution of $\mathrm{MeOH}$ and PBS pH 7. Sample was stirred and irradiated for 3 hours. DCM extraction was followed by silica gel column chromatography (MeOH: DCM, $0 \%-100 \%$ $\mathrm{MeOH})$. Product was a bright red solid $(4.5 \mathrm{mg}, 40 \%)$. The compound's spectra matched the literature values. ${ }^{10}$

\section{pH 4}

Sample was stirred void of light in citrate buffer, $\mathrm{pH} 4$ for 3 hours. DCM extraction was followed by purification by silica gel column chromatography (MeOH: DCM, $0 \%-100 \%$ $\mathrm{MeOH})$. Product provided was a bright red solid $(2.3 \mathrm{mg}, 20 \%)$.

${ }^{1} \mathrm{H}$ NMR (400 MHz, DMSO) $\delta 12.44(1 \mathrm{H}, \mathrm{s}), 10.57(\mathrm{~s}, 1 \mathrm{H}), 7.84(\mathrm{~d}, J=7.4 \mathrm{~Hz}, 2 \mathrm{H}), 7.68$ $(\mathrm{d}, J=8.8 \mathrm{~Hz}, 1 \mathrm{H}), 7.53(\mathrm{t}, J=7.5 \mathrm{~Hz}, 2 \mathrm{H}), 7.45(\mathrm{t}, J=7.2 \mathrm{~Hz}, 1 \mathrm{H}), 6.51$ (dd, $J=8.8,2.5$ $\mathrm{Hz}, 1 \mathrm{H}), 6.36(\mathrm{~d}, J=2.5 \mathrm{~Hz}, 1 \mathrm{H})$.

${ }^{13} \mathrm{C}$ NMR (100 MHz, DMSO) $\delta$ 163.0, 156.4, 150.6, 132.3, 130.1, 129.4, 121.7, 109.1, 103.0. 


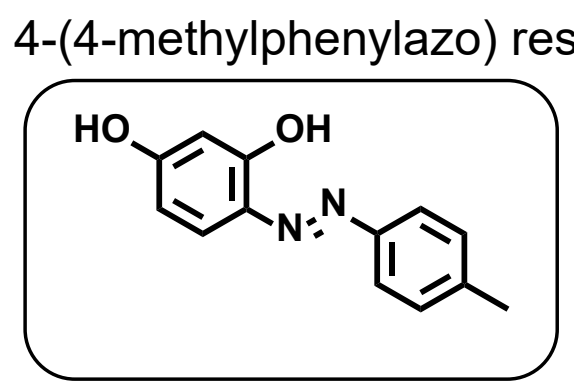

$-(2 h)$

$\mathrm{pH} 7+\mathrm{UV}$

In $20 \mathrm{~mL}$ glass vial $10 \mathrm{mg} 1 \mathrm{~h}$ (0.049 mmoles) was dissolved with resorcinol (5.4 $\mathrm{mg}, 0.049$ mmoles) in a 4 $\mathrm{mL}, 50: 50$ solution of $\mathrm{MeOH}$ and $\mathrm{PBS} \mathrm{pH}$ 7. Sample was stirred and irradiated for 3 hours. DCM extraction was followed by purification by silica gel column chromatography by silica gel column chromatography (MeOH: DCM, $0 \%-100 \% \mathrm{MeOH})$. Product was bright red solid $(5.2 \mathrm{mg}, 46 \%)$. The compound's spectra matched the literature values. ${ }^{10}$

\section{$\mathrm{pH} 4$}

Sample was stirred void of light in citrate buffer, $\mathrm{pH} 4$ for 3 hours. DCM extraction was followed by purification by silica gel column chromatography (MeOH: DCM, 0\%-100\% $\mathrm{MeOH})$. Product provided bright red solid (3.5 mg, 31\%).

${ }^{1} \mathrm{H}$ NMR (400 MHz, DMSO) $\delta 12.44(\mathrm{~s}, 1 \mathrm{H}), 10.49(\mathrm{~s}, 1 \mathrm{H}), 7.75(\mathrm{~d}, \mathrm{~J}=8.2 \mathrm{~Hz}, 2 \mathrm{H}), 7.66$ $(\mathrm{d}, \mathrm{J}=8.8 \mathrm{~Hz}, 1 \mathrm{H}), 7.34(\mathrm{~d}, \mathrm{~J}=8.2 \mathrm{~Hz}, 2 \mathrm{H}), 6.49(\mathrm{dd}, \mathrm{J}=8.8,2.5 \mathrm{~Hz}, 1 \mathrm{H}), 6.34(\mathrm{~d}, \mathrm{~J}=$ $2.5 \mathrm{~Hz}, 1 \mathrm{H}), 2.38(\mathrm{~s}, 3 \mathrm{H})$.

${ }^{13} \mathrm{C}$ NMR (100 MHz, DMSO) $\delta 162.7,156.1,148.60,140.2,132.1,130.1,129.9,121.59$, 108.9, 103.0, 20.9.

IR (ATR) 3103 (br), 1598 (s), 1482 (w), 1428 (w), $1360(w), 1261$ (m), 1197 (m), 1035 (s), $847(w), 790(w)$.

HRMS (ESI) m/z: [M+H] Calculated for $\mathrm{C}_{13} \mathrm{H}_{12} \mathrm{~N}_{2} \mathrm{O}_{2} \mathrm{H}$ 229.0978; Found 229.0970. 


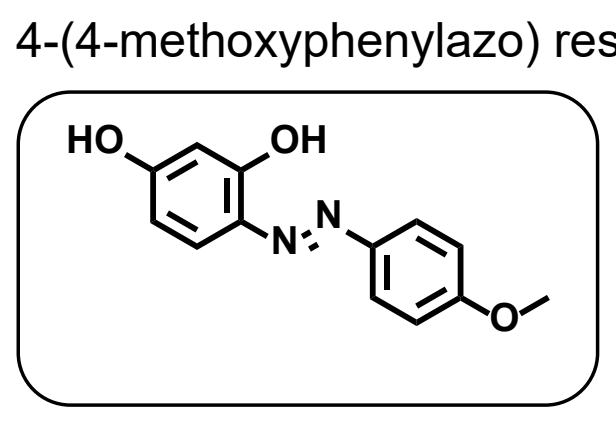

\section{$\mathrm{pH} 7+\mathrm{UV}$}

In $20 \mathrm{~mL}$ glass vial $10 \mathrm{mg}$ of $1 \mathbf{i}(0.049$ mmoles $)$ was dissolved with resorcinol ( $5.3 \mathrm{mg}, 0.049 \mathrm{mmoles})$ in a $4 \mathrm{~mL}, 50: 50$ solution of $\mathrm{MeOH}$ and PBS $\mathrm{pH}$ 7. Sample was stirred and irradiated for 3 hours. DCM extraction was followed by purification by silica gel column chromatography ( $\mathrm{MeOH}$ : DCM, 0\%-100\% $\mathrm{MeOH})$. Product was a crimson-red solid $(8.2 \mathrm{mg}, 74 \%)$. The compound's spectra matched the literature values. ${ }^{11}$

\section{$\mathrm{pH} 4$}

Sample was stirred void of light in citrate buffer, $\mathrm{pH} 4$ for 3 hours. DCM extraction was followed by purification by silica gel column chromatography (MeOH: DCM, 0\%-100\% $\mathrm{MeOH}$ ). Product provided was a crimson-red solid (6.2 mg, 56\%).

${ }^{1} \mathrm{H}$ NMR $\left(400 \mathrm{MHz}, \mathrm{CDCl}_{3}\right) \delta 13.70(\mathrm{~s}, 1 \mathrm{H}), 7.75(\mathrm{~d}, J=8.9 \mathrm{~Hz}, 2 \mathrm{H}), 7.67(\mathrm{~d}, J=8.7 \mathrm{~Hz}$, $1 \mathrm{H}), 6.98(\mathrm{~d}, J=8.9 \mathrm{~Hz}, 2 \mathrm{H}), 6.54(\mathrm{dd}, J=8.7,2.5 \mathrm{~Hz}, 1 \mathrm{H}), 6.43(\mathrm{~d}, J=2.4 \mathrm{~Hz}, 1 \mathrm{H}), 3.87$ $(\mathrm{s}, 3 \mathrm{H}) .^{12}$

${ }^{13} \mathrm{C}$ NMR $\left(100 \mathrm{MHz}, \mathrm{CDCl}_{3}\right) \delta 161.4,156.0,144.5,134.6,132.7,123.3,114.6,108.9$, 103.7, 55.7 . 
Synthesis and evaluation of 3-ethynyl triazene - (3)

Piperidine, 1-[2-(3-ethynylphenyl)diazenyl] - (3)

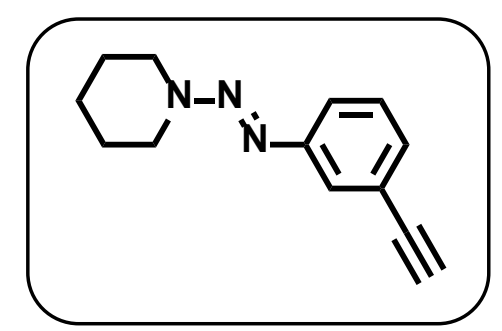

$0.05 \mathrm{mg}$ of 3-ethynyl aniline $(0.05 \mathrm{~g} 0.427 \mathrm{mmol})$ was dissolved in $10 \% \mathrm{HCl}$ solution of $3 \mathrm{~mL}$ of methanol and $3 \mathrm{~mL}$ of water. Solution was magnetically stirred on ice. Next, addition of 5 equivalents of sodium nitrite $(0.147 \mathrm{~g}, 2.13$ mmoles) was dissolved in $1 \mathrm{~mL}$ of water and added slowly for diazotization. Solution was clear with light yellow coloration. After 20 minutes, the aryl diazonium ion solution was added to piperidine $(0.108 \mathrm{~g}, 1.27$ mmoles, $0.125 \mathrm{~mL}$ ) in borate buffer ( $\mathrm{pH}$ 9.5). Solution was let stir on ice for 30 minutes and then filtered. Precipitate was removed from filter paper via extraction with methanol. Solution was vacuum pumped and provided a dark brown oil. (0.076 g, 83\%).

${ }^{1} \mathrm{H}$ NMR $\left(400 \mathrm{MHz}, \mathrm{CDCl}_{3}\right) \delta 7.60-7.56(\mathrm{~m}, 1 \mathrm{H}), 7.46-7.39(\mathrm{~m}, 1 \mathrm{H}), 7.31-7.26(\mathrm{~m}$, $2 \mathrm{H}), 3.79(\mathrm{~s}, 4 \mathrm{H}), 3.06(\mathrm{~s}, 1 \mathrm{H}), 1.70(\mathrm{~s}, 6 \mathrm{H})$.

${ }^{13} \mathrm{C}$ NMR $\left(100 \mathrm{MHz}, \mathrm{CDCl}_{3}\right) \delta 150.9,129.2,128.9,124.0,122.6,121.6,84.0,44.6,25.4$ (bs), 24.4, 22.7.

IR (ATR) 2934 (w), 1622 (s),1476 (w), 1361 (s), 1259 (s), 1294 (m), 1105 (m), 1007 (w), $826(\mathrm{~m}), 704(\mathrm{~s})$.

HRMS (ESI) m/z: $[\mathrm{M}+\mathrm{H}]$ Calculated for $\mathrm{C}_{11} \mathrm{H}_{14} \mathrm{~N}_{4} \mathrm{O}_{2} \mathrm{H}$ 214.1345; Found 214.1335. 
Synthesis and characterization of ethynyl-cresol azo-adduct (4) - (Figure S6)

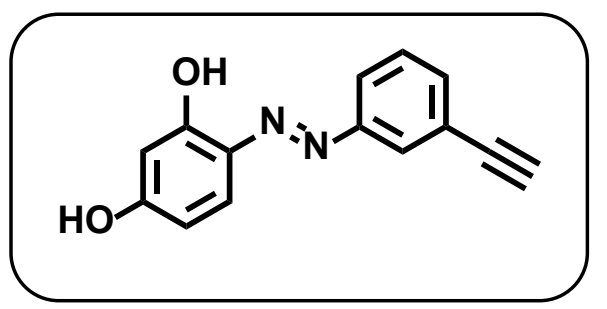

4-(3-ethynylphenylazo) resorcinol - (4)

$10 \mathrm{mg}$ of $3(0.0469 \mathrm{mmol})$ was dissolved in $2 \mathrm{~mL}$ of methanol and transferred to $20 \mathrm{~mL}$ synthetic vial. 5.1 $\mathrm{mg}$ of resorcinol $(0.0469 \mathrm{mmol}, 1$ equiv.) was added to the solution followed by the addition of $2 \mathrm{~mL}$ of $0.1 \mathrm{M}$ PBS buffer $(\mathrm{pH} 7)$. The solution was magnetically stirred and irradiated for 3 hours using our $370 \mathrm{~nm}$ UV LED source. Products were extracted with DCM, vacuum pumped and purified by silica gel column chromatography (MeOH: DCM, 0\%-100\% MeOH). Product was an orange-red solid (3.7 $\mathrm{mg}, 33 \%)$.

${ }^{1} \mathrm{H}$ NMR $(500 \mathrm{MHz}, \mathrm{DMSO}) \delta 7.97-7.94(\mathrm{~m}, 1 \mathrm{H}), 7.90-7.85(\mathrm{~m}, 1 \mathrm{H}), 7.67$ (d, $J=8.9$ $\mathrm{Hz}, 1 \mathrm{H}), 7.54(\mathrm{dd}, J=4.0,1.2 \mathrm{~Hz}, 2 \mathrm{H}), 6.49(\mathrm{dd}, J=8.9,2.5 \mathrm{~Hz}, 1 \mathrm{H}), 6.37(\mathrm{~d}, J=2.5 \mathrm{~Hz}$, $1 \mathrm{H}), 4.30(\mathrm{~s}, 1 \mathrm{H})$.

${ }^{13} \mathrm{C}$ NMR (100 MHz, DMSO) $\delta 163.9,157.1,150.9,132.7,132.4,129.8,128.6,124.1$, 122.84, 122.77, 109.9, 103.0, 82.9, 81.5.

IR (ATR) 3281 (br), 1623 (s), $1482(\mathrm{~s}), 1321(\mathrm{w}), 1246(\mathrm{~s}), 1120(\mathrm{~m}), 1216(\mathrm{~m}), 1120$ (w), $819(\mathrm{~m}), 743(\mathrm{~m})$.

HRMS (ESI) m/z: [M+H] Calculated for $\mathrm{C}_{14} \mathrm{H}_{10} \mathrm{~N}_{2} \mathrm{O}_{2} \mathrm{H}$ 239.0821; Found 239.0815.

Synthesis of additional novel piperidine triazenes - (S1-2)

Piperidine, 1-[2-(3-nitrophenyl)diazenyl] - (S1)

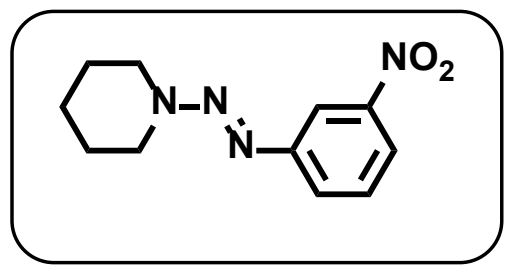

General synthesis starting with diazotization of 3-nitroaniline $(0.100 \mathrm{~g}, 0.724 \mathrm{mmoles})$ in $4 \mathrm{~mL}$ of $10 \% \mathrm{HCl}$ via addition of sodium nitrite $(0.25 \mathrm{~g}, 3.62 \mathrm{mmoles})$. Solution was added to piperidine $(0.3 \mathrm{~g}, 3.62 \mathrm{mmoles}, 0.362 \mathrm{~mL})$ in borate $\mathrm{pH} 9.5$ to yield dark brown solid $(0.168 \mathrm{~g}, 99 \%)$.

${ }^{1} \mathrm{H}$ NMR $\left(400 \mathrm{MHz}, \mathrm{CDCl}_{3}\right) \delta 8.26(\mathrm{t}, J=2.0 \mathrm{~Hz}, 1 \mathrm{H}), 7.99-7.91(\mathrm{~m}, 1 \mathrm{H}), 7.74-7.67(\mathrm{~m}$, $1 \mathrm{H}), 7.45$ (t, $J=8.0 \mathrm{~Hz}, 1 \mathrm{H}), 3.85(\mathrm{~s}, 4 \mathrm{H}), 1.74(\mathrm{~s}, 6 \mathrm{H})$.

${ }^{13} \mathrm{C}$ NMR $\left(100 \mathrm{MHz}, \mathrm{CDCl}_{3}\right) \delta 152.2,149.1,129.5,127.1,119.7,114.8,44.7,24.4,22.8$.

IR (ATR) 2946 (w), 1526 (s), 1445 (w), $1420(\mathrm{~m}), 1351$ (s), 1295 (w), 1188 (m), 1109 $(\mathrm{m}), 894(\mathrm{w}), 784(\mathrm{w})$.

HRMS (ESI) m/z: [M+H] Calculated for $\mathrm{C}_{34} \mathrm{H}_{33} \mathrm{~N}_{5} \mathrm{O}_{2} \mathrm{H}$ 235.1196; Found 235.1190 
Benzoic acid, 4-[2-(1-piperidinyl)diazenyl] - (S2)

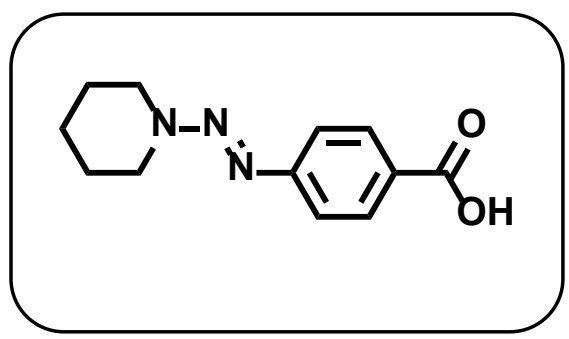

General synthesis starting with diazotization of 4aminobenzoic acid $(0.100 \mathrm{~g}, 0.729$ mmoles) in $4 \mathrm{~mL}$ of $10 \% \mathrm{HCl}$ via addition of sodium nitrite $(0.252 \mathrm{~g}, 3.65$ mmoles). Solution was added to piperidine $(0.310 \mathrm{~g}, 3.65$ mmoles, $0.360 \mathrm{~mL}$ ) in borate $\mathrm{pH}$ 9.5. Following incubation for 30 minutes, sample was treated with small amounts of acetic acid until precipitate was formed.

Solution was then filtered to yield an off-white, cream colored solid $(0.180 \mathrm{~g}, 99 \%)$.

${ }^{1} \mathrm{H}$ NMR $\left(400 \mathrm{MHz}, \mathrm{CDCl}_{3}\right) \delta 8.09(\mathrm{~d}, J=8.7 \mathrm{~Hz}, 2 \mathrm{H}), 7.49(\mathrm{~d}, J=8.7 \mathrm{~Hz}, 2 \mathrm{H}), 3.86(\mathrm{~s}$, $4 \mathrm{H}), 1.74(\mathrm{~s}, 6 \mathrm{H})$.

${ }^{13} \mathrm{C}$ NMR (100 MHz, CDCl $)$ ) $\delta 172.1,155.4,131.5,125.8,120.4,25.5$ (ws), 24.2.

IR (ATR) 3370 (br), $2971(\mathrm{~m}), 1467(\mathrm{w}), 1379(\mathrm{~m}), 1296(\mathrm{w}), 1130(\mathrm{~m}), 952(\mathrm{~s}), 823(\mathrm{w})$, $749(\mathrm{~s}), 709(\mathrm{w})$.

HRMS (ESI) m/z: [M-H+Na] Calculated for $\mathrm{C}_{12} \mathrm{H}_{14} \mathrm{~N}_{3} \mathrm{O}_{2} \mathrm{Na}$ 256.1062; Found 256.1057.

Synthesis \& characterization of triazenes from various cyclic amines (S3-S5)

Pyrrolidine, 1-[2-(phenyl)diazenyl] -(S3)

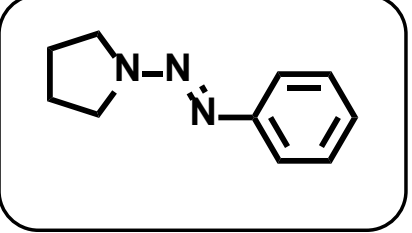

literature values. ${ }^{8}$

General synthesis starting with diazotization of aniline $(0.050 \mathrm{~g}$, 0.386 mmoles) in $4 \mathrm{~mL}$ of $10 \% \mathrm{HCl}$ in water via addition of sodium nitrite $(0.133 \mathrm{~g}, 1.93 \mathrm{mmoles})$. Solution was added to pyrrolidine $(0.137 \mathrm{~g}, 1.93 \mathrm{mmoles}, 0.159 \mathrm{~mL})$ in borate $\mathrm{pH} 9.5$ to yield a light brown solid $(0.038 \mathrm{~g}, 56 \%)$. The compound's spectra matched the

${ }^{1} \mathrm{H}$ NMR $\left(400 \mathrm{MHz}, \mathrm{CDCl}_{3}\right) \delta 7.50-7.42(\mathrm{~m}, 2 \mathrm{H}), 7.36(\mathrm{t}, J=7.8 \mathrm{~Hz}, 2 \mathrm{H}), 7.16(\mathrm{t}, J=7.3$ $\mathrm{Hz}, 1 \mathrm{H}), 3.81(\mathrm{~s}, 4 \mathrm{H}), 2.10-1.91(\mathrm{~m}, 4 \mathrm{H})$.

${ }^{13} \mathrm{C}$ NMR $\left(100 \mathrm{MHz}, \mathrm{CDCl}_{3}\right) \delta 151.5,128.8,125.2,120.4,48.7$ (ws), 23.8. 


\section{1-(2-phenyldiazenyl)piperazine - (S4)}

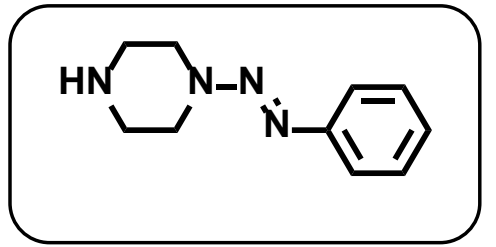

$50 \mathrm{mg}$ of aniline $(0.386 \mathrm{mmol})$ was dissolved into $5 \mathrm{~mL}$ of water along with $0.2 \mathrm{~mL}$ concentrated $\mathrm{HCl}$. The mixture was magnetically stirred on ice. Five equivalencies of sodium nitrite $(1.94 \mathrm{mmol}, 0.1334 \mathrm{~g})$ was dissolved in $1 \mathrm{~mL}$ water and then added dropwise to the reaction solution. The reaction was stirred on ice $\left(0\right.$ to $\left.4{ }^{\circ} \mathrm{C}\right)$ for 20 minutes. In a separate reaction flask, one equivalency of piperazine $(0.386 \mathrm{~mol}, 0.033 \mathrm{~g})$ was dissolved in $20 \mathrm{~mL}$ borate buffer $(\mathrm{pH} 9.5)$ and stirred. The aryl diazonium ion reaction solution was added slowly to the piperazine solution and $\mathrm{pH}$ was monitored to ensure alkalinity. The combined solution was stirred on ice for 30 minutes. Reaction precipitates were filtered off via gravity filtration and filtrate was extracted two times with $20 \mathrm{~mL} \mathrm{CH} \mathrm{Cl}_{2}$ (DCM). Filtered products were washed off with DCM and collected in separate vials from the extraction products. The resulting monomeric triazene was isolated as a brown oil $(0.025 \mathrm{~g}, 34 \%)$. The compound's spectra matched the literature values. ${ }^{13}$

${ }^{1} \mathrm{H}$ NMR $\left(\mathrm{CDCl}_{3}, 500 \mathrm{MHz}\right) \delta 7.48-7.40(\mathrm{~m}, 2 \mathrm{H}), 7.34(\mathrm{t}, J=7.8 \mathrm{~Hz}, 2 \mathrm{H}), 7.18(\mathrm{t}, J=$ $7.3 \mathrm{~Hz}, 1 \mathrm{H}), 3.83-3.71(\mathrm{~m}, 4 \mathrm{H}), 3.08-2.96(\mathrm{~m}, 4 \mathrm{H}), 1.78(\mathrm{~s}, 1 \mathrm{H})$.

${ }^{13} \mathrm{C} \mathrm{NMR}\left(\mathrm{CDCl}_{3}, 400 \mathrm{MHz}\right) \delta 150.6,129.0,126.2,120.8,48.9,45.7$.

\section{4-(phenyldiazenyl)morpholine - (S5)}

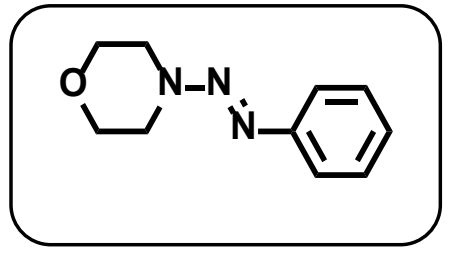

$50 \mathrm{mg}$ of aniline $(0.386 \mathrm{mmol})$ was dissolved into $5 \mathrm{~mL}$ of water along with $0.2 \mathrm{~mL}$ concentrated $\mathrm{HCl}$. The mixture was magnetically stirred on ice. Five equivalencies of sodium nitrite $(1.94 \mathrm{mmol}, 0.1334 \mathrm{~g})$ was dissolved in $1 \mathrm{~mL}$ water and then added dropwise to the reaction solution. The reaction was stirred on ice $\left(0\right.$ to $\left.4{ }^{\circ} \mathrm{C}\right)$ for 20 minutes. In a separate reaction flask, one equivalency of morpholine $(0.386 \mathrm{~mol}, 0.034 \mathrm{~g}, 0.033 \mathrm{~mL})$ was dissolved in $20 \mathrm{~mL}$ borate buffer ( $\mathrm{pH} 9.5)$ and stirred. The aryl diazonium ion reaction solution was added slowly to the morpholine solution and $\mathrm{pH}$ was monitored. The combined solution was stirred on ice for 30 minutes. Reaction precipitates were filtered off via gravity filtration. Filtered products were washed off with DCM and vacuum pumped yielding a yellow oil $(0.049 \mathrm{~g}, 66 \%)$. The compound's spectra matched the literature values. ${ }^{14}$

${ }^{1} \mathrm{H}$ NMR $(\mathrm{CDCl} 3,500 \mathrm{MHz}) \delta 7.45(\mathrm{dt}, J=8.4,1.6 \mathrm{~Hz}, 2 \mathrm{H}), 7.38-7.33(\mathrm{~m}, 2 \mathrm{H}), 7.23-$ $7.18(\mathrm{~m}, 1 \mathrm{H}), 3.86(\mathrm{dd}, J=5.8,4.2 \mathrm{~Hz}, 4 \mathrm{H}), 3.78(\mathrm{dd}, J=5.8,3.9 \mathrm{~Hz}, 4 \mathrm{H})$.

${ }^{13} \mathrm{C} \mathrm{NMR}\left(\mathrm{CDCl}_{3}, 400 \mathrm{MHz}\right) \delta 150.2,129.0,126.6,120.9,66.5,63.9,48.2,43.4$. 
Synthesis and characterization of pyrrolidine triazenes (S7-S10)

Pyrrolidine, 1-[2-(4-Bromophenyl)diazinyl] - (S7)

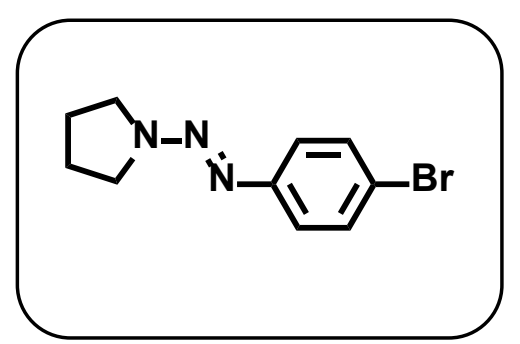

General synthesis starting with diazotization of 4bromoaniline $(0.05 \mathrm{~g}, 0.290$ mmoles) in $4 \mathrm{~mL}$ of $10 \% \mathrm{HCl}$ via addition of sodium nitrite $(0.100 \mathrm{~g}, 1.45 \mathrm{mmoles})$. Solution was added to piperidine $(0.103 \mathrm{~g}, 1.45$ mmoles, $0.119 \mathrm{~mL})$ in borate $\mathrm{pH} 9.5$ to yield an orange-brown solid $(0.027 \mathrm{~g}, 37 \%)$. The compound's spectra matched the literature values. ${ }^{15}$

${ }^{1} \mathrm{H}$ NMR $\left(400 \mathrm{MHz}, \mathrm{CDCl}_{3}\right) \delta 7.45-7.38(\mathrm{~m}, 2 \mathrm{H}), 7.32-7.26(\mathrm{~m}, 2 \mathrm{H}), 3.77(\mathrm{~s}, 4 \mathrm{H}), 2.03$ $(\mathrm{m}, 4 \mathrm{H})$.

${ }^{13} \mathrm{C}$ NMR $\left(100 \mathrm{MHz}, \mathrm{CDCl}_{3}\right) \delta 150.6,131.9,122.1,118.2,23.9$.

Pyrrolidine, 1-[2-(3-methoxyphenyl)diazinyl] - (S8)

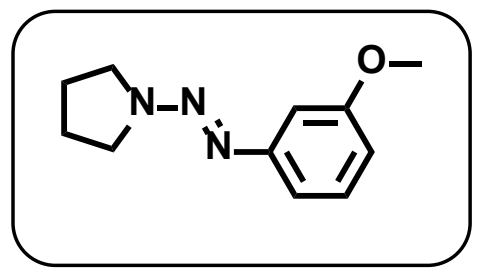

General synthesis starting with diazotization of 3methoxyaniline $(0.050 \mathrm{~g}, 0.407 \mathrm{mmoles})$ in $4 \mathrm{~mL}$ of $10 \% \mathrm{HCl}$ via addition of sodium nitrite $(0.370 \mathrm{~g}, 2.04 \mathrm{mmoles})$. Solution was added to pyrrolidine $(0.274 \mathrm{~g}, 2.04$ mmoles, $0.316 \mathrm{~mL})$ in borate $\mathrm{pH} 9.5$ to yield a light brown solid $(0.130 \mathrm{~g}, 96 \%)$. The compound's spectra matched the literature values. ${ }^{16}$

${ }^{1} \mathrm{H}$ NMR $\left(400 \mathrm{MHz}, \mathrm{CDCl}_{3}\right) \delta 7.23(\mathrm{t}, J=8.0 \mathrm{~Hz}, 1 \mathrm{H}), 7.07-6.97(\mathrm{~m}, 2 \mathrm{H}), 6.70$ (ddd, $J=$ 8.2, 2.5, $0.8 \mathrm{~Hz}, 1 \mathrm{H}), 3.93-3.67(\mathrm{~m}, 7 \mathrm{H}), 2.02(\mathrm{~m}, 4 \mathrm{H})$.

${ }^{13} \mathrm{C}$ NMR $\left(100 \mathrm{MHz}, \mathrm{CDCl}_{3}\right) \delta 160.3,152.9,129.6,113.3,111.6,105.2,55.4,23.9$.

Pyrrolidine, 1-[2-(4-methylphenyl)diazinyl] - (S9)

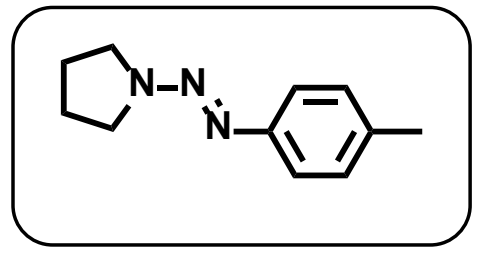

General synthesis starting with diazotization of 4-methylaniline ( $0.05 \mathrm{~g}, 0.467 \mathrm{mmoles})$ in $4 \mathrm{~mL}$ of $10 \% \mathrm{HCl}$ in water via addition of sodium nitrite $(0.160 \mathrm{~g}, 2.34$ mmoles $)$. Solution was added to pyrrolidine $(0.165 \mathrm{~g}, 2.34$ mmoles, $0.191 \mathrm{~mL})$ in borate $\mathrm{pH}$ 9.5 to yield a light brown solid $(0.130 \mathrm{~g}, 96 \%)$. The compound's spectra matched the literature values. ${ }^{16}$

${ }^{1} \mathrm{H}$ NMR $\left(400 \mathrm{MHz}, \mathrm{CDCl}_{3}\right) \delta 7.32(\mathrm{~d}, J=8.3 \mathrm{~Hz}, 2 \mathrm{H}), 7.14(\mathrm{~d}, J=8.1 \mathrm{~Hz}, 2 \mathrm{H}), 3.79(\mathrm{~s}$, $4 \mathrm{H}), 2.35(\mathrm{~s}, 3 \mathrm{H}), 2.11-1.87(\mathrm{~m}, 4 \mathrm{H})$.

${ }^{13} \mathrm{C}$ NMR $\left(100 \mathrm{MHz}, \mathrm{CDCl}_{3}\right) \delta$ 149.3, 134.8, 129.5, 120.3, 48.7 (ws), 23.9, 21.1. 
Pyrrolidine, 1-[2-(4-methoxyphenyl)diazinyl] - (S10)

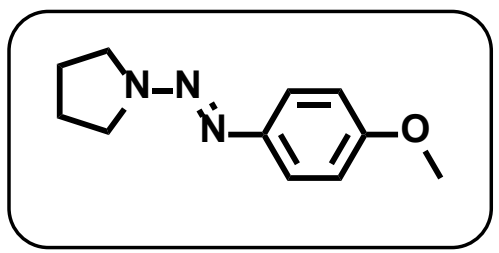

General synthesis starting with diazotization of 4methoxyaniline $(0.050 \mathrm{~g}, 0.407$ mmoles) in $4 \mathrm{~mL}$ of $10 \% \mathrm{HCl}$ in water via addition of sodium nitrite $(0.370 \mathrm{~g}, 2.04 \mathrm{mmoles})$. Solution was added to pyrrolidine $(0.274 \mathrm{~g}, 2.04 \mathrm{mmoles}$, $0.316 \mathrm{~mL})$ in borate $\mathrm{pH} 9.5$ to yield a light brown solid $(0.053$ g, 58\%). The compound's spectra matched the literature values. ${ }^{17}$

${ }^{1} \mathrm{H}$ NMR $\left(400 \mathrm{MHz}, \mathrm{CDCl}_{3}\right) \delta 7.37(\mathrm{~d}, J=9.0 \mathrm{~Hz}, 2 \mathrm{H}), 6.87(\mathrm{~d}, J=9.0 \mathrm{~Hz}, 2 \mathrm{H}), 3.78(\mathrm{~d}, J$ $=16.5 \mathrm{~Hz}, 7 \mathrm{H}), 2.00(\mathrm{~m}, 4 \mathrm{H})$.

${ }^{13} \mathrm{C}$ NMR (100 MHz, $\left.\mathrm{CDCl}_{3}\right) \delta 157.5,145.4,121.3,114.1,55.5,48.4$ (ws), 23.9.

Comparing yields of pyrrolidine triazenes

SI Table 1. Yields of various pyrrolidine triazenes

\begin{tabular}{c|l|l|l}
$\begin{array}{c}\text { Triazene } \\
\#\end{array}$ & R Group & $\begin{array}{c}\text { Hammett } \\
\text { Value }\end{array}$ & $\begin{array}{c}\text { Yield } \\
\%\end{array}$ \\
\hline S7 & $p-\mathrm{Br}$ & +0.23 & 37 \\
S8 & $m-\mathrm{OMe}$ & +0.15 & 52 \\
S3 & $\mathrm{H}$ & 0.00 & 56 \\
S9 & $p-\mathrm{CH}_{3}$ & -0.17 & 33 \\
S10 & $p-\mathrm{OMe}$ & -0.27 & 58
\end{tabular}




\section{Characterization of Azo-Adducts- Low pH \& UV irradiation}

Triazene reactivity with resorcinol at $\mathrm{pH} 4$ (citrate buffer) with various substituents - (Figure S1)

$10 \mathrm{mg}$ of triazene was measured out into respective $20 \mathrm{~mL}$ glass synthetic vials. Triazenes were dissolved in $2 \mathrm{~mL} \mathrm{MeOH}$. Resorcinol (1 equiv.) was dissolved in buffer $1.6 \mathrm{~mL}$ Eppendorf's via addition of $1 \mathrm{~mL}$ of $0.1 \mathrm{M}$ citrate buffer $(\mathrm{pH} 4)$. An additional $1 \mathrm{~mL}$ of $0.1 \mathrm{M}$ citrate $\mathrm{pH} 4$ was then added to each reaction vessel to make a $4 \mathrm{~mL}, 50 \%$ citrate solution $(\mathrm{pH} 4)$. Solutions were then magnetically stirred at room temp and incubated void of light for 3 hours. Following incubation, extraction was performed with DCM and products were dried by vacuum. Resulting products were then washed with nanopore water and isolated by gravity filtrations, and further extracted from the filter paper with DCM and vacuum pumped. Crude extracts were dissolved in deuterated DMSO and characterized by ${ }^{1} \mathrm{HNMR}$. Samples containing azo-adducts were further purified on silica column with $100 \%$ DCM until elution was clear. Products were washed off column with $\mathrm{MeOH}$ and vacuumed before final characterization by ${ }^{1} \mathrm{HNMR}$.

Triazene reactivity with resorcinol under UV with various substituents (Figure S1)

$10 \mathrm{mg}$ of triazene was measured out into respective $20 \mathrm{~mL}$ glass synthetic vials. Triazenes were dissolved in $2 \mathrm{~mL} \mathrm{MeOH}$. Resorcinol (1 equiv.) was dissolved in separate $1.6 \mathrm{~mL}$ Eppendorf's via addition of $1 \mathrm{~mL}$ of $0.1 \mathrm{M} \mathrm{PBS}(\mathrm{pH} 7)$. An additional $1 \mathrm{~mL}$ of 0.1 M PBS ( $\mathrm{pH} 7$ ) was then added to each reaction vessel to make a $4 \mathrm{~mL}, 50 \%$ PBS solution $(\mathrm{pH} 7)$. Solutions were then placed in a doer and magnetically stirred at room temp. They were then irradiated with $370 \mathrm{~nm}$ LED for 3 hours. Following irradiation, extraction was performed with DCM and products were dried by vacuum. Resulting products were then washed with nanopore water and isolated by gravity filtrations, and further extracted from the filter paper with DCM and vacuum pumped. Crude extracts were dissolved in deuterated DMSO and characterized by ${ }^{1} \mathrm{HNMR}$. Samples containing azo-adducts were further purified on silica column with $100 \%$ DCM until elution was clear. Products were washed off column with $\mathrm{MeOH}$ and vacuumed before characterization by ${ }^{1} \mathrm{HNMR}$. 
Percent yield of azo-adduct vs. substituent Hammett value post UV

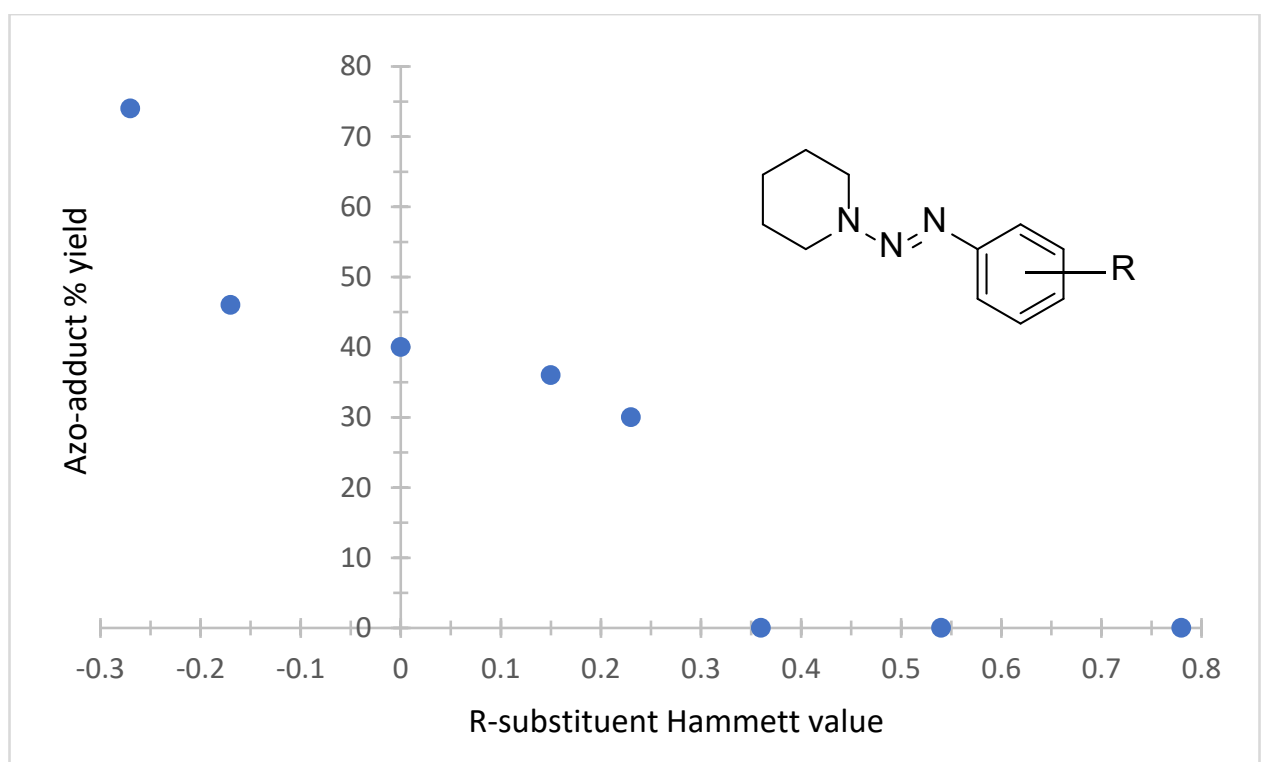

Figure S12. The percent yield of various azo-adduct formation from the reaction of triazenes (1a-i) and resorcinol following 3 hours of $370 \mathrm{~nm}$ UV irradiation was plotted against the respective Hammett values corresponding with the aryl substituents. There is a clear trend that triazenes with lower Hammett values had higher aryl diazonium ion reactivity. 


\section{Effect of cyclic secondary amine on aryl diazonium ion release}

General procedure for comparing reactivities of piperidine, pyrrolidine, piperazine, and morpholine derived benzene triazenes (19, S3-S5) - (Figure S2)

$10 \mathrm{mg}$ of respective triazenes made from the various cyclic amine nucleophiles (piperidine, pyrrolidine, piperazine, and morpholine) were measured out into respective $20 \mathrm{~mL}$ glass synthetic vials. Triazenes were dissolved in $2 \mathrm{~mL} \mathrm{MeOH}$. Resorcinol (1 equiv.) was dissolved in $1 \mathrm{~mL}$ of $0.1 \mathrm{M} \mathrm{PBS}(\mathrm{pH} 7)$ and added to solution. An additional $1 \mathrm{~mL}$ of $0.1 \mathrm{M} \mathrm{PBS} \mathrm{pH} 7$ was then added to each reaction vessel to make a $4 \mathrm{~mL}, 50: 50$ PBS and $\mathrm{MeOH}$ solution $(\mathrm{pH} 7)$. Solutions were then placed in a doer and magnetically stirred at room temp. They were then irradiated with $370 \mathrm{~nm}$ LED for 1 hour. TLC was performed after 1 hour with 100\% DCM and azo-adducts were confirmed. Products were extracted with DCM and dried by vacuum. Resulting products were then washed with nanopore water, isolated by gravity filtrations, and further extracted from the filter paper with DCM before being vacuum pumped. Lastly, products were purified on a mini-silica column with $100 \%$ DCM. Impurities were removed by gravity elution (no flash) until no color further eluted. Azo-product was washed off column with methanol and vacuumed. Products were dissolved in deuterated DMSO or chloroform and characterized by ${ }^{1}$ HNMR.

Synthesis of 4-(Phenylazo)resorcinol (2g) from various triazene

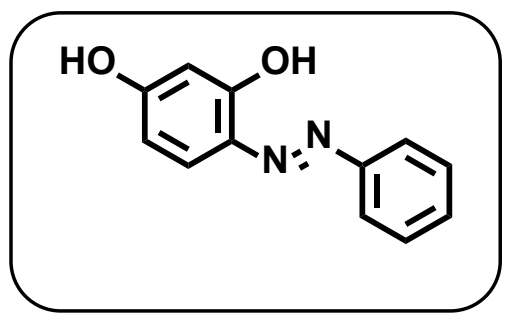

Synthesis from pyrrolidine triazene - (S3)

In a second $20 \mathrm{~mL}$ vial $10 \mathrm{mg}$ of $\mathbf{S} 3(0.053 \mathrm{mmol})$ was dissolved with resorcinol $(5.7 \mathrm{mg}$, $0.053 \mathrm{mmol}$ ) in a $4 \mathrm{~mL} 50: 50$ solution of $\mathrm{MeOH}$ and PBS pH 7. Sample was stirred and irradiated for 1 hour and extracted by DCM and column purified $(3.9 \mathrm{mg}, 32 \%)$.

Synthesis from piperazine triazene - (S4)

In a second $20 \mathrm{~mL}$ vial $10 \mathrm{mg}$ of $\mathbf{S 4}(0.052 \mathrm{mmol})$ was dissolved with resorcinol $(5.7 \mathrm{mg}$, $0.052 \mathrm{mmol}$ ) in a $4 \mathrm{~mL} 50: 50$ solution of $\mathrm{MeOH}$ and PBS pH 7. Samples were stirred and irradiated for 1 hour and extracted by DCM and column purified (3.2 mg, 28\%). 
Synthesis from morpholine triazene - (S5)

In a second $20 \mathrm{~mL}$ vial $10 \mathrm{mg}$ of $\mathbf{S 5}(0.057 \mathrm{mmol})$ was dissolved with resorcinol $(6.3 \mathrm{mg}$, $0.057 \mathrm{mmol}$ ) in a $4 \mathrm{~mL} 50: 50$ solution of $\mathrm{MeOH}$ and PBS pH 7. Samples were stirred and irradiated for 1 hour and extracted by DCM and column purified $(0.9 \mathrm{mg}, 8 \%)$.

\section{Determining mechanism of UV initiated aryl diazonium ion release}

Measuring $\mathrm{pH}$ change upon irradiation of triazene treated water solutions (Figure 2)

Triazene stocks were made by dissolving compound in DMSO. $8 \mathrm{mg}$ of $1 \mathrm{a}\left(p-\mathrm{NO}_{2}\right), \mathbf{1 g}$ (Benzene), and $1 \mathrm{i}\left(p-\mathrm{CH}_{3}\right)$ were measured out into separate $1.6 \mathrm{~mL}$ Eppendorf tubes and dissolved in $1 \mathrm{~mL}$ of DMSO, making stocks of $34.2 \mathrm{mM} 42.3 \mathrm{mM}$ and $36.5 \mathrm{mM}$ respectively. Next, $16 \mathrm{~mL}$ of nanopore water was measured out in small glass beakers. For the 1a sample, $234 \mu \mathrm{L}$ of the stock was added to the $16 \mathrm{~mL}$ solution. For the $1 \mathrm{~g}$ sample, $189 \mu \mathrm{L}$ of stock was added to the $16 \mathrm{~mL}$ solution. For the $1 \mathrm{i}$ sample, $219 \mu \mathrm{L}$ was added to the water solution. All samples had a final triazene concentration of $0.5 \mathrm{mM}$ ( $1 \%$ DMSO solution). A pH probe was placed in the solution and $\mathrm{pH}$ was measured over time. Samples were let sit for an initial period of 30-60 seconds to allow for establishment of a baseline $\mathrm{pH}$. After reaching stable nascent $\mathrm{pH}$, measurements were taken void of irradiation for 30 seconds. After 30 seconds, the $370 \mathrm{~nm}$ LED lamp was turned on directly above the solution. Samples were irradiated and monitored for 60 seconds. After the light was switched off, monitoring continued for an additional 60 seconds to watch the $\mathrm{pH}$ return to equilibrium. Each triazene sample was monitored in triplicate $(n=3)$ and the values were averaged. The $\Delta \mathrm{pH}$ was then plotted as a function of time and overlapped with corresponding irradiation times. 


\section{Kinetic experiments with $p$-methyl piperidine triazene}

Kinetic measurement of p-methyl piperidine triazene (1 h) - (Figure 3)

$10 \mathrm{mg}$ of $1 \mathrm{~h}\left(\mathrm{p}-\mathrm{CH}_{3}\right)$ was dissolved in $710 \mu \mathrm{L}$ of deuterated $\mathrm{MeOH}(0.0692 \mathrm{M})$. Next, 5.3 $\mathrm{mg}$ of resorcinol $(0.0692 \mathrm{M}, 1$ equiv.) was measured out and dissolved in the $710 \mu \mathrm{L}$ deuterated $\mathrm{MeOH}$. Solution was transferred to an NMR tube and capped. Following an initial proton NMR, the tube was then placed perpendicular to the $370 \mathrm{~nm}$ UV LED light source, centered $\sim 2 \mathrm{~cm}$ in front of the sample in the tube. Sample was initially irradiated for 10 minutes and then evaluated by ${ }^{1} \mathrm{HNMR}$. The sample was then irradiated for 20 minutes and evaluated by ${ }^{1} \mathrm{HNMR}$. Following these initial scans, the sample was irradiated in 30-minute stints for the next 390 minutes. After 420 minutes of total irradiation time, the irradiation time was increased to 60 minutes between NMR scans until a total time of 540 minutes was reached. In all, 18 scans were taken over the course of 540 minutes ( $9 \mathrm{hrs}$ ) of irradiation and a total time of 1779 minutes. The reaction never reached completion. Following the final scan, the produced azo-adduct $\mathbf{2 h}$ was purified on silica and confirmed by ${ }^{1} \mathrm{HNMR}$. Product was a bright red solid $(9.6 \mathrm{mg}, 86 \%)$.

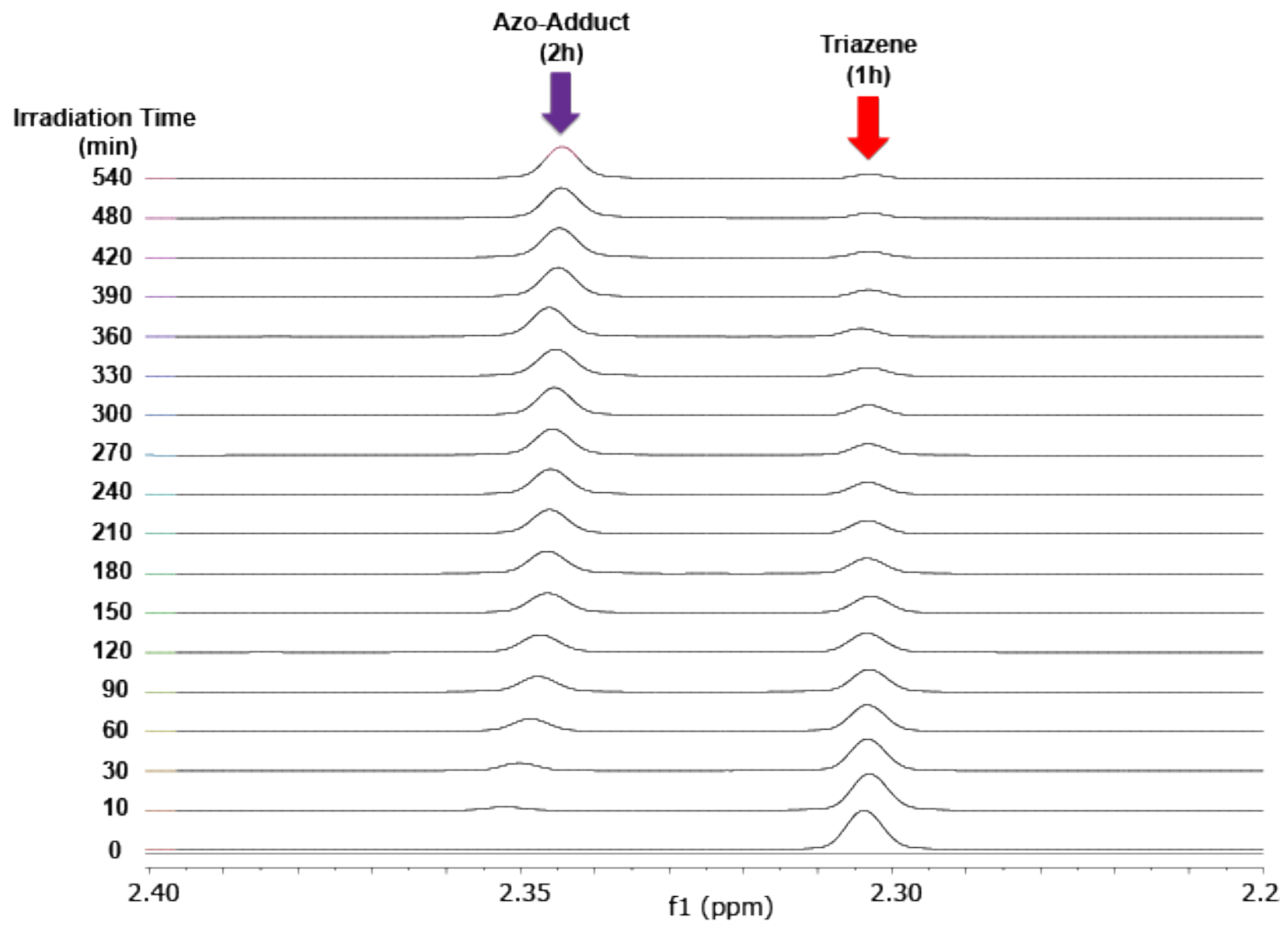

Figure S13. Overlaid ${ }^{1} \mathrm{HMNR}$ spectra zoomed in on the respective methyl proton signals for the $\mathbf{2 h}$ azo-adduct (purple arrow) and the $1 \mathrm{~h}$ triazene starting material (red arrow). 


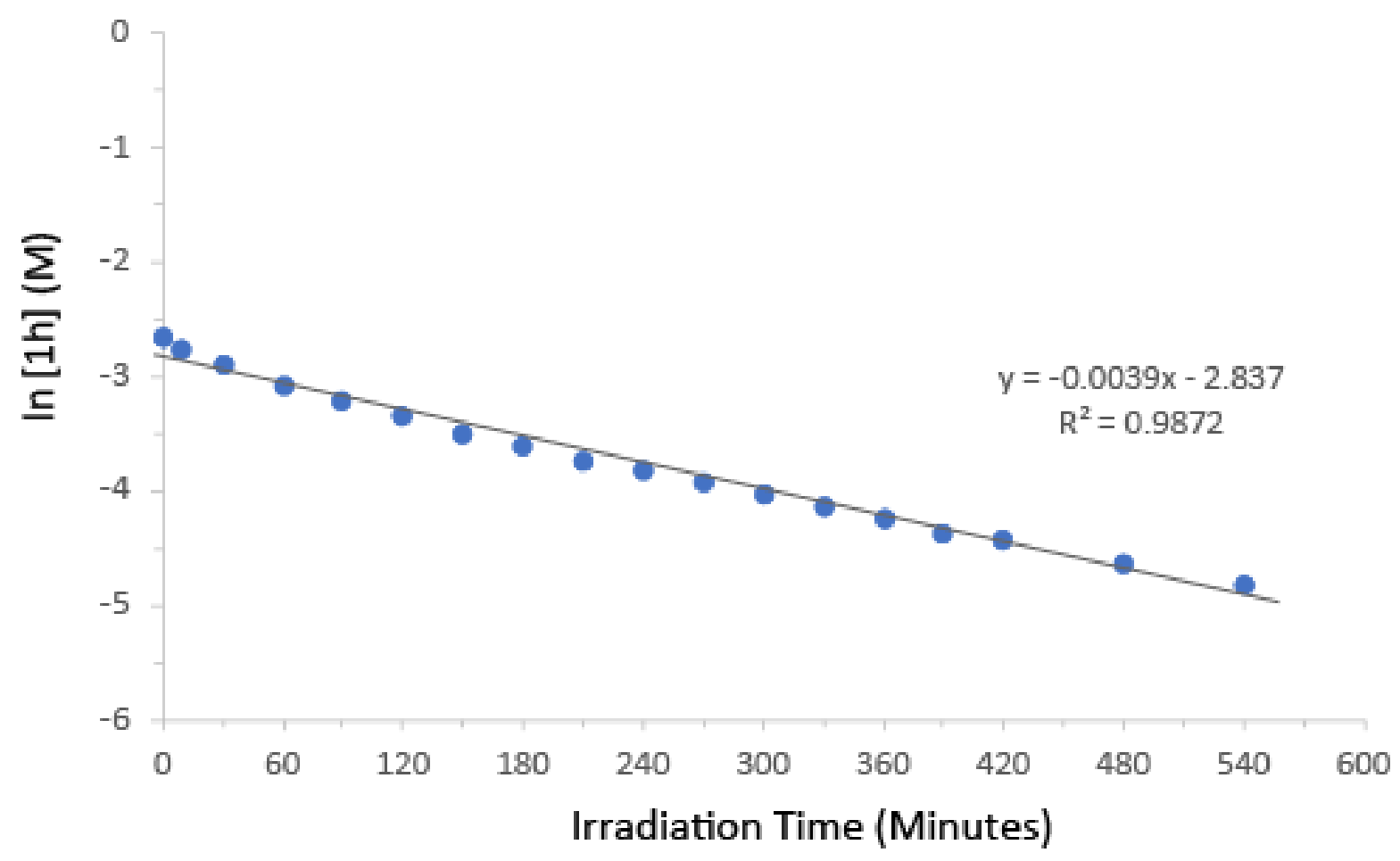

Figure S14. Natural log of $1 \mathrm{~h}$ triazene concentration plotted as a function of irradiation time (UV $370 \mathrm{~nm}$ ).

Plotting Kinetic data: Triazene (1h) concentration (mM) vs Time (min) (Figure S14)

The relative integrations for the methyl peaks for the starting material (1h) and the resulting azo-adduct product $(\mathbf{2} \mathbf{h})$ were measured using MestReNova NMR analysis software (Figure S4). They were then plotted in Excel as a ratio (starting material integration /product integration) as a function of irradiation time (minutes) (See manuscript Figure 3). Following this initial plot, the ratio was converted to concentration of triazene $(\mathbf{1 h})$ at each time point by multiplying the respective ratio by the starting concentration $(0.0692 \mathrm{M})$. This was then plotted as a function of time. Next, we calculated the natural log of the concentration of triazene $1 \mathrm{~h}$ and plotted it as a function of time to produce a linear curve with an $R^{2}$ of 0.99 (Figure S14). 


\section{Biochemical Studies and Protocols}

Confirmation of azo-modification by sodium dithionite reduction - (Figure 4B)

$1 \mathrm{mM}$ BSA was diluted into PBS buffer to make 6 separate samples of $100 \mu \mathrm{M}$ BSA (100 $\mu \mathrm{L}$ of $1 \mathrm{mM}$ BSA into $1 \mathrm{~mL}$ of solution). 3 was added to separate samples in varying concentrations of $0.1 .0 .2,0.4,0.6$ and $0.8 \mathrm{mM}$ with a duplicate $0.8 \mathrm{mM}$ sample to act as a non-irradiated control sample. All experimental samples were simultaneously irradiated by the $370 \mathrm{~nm}$ UV LED for 20 minutes. Following irradiation, the samples were incubated further for 15 minutes void of light. Each sample was then split in half to provide 2 aliquots of $500 \mu \mathrm{L}$. Each aliquot was quenched via the addition of $25 \mu \mathrm{L}$ of $100 \mathrm{mM}$ resorcinol giving a final resorcinol concentration of $5 \mathrm{mM}$. Next, one aliquot from each respective sample duo was further treated with $20 \mathrm{mM}$ sodium dithionite (10 $\mu \mathrm{L}$ of a $1 \mathrm{M}$ sodium dithionite sample added to $500 \mu \mathrm{L}$ total). The reduction reaction was incubated for 2 hours. Next, all samples were passed through SEC using a G-10 resin. Samples were collected and normalized for concentration. All samples were then subsequently treated with 'copper-click' conditions $(0.5 \mathrm{mM}$ copper chloride, $5 \mathrm{mM}$ ascorbic acid, $0.1 \mathrm{mM}$ AlexaFluor $^{\mathrm{TM}}$ azide) for 30 minutes. Samples were then loaded onto a $12 \%$ SDS gel and band fluorescence was evaluated using a $488 \mathrm{~nm}$ laser line. Protein presence was confirmed by Coomassie staining.

Confirmation of azo-modification by resorcinol competition during lysozyme labeling - (Figure 4C)

A $2 \mathrm{mM}$ stock of lysozyme was made by dissolving $14.3 \mathrm{mg}$ of lysozyme in $1 \mathrm{~mL}$ of 0.1 PBS buffer ( $\mathrm{pH} 7$ ). Concentration was confirmed by A280 measurements using an Agilent 8453 UV-visible spectroscopy system and referencing of the molar absorptivity. ${ }^{18} \mathrm{Next}$, a sample was made via addition of $25 \mu \mathrm{L}$ of $2 \mathrm{mM}$ lysozyme stock to $960 \mu \mathrm{L}$ of $0.1 \mathrm{M}$ PBS pH 7 buffer. To this solution was also added $15 \mu \mathrm{L}$ of a $33.3 \mathrm{mM}$ stock of 3 bringing the final concentrations of $0.5 \mathrm{mM} \mathrm{3}$, and $50 \mu \mathrm{M}$ lysozyme. $250 \mu \mathrm{L}$ of this sample was removed and kept void of light to act as a control. A third sample was made by the addition of $6.25 \mu \mathrm{L}$ of $2 \mathrm{mM}$ Lysozyme to $235 \mu \mathrm{L}$ of PBS buffer. Additionally, this sample was also treated with $3.75 \mu \mathrm{L}$ of $33.3 \mathrm{mM} 3$ and $5 \mu \mathrm{L}$ of $1 \mathrm{M}$ resorcinol, providing a final volume of $250 \mu \mathrm{L}$ and final concentrations of $50 \mu \mathrm{M}$ Lysozyme, $0.5 \mathrm{mM}$ 3 , and $20 \mathrm{mM}$ resorcinol. The two non-control samples were then irradiated in separate wells of a 96-well plate by a $370 \mathrm{~nm}$ LED for 10 minutes. All samples were then subsequently treated with 'copper-click' conditions $(0.5 \mathrm{mM}$ copper chloride, $5 \mathrm{mM}$ ascorbic acid, $0.2 \mathrm{mM}$ AlexaFluor ${ }^{\mathrm{TM}}$ azide, and $1.5 \mathrm{mM}$ THPTA) for 30 minutes. Samples were then loaded onto a $12 \%$ SDS gel and band fluorescence was evaluated using a 488 $\mathrm{nm}$ laser line. Protein presence was confirmed by Coomassie staining. 
Time point assessment for pre-acidification treatment of BSA with 3 (Figure S7)

3 was dissolved into DMSO and an aliquot of $20 \mu \mathrm{L}$ was treated with $5 \mu \mathrm{L}$ of concentrated $\mathrm{HCl}$ with a final triazene concentration of $30 \mathrm{mM}$. Four $25 \mu \mathrm{M}$ BSA samples were made by diluting $25 \mu \mathrm{L}$ of $1 \mathrm{mM}$ BSA stock into $958 \mu \mathrm{L}$ of PBS buffer (pH 7). At various points of pre-acidification time, $0,1,5$, and 15 minutes, $16.7 \mu \mathrm{L}$ of the triazene stock was added to the respective BSA samples to provide a final triazene concentration of $\sim 0.5 \mathrm{mM}$. Samples were incubated at RT for 30 minutes before being quenched by the addition of $5 \mathrm{mM}$ resorcinol ( $50 \mu \mathrm{L}$ of a $100 \mathrm{mM}$ resorcinol stock). After being quenched, sub aliquots of each time point were then treated with $0.3 \mathrm{mM}$ AlexaFluor ${ }^{\mathrm{TM}}$ azide under 'copper-click' conditions ( $0.2 \mathrm{mM}$ copper chloride, $5 \mathrm{mM}$ ascorbic acid, and $1 \mathrm{mM}$ THPTA) for 30 minutes. Samples were loaded onto an 12\% SDS gel and evaluated for band fluorescence using a $488 \mathrm{~nm}$ laser line. Protein presence was confirmed by Coomassie staining.

\section{Reactivity of $\mathbf{3}$ with BSA upon UV irradiation - (Figure S8)}

A $60 \mathrm{mM}$ stock of 3 was made by dissolving $3.2 \mathrm{mgs}$ of 3 into $250 \mu \mathrm{L}$ of DMSO. A sample of $25 \mu \mathrm{M}$ BSA was made by adding $25 \mu \mathrm{L}$ of $1 \mathrm{mM}$ BSA to $973.3 \mu \mathrm{L} 0.1 \mathrm{M}$ PBS buffer, $\mathrm{pH}$ 7. To these solutions were added $1.7 \mu \mathrm{L}$ of the respective $60 \mathrm{mM}$ stocks to provide a final triazene concentrations of $0.1 \mathrm{mM}$. The samples were then irradiated for time points of $0,5,10,15$, and 30 minutes using the $370 \mathrm{~nm}$ UV LED. Samples were aliquoted via removal of $50 \mu \mathrm{L}$ at each time point. All samples were quenched with $5 \mu \mathrm{L}$ of $100 \mathrm{mM}$ resorcinol ( $\sim 9 \mathrm{mM}$ final resorcinol concentration) following a 1-hour post irradiation incubation time. All aliquots were then treated with 'copper-click' conditions $(0.5 \mathrm{mM}$ copper chloride, $5 \mathrm{mM}$ ascorbic acid, and $0.1 \mathrm{mM}$ AlexaFluor ${ }^{\mathrm{TM}} 488 \mathrm{~nm}$ azide) for 30 minutes. Samples were evaluated for band fluorescence on a $12 \%$ SDS gel. Protein presence was confirmed by Coomassie staining.

\section{SDS-PAGE time point assessment of 3 labeling of MSP - (Figure 5A)}

$20 \mu \mathrm{L}$ of $150 \mu \mathrm{M}$ MSP stock was added to $99 \mu \mathrm{L}$ of a PBS buffer solution ( $\mathrm{pH} 7$ ). It was then treated with $0.5 \mu \mathrm{L}$ of $60 \mathrm{mM} 3$ to provide a triazene concentration of $0.5 \mathrm{mM}$. The sample was then transferred to a 96-well plate and irradiated for increasing time points by a $370 \mathrm{~nm}$ LED. $10 \mu \mathrm{L}$ aliquots were removed at time points of $0,1,2,3,4,5,6,8$, and 10 minutes of UV irradiation. Aliquots were then treated with 'copper-click' conditions ( 0.5 $\mathrm{mM}$ copper chloride, $5 \mathrm{mM}$ ascorbic acid, and $0.5 \mathrm{mM}$ AlexaFluor ${ }^{\mathrm{TM}}$ azide with $1 \mathrm{mM}$ THPTA). Samples were loaded on a $18 \%$ SDS gel and evaluated for fluorescence with a $488 \mathrm{~nm}$ laser line. Protein presence was confirmed by Coomassie staining. 
Assessment of aryl diazonium ion stability with and without UV irradiation (Figure 5B)

A $30 \mathrm{mM}$ stock of 3 was made by dissolving 3 in methanol. $20 \mu \mathrm{L}$ of 3 stock was transferred to a separate Eppendorf and treated with $2 \mu \mathrm{L}$ of concentrated $\mathrm{HCl}$ to bring the $\mathrm{pH}$ to $\sim 1$. This sample was incubated for 20 minutes of pre-acidification. $1.7 \mu \mathrm{L}$ of the pre-acidified 3 stock was then added to 4 different samples containing $81.6 \mu \mathrm{L}$ of PBS buffer pH 8 to provide an aryl diazonium ion concentration of $\sim 0.5 \mathrm{mM}$. $16.7 \mu \mathrm{L}$ of MSP protein stock $(150 \mu \mathrm{M})$ was then added to respective samples at time point of 0,5 , 10 , and 30 -minute incubation to trap the remaining aryl diazonium ion in solution. These samples were all compared to a control sample containing $0.5 \mathrm{mM}$ of 3 that had not been pre-acidified. A second subset of samples was made containing the same relative amounts of aryl diazonium ion, but these aliquots were irradiated during incubation and protein was added to quench remaining aryl diazonium ion following irradiation times of $0,1,5$ and 10 minutes. These samples were also compared to a control sample that had not been pre-acidified. All samples were then treated with 'copper-click' conditions ( $5 \mathrm{mM}$ ascorbic acid, $0.5 \mathrm{mM}$ copper chloride and $1 \mathrm{mM}$ THPTA; 1 hour) along with 0.5 $\mathrm{mM}$ Alexa Fluor Azide $(488 \mathrm{~nm})$. Samples were then loaded on an SDS gel and later evaluated for fluorescence.

\section{Native MS evaluation of MSP treatment by 3 under increasing UV irradiation times - (Figure S10-A)}

A $25 \mu \mathrm{M}$ sample of MSP was made in PBS buffer $(\mathrm{pH} 7)$ via addition of $41.7 \mu \mathrm{L}$ of a 150 $\mu \mathrm{M}$ stock to a total volume of $250 \mu \mathrm{L}$. This sample was further treated with $4.2 \mu \mathrm{L}$ of a 60 $\mathrm{mM}$ stock of 3 to provide a final triazene concentration of $0.5 \mathrm{mM}$. Next the sample was transferred to a 96 well plate. $50 \mu \mathrm{L}$ aliquots were removed at irradiation times of $0,1,3$, 5 , and 10 minutes. Following irradiation, the samples were incubated overnight. Samples were evaluated for modification via native mass spec. Buffer exchange was performed on each sample twice into $0.2 \mathrm{M}$ ammonium acetate $(\mathrm{pH} 6.8)$ using a Micro Bio-spin P-6 column (BioRad). The final concentration of each sample prior to analysis was $\sim 65 \mu \mathrm{M}$. Native mass spectrometry (MS) was performed using the QExactive HF quadrupoleOrbitrap mass spectrometer with Ultra-High Mass Range modifications (Thermo Fisher Scientific). Native mass spectrometry was performed in positive-ion mode using borosilicate nano-electrospray ionization needles pulled using a P-1000 micropipette puller (Sutter Instrument, Novato, CA). Instrumental parameters applied include $1.1 \mathrm{kV}$ spray voltage, $50 \mathrm{~V}$ source voltage, and $50 \mathrm{~V}$ collisional voltage. The instrument had a trapping gas pressure set to 3 . The scan range for all samples was 1,500-15,000 m/z, and the instrumental resolution was set to 15,000 . Data was analyzed with UniDec. ${ }^{19}$ 


\section{Quantification of protein band fluorescence - (Figure S10-B)}

Quantification of band fluorescence was evaluated via Image J Software. Band intensity was first measured for both the fluorescence image and the corresponding Coomassie image. Band intensity for each individual sample was quantified using band integration tools on ImageJ software, measuring densitometry. Relative band concentration was normalized to the sample with the largest integration value, resulting in a respective ratio. Fluorescence integrations were then divided by respective intensity ratios of the Coomassie stain.

\section{Labeling of MSP with pre-acidified 3 - (Figure S11)}

Two samples containing $25 \mu \mathrm{M}$ MSP was made by adding $8.33 \mu \mathrm{L}$ of a $150 \mu \mathrm{M}$ stock to a volume of $100 \mu \mathrm{L}$ of $0.1 \mathrm{M}$ PBS buffer (pH 7). In the first sample, $1.7 \mu \mathrm{L}$ of $30 \mathrm{mM} 3$ was added to provide a final concentration of $0.5 \mathrm{mM} \mathrm{3}$. This sample was covered with foil and stored void of light. For the second sample, a $20 \mu \mathrm{L}$ aliquot of 3 stock was treated with $1 \mu \mathrm{L}$ of concentrated $\mathrm{HCl}$ and incubated void of light for 10 minutes. Then, $1.7 \mu \mathrm{L}$ of the pre-acidified 3 stock was added to the MSP sample. Following addition, $\mathrm{pH}$ was checked via $\mathrm{pH}$ paper to ensure neutral $\mathrm{pH}$. All samples were then incubated overnight. Both samples were then evaluated for modifications use native mass spectrometry.

Determining optimal $\mathrm{pH}$ for 3 labeling of MSP via UV irradiation - (Figure S12)

$25 \mu \mathrm{M}$ MSP samples were made by diluting $16.7 \mu \mathrm{L}$ of $150 \mu \mathrm{M}$ MSP stock into a total volume of $100 \mu \mathrm{L}$. To each sample was then added $1 \mu \mathrm{L}$ of a $50 \mathrm{mM} 3$ stock to provide a final concentration of $0.5 \mathrm{mM}$. Samples were brought to final volume via addition of the appropriate $\mathrm{pH}$ buffer ( $\mathrm{pH} 5-10)$. A $20 \mu \mathrm{L}$ aliquot was removed from each $\mathrm{pH}$ sample and set aside to incubate void of light to act as our negative control. The remaining samples were then transferred to a 96 well plate. The samples were then simultaneously irradiated by $370 \mathrm{~nm}$ LED for 3 minutes. Then samples were placed back into Eppendorf's and incubated void of light for 2 hours. Samples were treated with 'copper-click' conditions (5 $\mathrm{mM}$ ascorbic acid, $0.5 \mathrm{mM}$ copper chloride and $1 \mathrm{mM}$ THPTA; $1 \mathrm{hr}$ ) along with $0.5 \mathrm{mM}$ AlexaFluor $^{\mathrm{TM}}$ azide $(488 \mathrm{~nm})$. Samples were then loaded on a $18 \%$ SDS gel and evaluated by SDS-PAGE and scanned with a $488 \mathrm{~nm}$ Laser line. Protein bands were confirmed via Coomassie staining. 


\section{Characterization of UV LED source}

\section{General protocol for determination of emission max}

Emission intensity measure using a Newport Oriel 74100 Cornerstone 1/4m Monochromator. Emission intensity was measured every $5 \mathrm{~nm}$ starting at $300 \mathrm{~nm}$ and continuing up to $460 \mathrm{~nm}$. Emission intensity was plotted in $\mathrm{mV}$ as a function of wavelength (340 $\mathrm{nm}$ to $420 \mathrm{~nm}$ ). Maximal emission was determined to be $\sim 370 \mathrm{~nm}$.

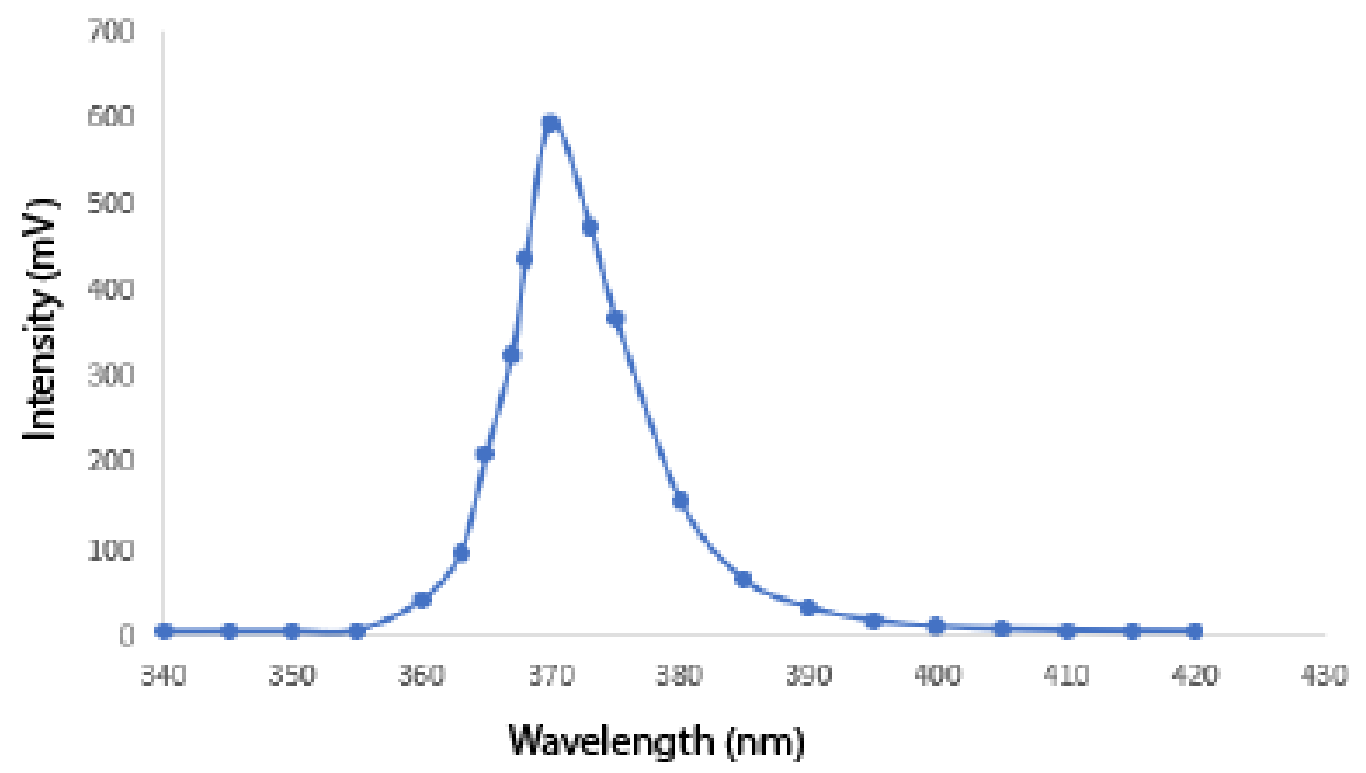

Figure S15. Excitation spectra for the UV LED light source tested for emission between $300 \mathrm{~nm}$ and $460 \mathrm{~nm}$. 


\section{LED apparatus and reaction setup}

A Front

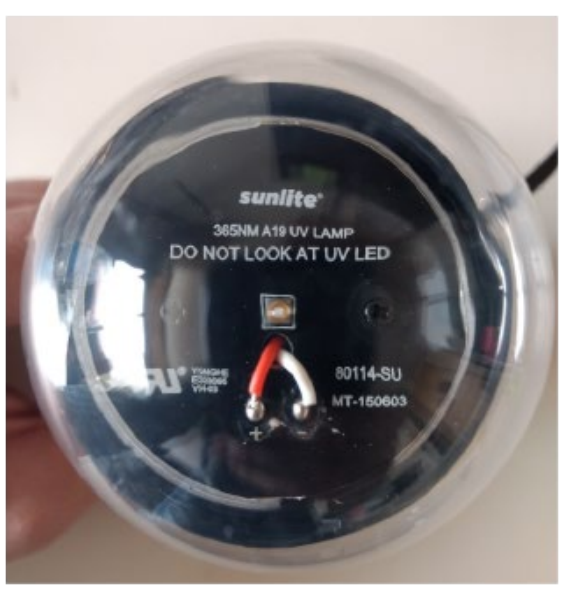

B

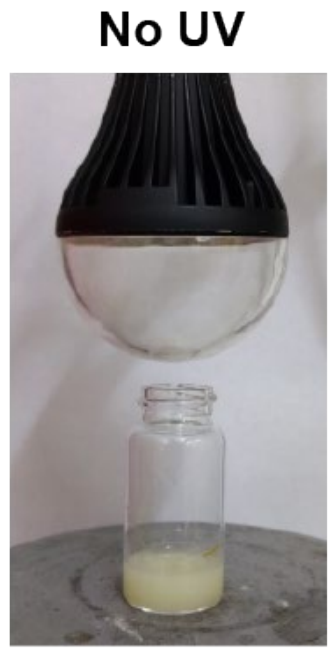

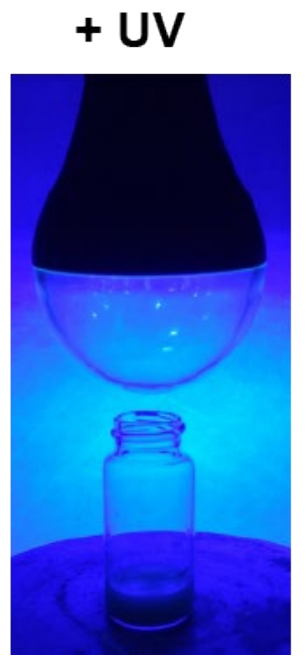

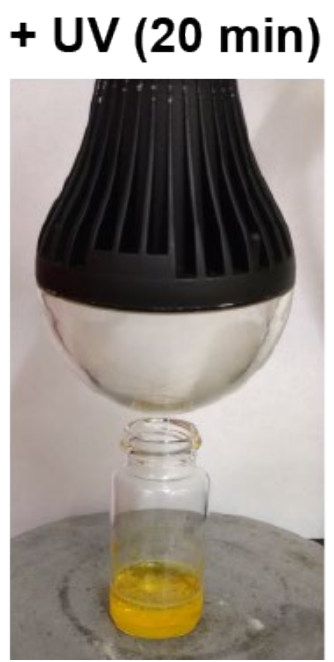

Figure S16. Setup of UV initiated reactions. (A) Front and side view of the UV LED light source. (B) Monitoring reaction progression for $\mathbf{1 g}$ with 1 equivalence of resorcinol before, during, and after irradiation up to $3 \mathrm{~h}$. Reaction was performed in 50/ 50 mixture of methanol and pH $70.1 \mathrm{M}$ PBS as described above. Note that the triazene $\mathbf{1 g}$ starts insoluble, but upon irradiation it becomes increasingly soluble along with a visible color change due to the formation of the respective azo-adduct $\mathbf{2 g}$. After $3 \mathrm{~h}$, the solution turns read and shows the production of a red precipitate $\mathbf{2} \mathbf{g}$. 


\section{Protocol for absorbance spectroscopy}

\section{General protocol}

$5 \mathrm{mg}$ of respective triazene were measured in $1.6 \mathrm{~mL}$ Eppendorf tubes. Triazenes were dissolved in $1 \mathrm{~mL}$ of $\mathrm{MeOH}$ and respective concentrations were determined. The appropriate amount of triazene stock was diluted into $1 \mathrm{~mL}$ of a $50 / 50$ mixture of $0.1 \mathrm{M}$ PBS $\mathrm{pH} 7$ and $\mathrm{MeOH}$ providing a final triazene concentration of $0.0492 \mathrm{mM}$. Scans were taken on a Cary UV spectrophotometer scanning from $180 \mathrm{~nm}-600 \mathrm{~nm}$ in a quartz cuvette.

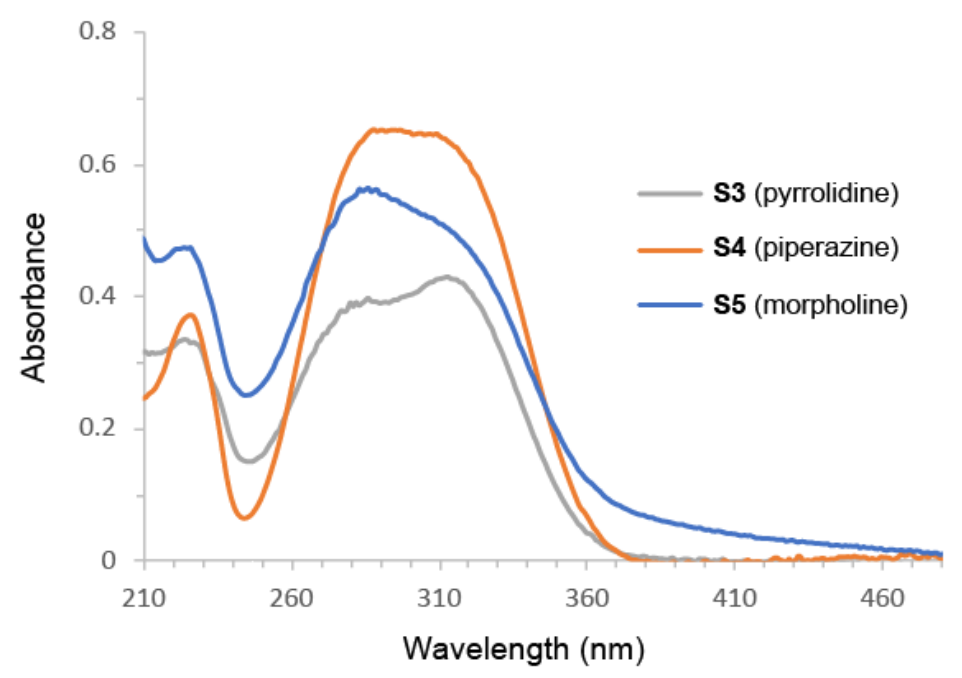

Figure S17. Overlaid absorbance profile for triazenes of various secondary amines including pyrrolidine, piperazine, and morpholine (S3-S5). Compounds were dissolved in stocks of $\mathrm{MeOH}$ and were diluted into a 50/50 mixture of $0.1 \mathrm{M} \mathrm{PBS} \mathrm{pH} 7$ and $\mathrm{MeOH}$. Final triazene concentration was $0.0492 \mathrm{mM}$. 


\section{References}

(1) Phosphate Buffer ( $\mathrm{pH} 5.8$ to 7.4) Preparation and Recipe | AAT Bioquest https://www.aatbio.com/resources/buffer-preparations-and-recipes/phosphatebuffer-ph-5-8-to-7-4 (accessed Aug 26, 2021).

(2) Citrate Buffer (pH 3.0 to 6.2) Preparation and Recipe | AAT Bioquest https://www.aatbio.com/resources/buffer-preparations-and-recipes/citrate-bufferph-3-to-6-2 (accessed Aug 26, 2021).

(3) Oliver Hardick, Buffer Recipes https://www.ucl.ac.uk/ ucbeoha/Buffer Recipes.html\#Borate (accessed Aug 26, 2021).

(4) Reid, D. J.; Keener, J. E.; Wheeler, A. P.; Zambrano, D. E.; Diesing, J. M.; Reinhardt-Szyba, M.; Makarov, A.; Marty, M. T. Engineering Nanodisc Scaffold Proteins for Native Mass Spectrometry. Anal. Chem. 2017, 89 (21), 1118911192.

(5) Schotten, C.; Leprevost, S. K.; Yong, L. M.; Hughes, C. E.; Harris, K. D. M.; Browne, D. L. Comparison of the Thermal Stabilities of Diazonium Salts and Their Corresponding Triazenes. Org. Process Res. Dev. 2020. 24, 2336-2341.

(6) Nishiwaki, K.; Okamoto, A.; Matsuo, K.; Kawaguchi, Y.; Hayase, Y.; Ohba, K. Antimalarial Activity of 1-Aryl-3,3-Dialkyltriazenes. Bioorganic Med. Chem. 2007, 15 (8), 2856-2859.

(7) Ng, J. S.; Katzenellenbogen, J. A.; Kilbourn, M. R. Aromatic Fluorinations Suitable for Fluorine-18 Labeling of Estrogens. J. Org. Chem. 1981, 46 (12), 2520-2528.

(8) Sutar, S. M.; Savanur, H. M.; Malunavar, S. S.; Prabhala, P.; Kalkhambkar, R. G.; Laali, K. K. 1-Aryltriazenes in the Suzuki, Heck, and Sonogashira Reactions in Imidazolium-ILs, with [BMIM(SO $\left.\left.{ }_{3} \mathrm{H}\right)\right][\mathrm{OTf} \text { or } \mathrm{Sc}(\mathrm{OTf}))_{3}$ as Promoter, and $\mathrm{Pd}(\mathrm{OAc})_{2}$ or $\mathrm{NiCl}_{2}$ glyme as Catalyst. European J. Org. Chem. 2019, 2019 (35),

(9) Schotten, C.; Leprevost, S. K.; Yong, L. M.; Hughes, C. E.; Harris, K. D. M.; Browne, D. L. Comparison of the Thermal Stabilities of Diazonium Salts and Their Corresponding Triazenes. Org. Process Res. Dev. 2020, 24, 2336-2341.

(10) Leriche, G.; Budin, G.; Brino, L.; Wagner, A. Optimization of the Azobenzene Scaffold for Reductive Cleavage by Dithionite; Development of an Azobenzene Cleavable Linker for Proteomic Applications. European J. Org. Chem. 2010, 4360-4364.

(11) Zha, R. H.; Vantomme, G.; Berrocal, J. A.; Gosens, R.; Waal, B. de; Meskers, S.; Meijer, E. W. Photoswitchable Nanomaterials Based on Hierarchically Organized Siloxane Oligomers. Adv. Funct. Mater. 2018, 28 (1), 1703952.

(12) Romsted, L. S.; Zhang, J.; Zhuang, L. Mechanism of Reaction of an Arenediazonium Ion in Aqueous Solutions of Acetamide, N-Methylacetamide, and 
N,N-Dimethylacetamide. A Potential Method for Chemically Tagging Peptide Bonds at Aggregate Interfaces. J. Am. Chem. Soc. 1998, 120 (39), 10046-10054.

(13) Lazny, R.; Sienkiewicz, M.; Bräse, S. Application of Triazenes for Protection of Secondary Amines. Tetrahedron 2001, 57 (27), 5825-5832.

(14) Fu, J.; Lau, K.; Barra, M. Kinetic Studies on the Thermal Cis-to-Trans Isomerization of 1-Phenyltriazenes Derived from Cyclic Amines. J. Org. Chem. 2009, 74 (4), 1770-1773.

(15) Disli, A.; Yildirir, Y. New Synthesis of Phenylthioglycolic Acids via Related Triazene Compounds. Org. Prep. Proced. Int. 1998, 30 (3), 349-352.

(16) Liu, C.; Miao, T.; Zhang, L.; Li, P.; Zhang, Y.; Wang, L. Palladium-Catalyzed Direct C2 Arylation of $N$-Substituted Indoles with 1-Aryltriazenes. Chem. - An Asian J. 2014, 9 (9), 2584-2589.

(17) Cao, D.; Zhang, Y.; Liu, C.; Wang, B.; Sun, Y.; Abdukadera, A.; Hu, H.; Liu, Q. Ionic Liquid Promoted Diazenylation of N-Heterocyclic Compounds with Aryltriazenes under Mild Conditions. Org. Lett. 2016, 18 (9), 2000-2003.

(18) Pace, C. N.; Vajdos, F.; Fee, L.; Grimsley, G.; Gray, T. How to Measure and Predict the Molar Absorption Coefficient of a Protein. Protein Sci. 1995, 4 (11), 2411-2423.

(19) Marty, M. T.; Baldwin, A. J.; Marklund, E. G.; Hochberg, G. K. A.; Benesch, J. L. P.; Robinson, C. V. Bayesian Deconvolution of Mass and Ion Mobility Spectra: From Binary Interactions to Polydisperse Ensembles. Anal. Chem. 2015, 87 (8), 4370-4376. 


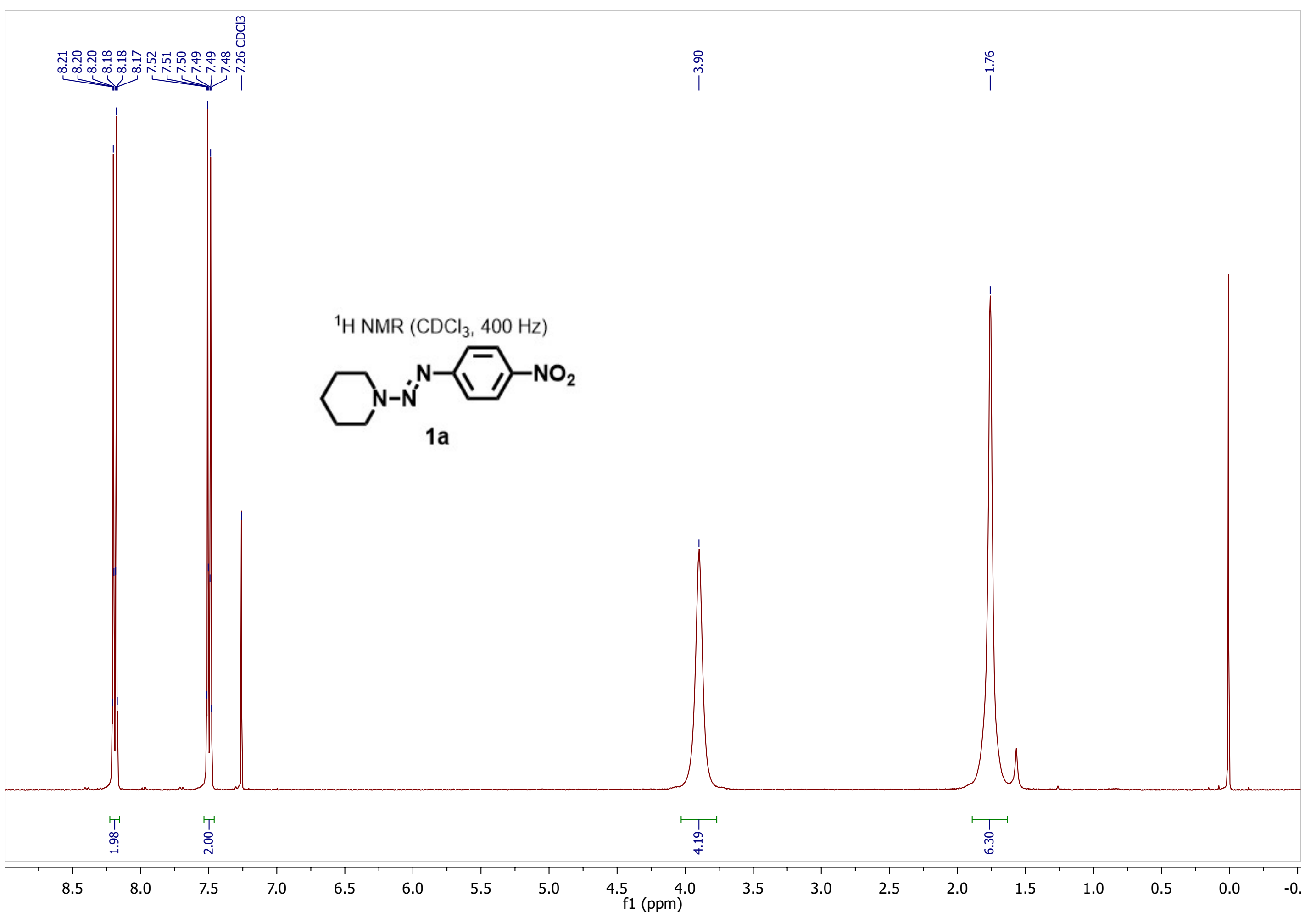




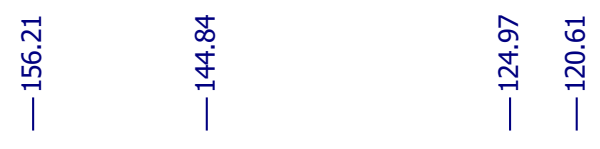

${ }^{13} \mathrm{C} \mathrm{NMR}\left(\mathrm{CDCl}_{3}, 100 \mathrm{~Hz}\right)$<smiles>O=[N+]([O-])c1ccc(N=NN2CCCCC2)cc1</smiles>

1a

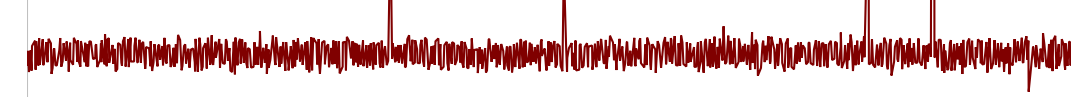$$
30
$$ 


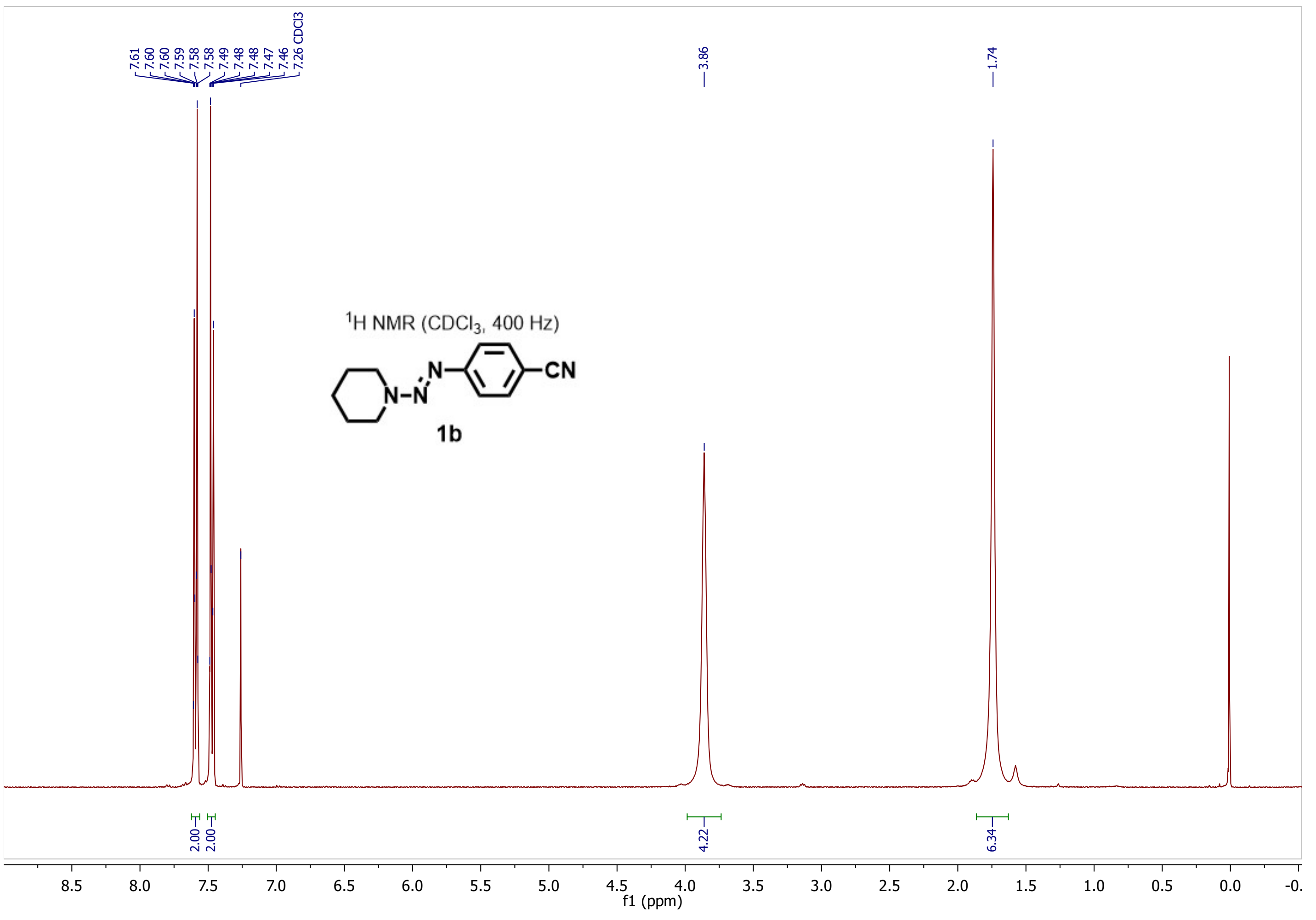




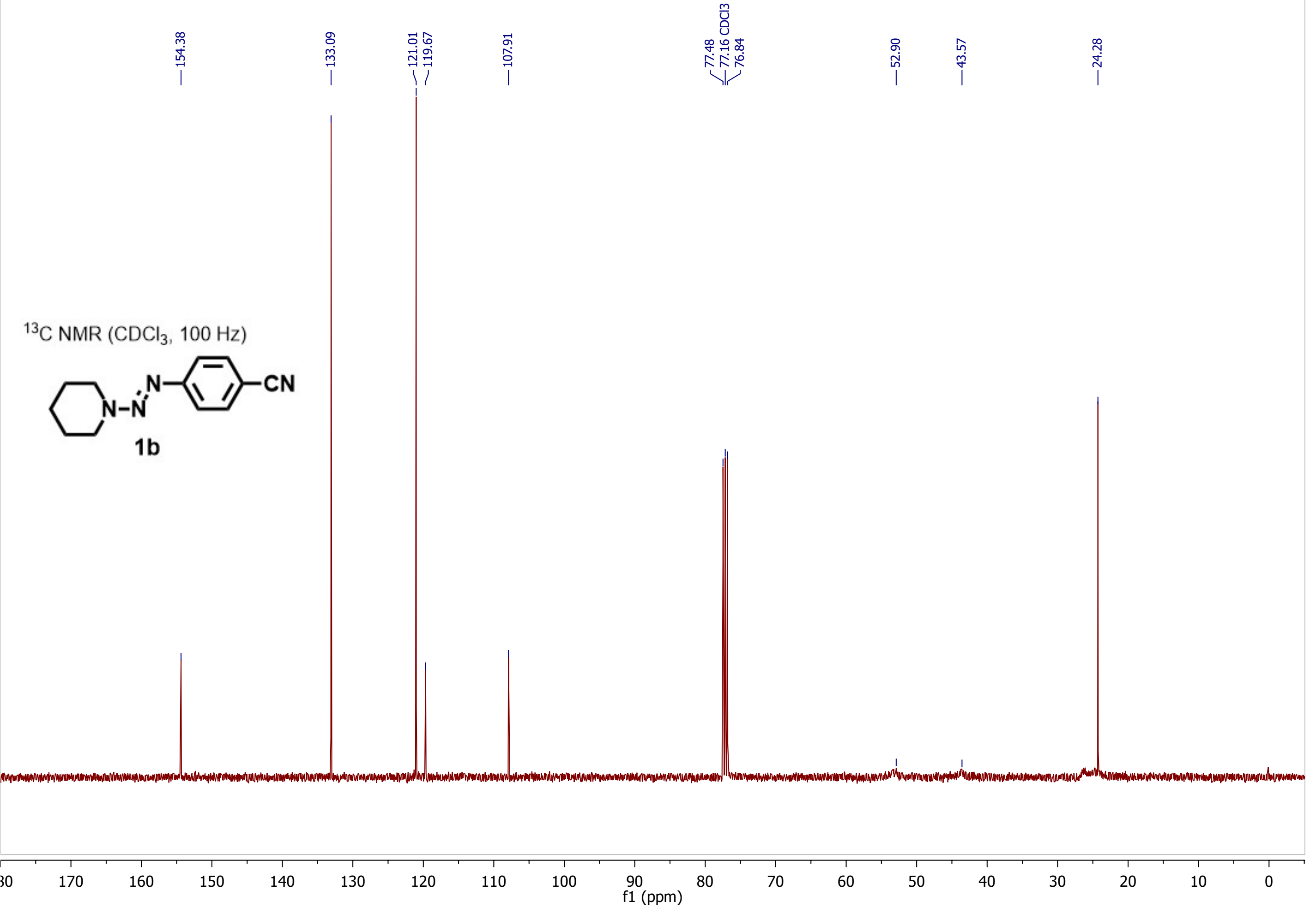




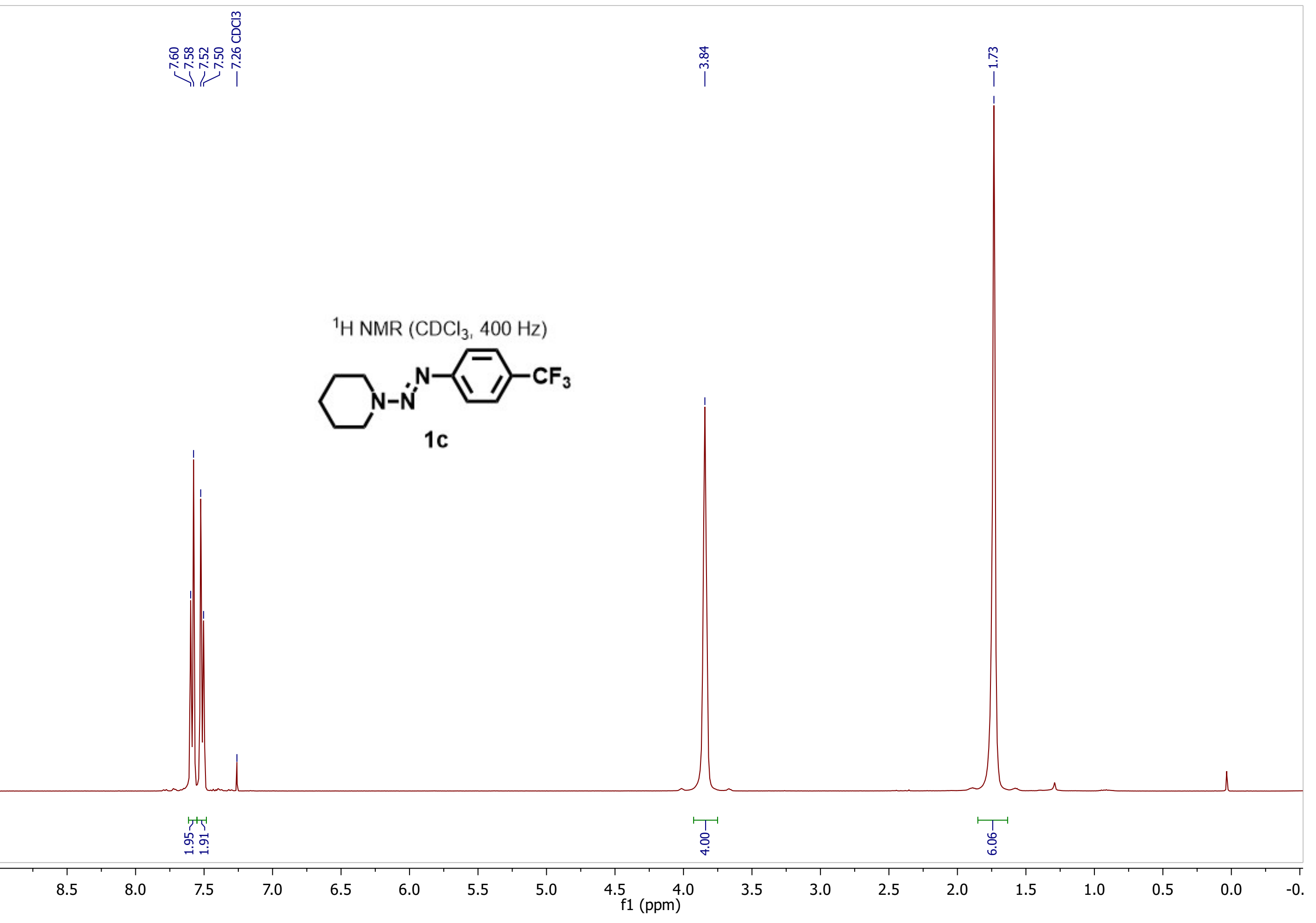




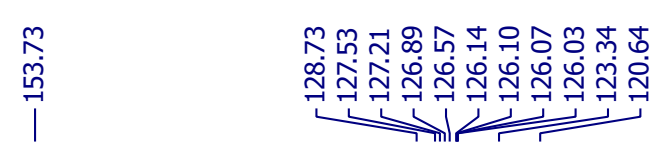

${ }^{13} \mathrm{C} \mathrm{NMR}\left(\mathrm{CDCl}_{3}, 100 \mathrm{~Hz}\right)$<smiles>FC(F)(F)c1ccc(/N=N/N2CCCCC2)cc1</smiles> 


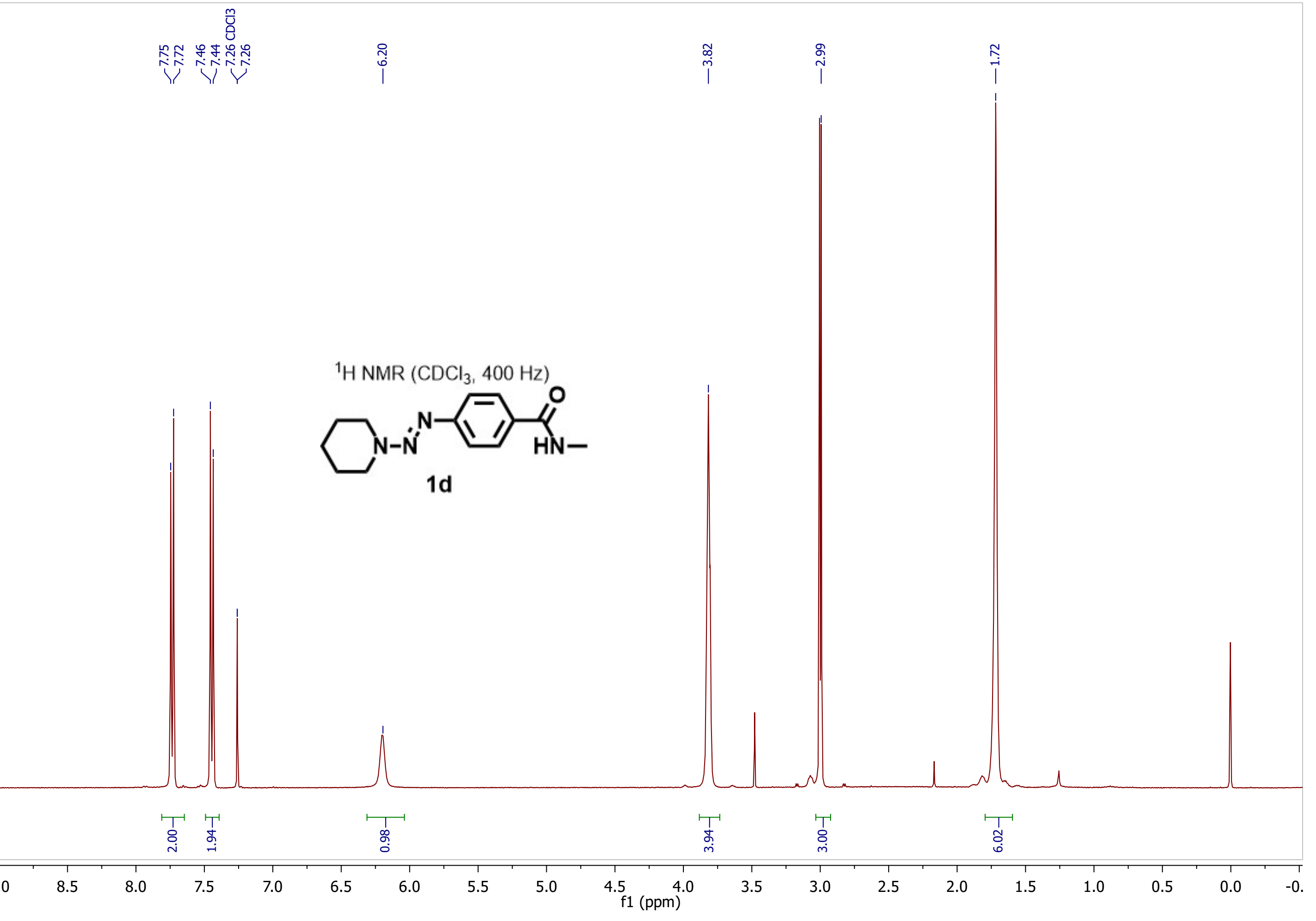




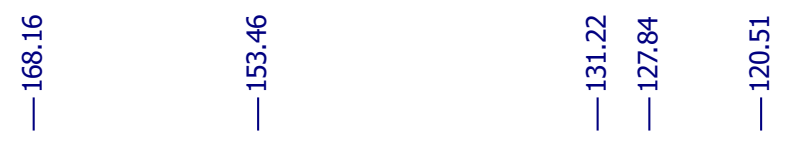

${ }^{13} \mathrm{C} \mathrm{NMR}\left(\mathrm{CDCl}_{3}, 100 \mathrm{~Hz}\right)$<smiles>CNC(=O)c1ccc(N=NN2CCCCC2)cc1</smiles>

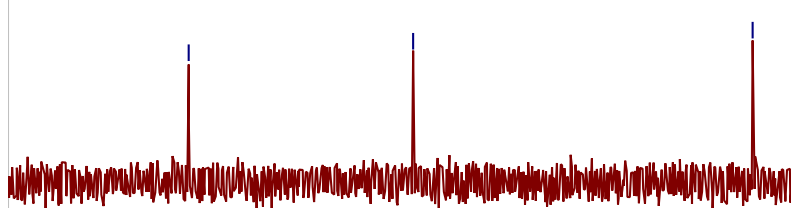



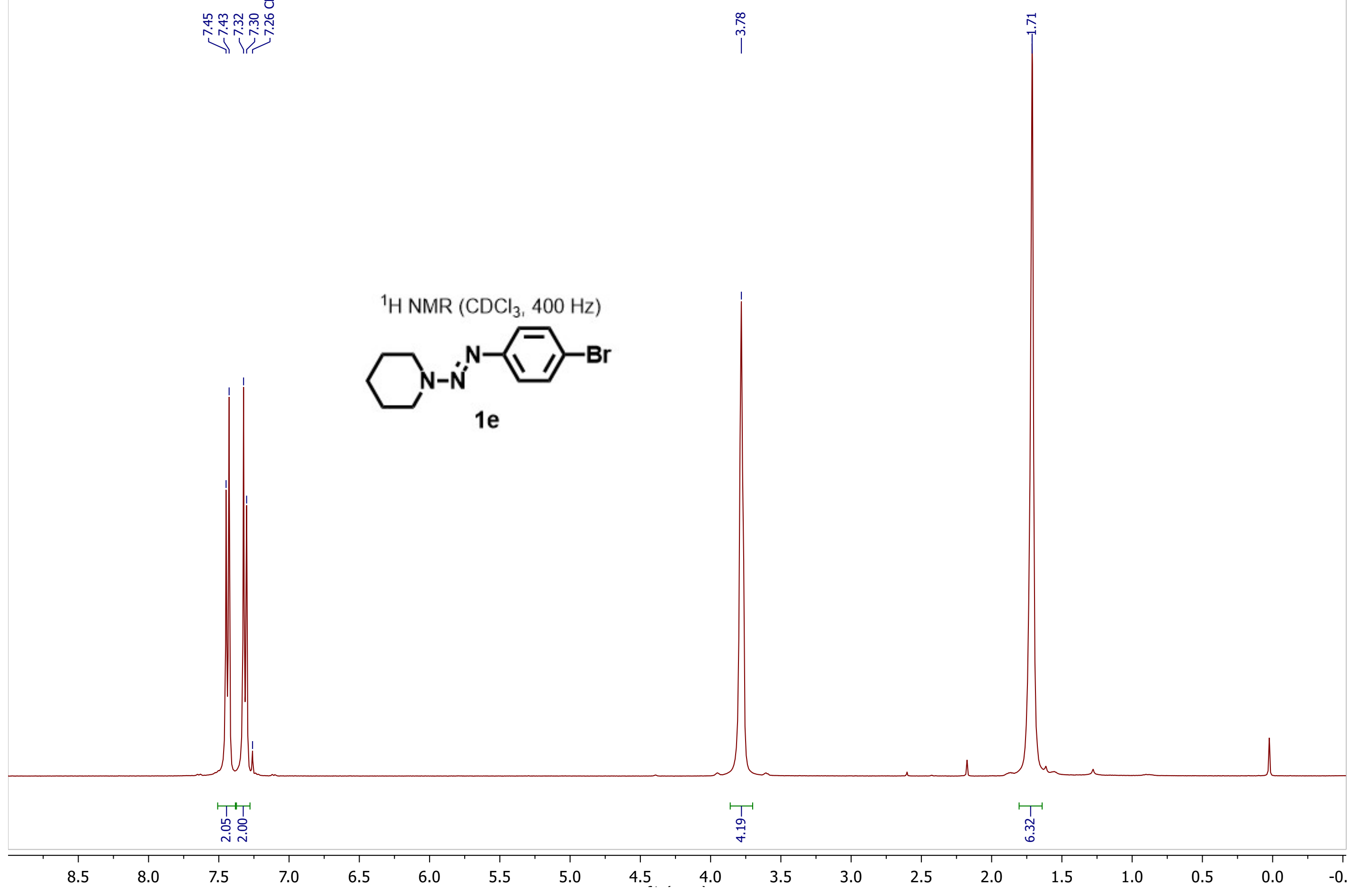
${ }^{13} \mathrm{C} \mathrm{NMR}\left(\mathrm{CDCl}_{3}, 100 \mathrm{~Hz}\right)$<smiles>Brc1ccc(N=NN2CCCCC2)cc1</smiles>
$1 \mathrm{e}$ 


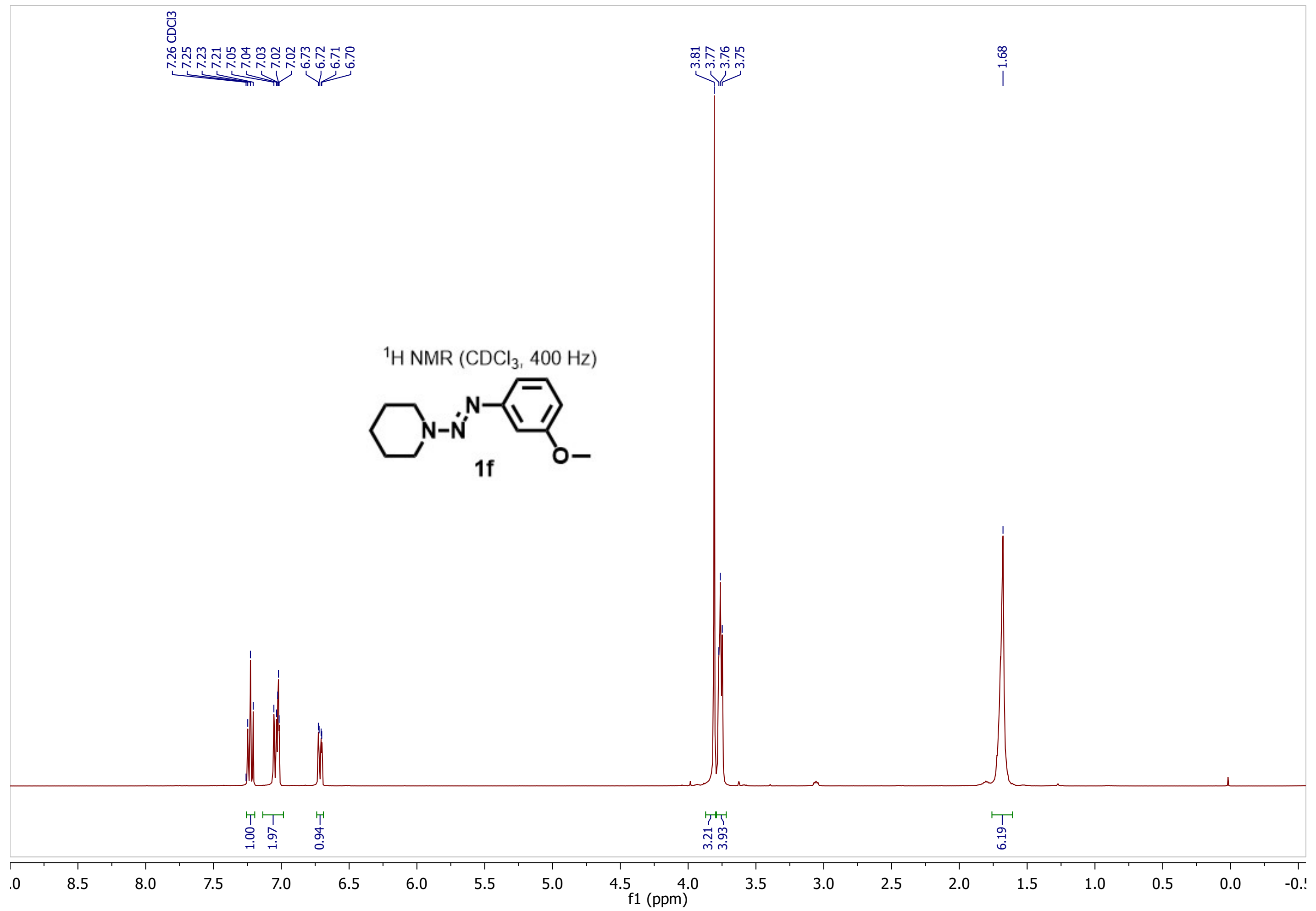


${ }^{13} \mathrm{C} \mathrm{NMR}\left(\mathrm{CDCl}_{3}, 100 \mathrm{~Hz}\right)$

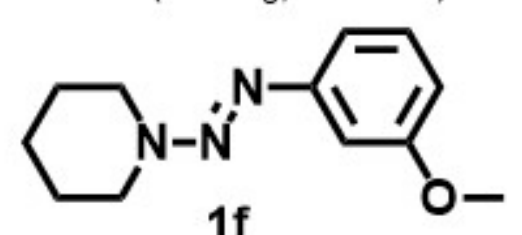

$1 f$
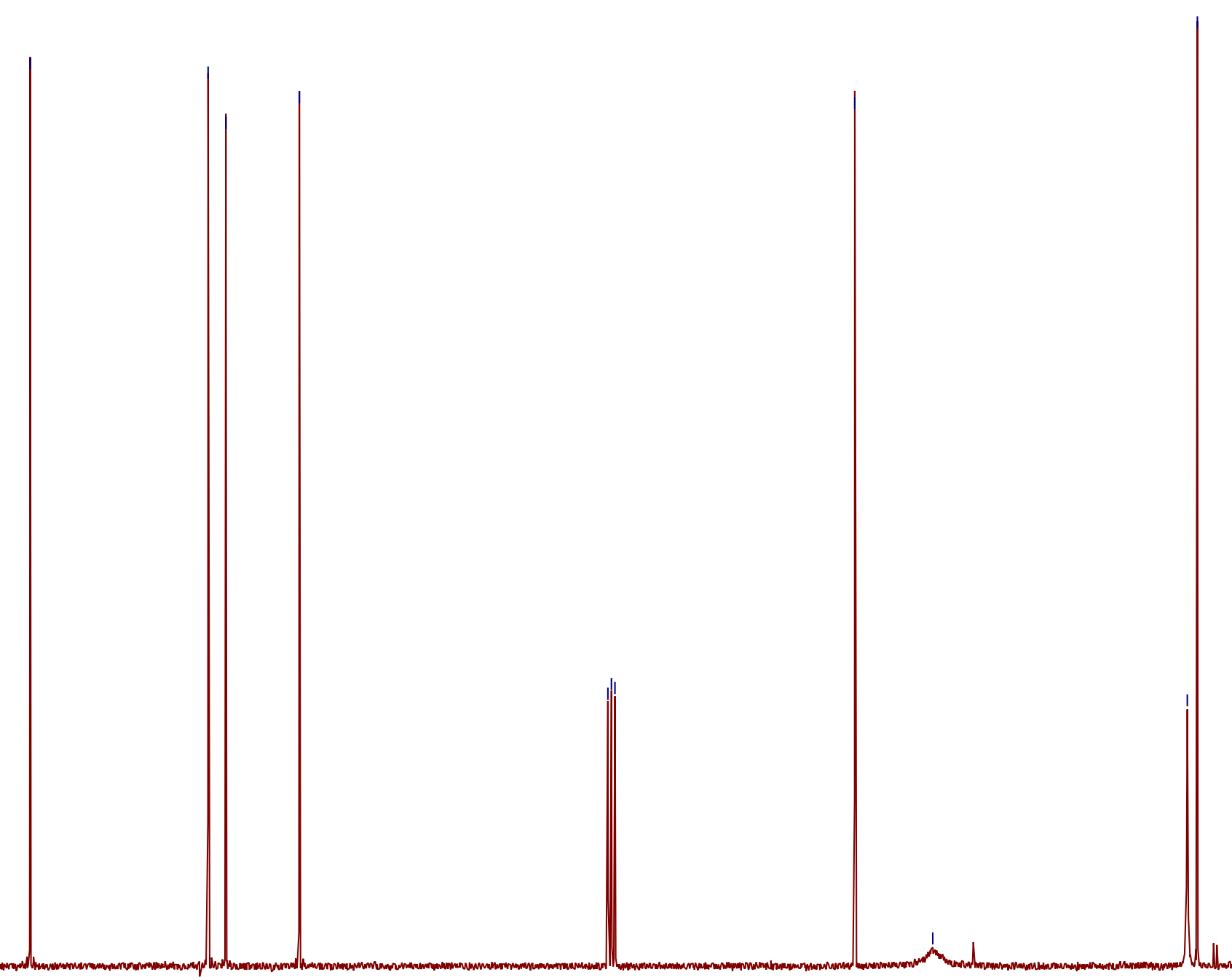
${ }^{1} \mathrm{H} \mathrm{NMR}\left(\mathrm{CDCl}_{3}, 400 \mathrm{~Hz}\right)$
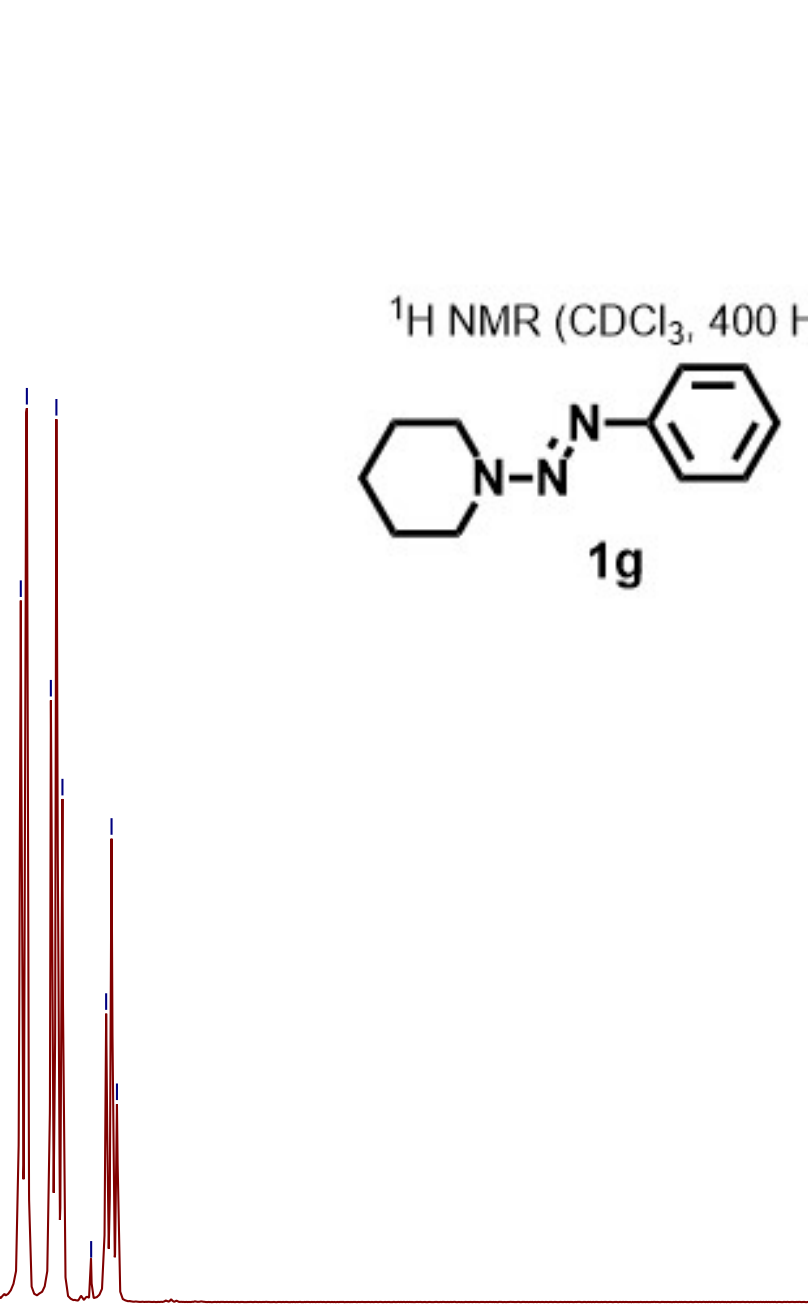

$1 \mathrm{~g}$

पात्र

7.5


${ }^{13} \mathrm{C} \mathrm{NMR}\left(\mathrm{CDCl}_{3}, 100 \mathrm{~Hz}\right)$<smiles>c1ccc(N=NN2CCCCC2)cc1</smiles>

1g

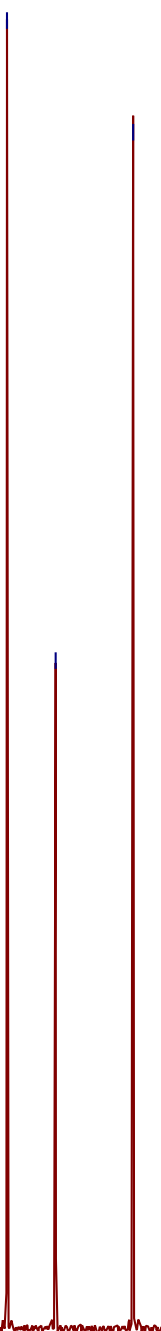

50

$50 \quad 40$

$40 \quad 30$


${ }^{1} \mathrm{H} \mathrm{NMR}\left(\mathrm{CDCl}_{3}, 400 \mathrm{~Hz}\right)$
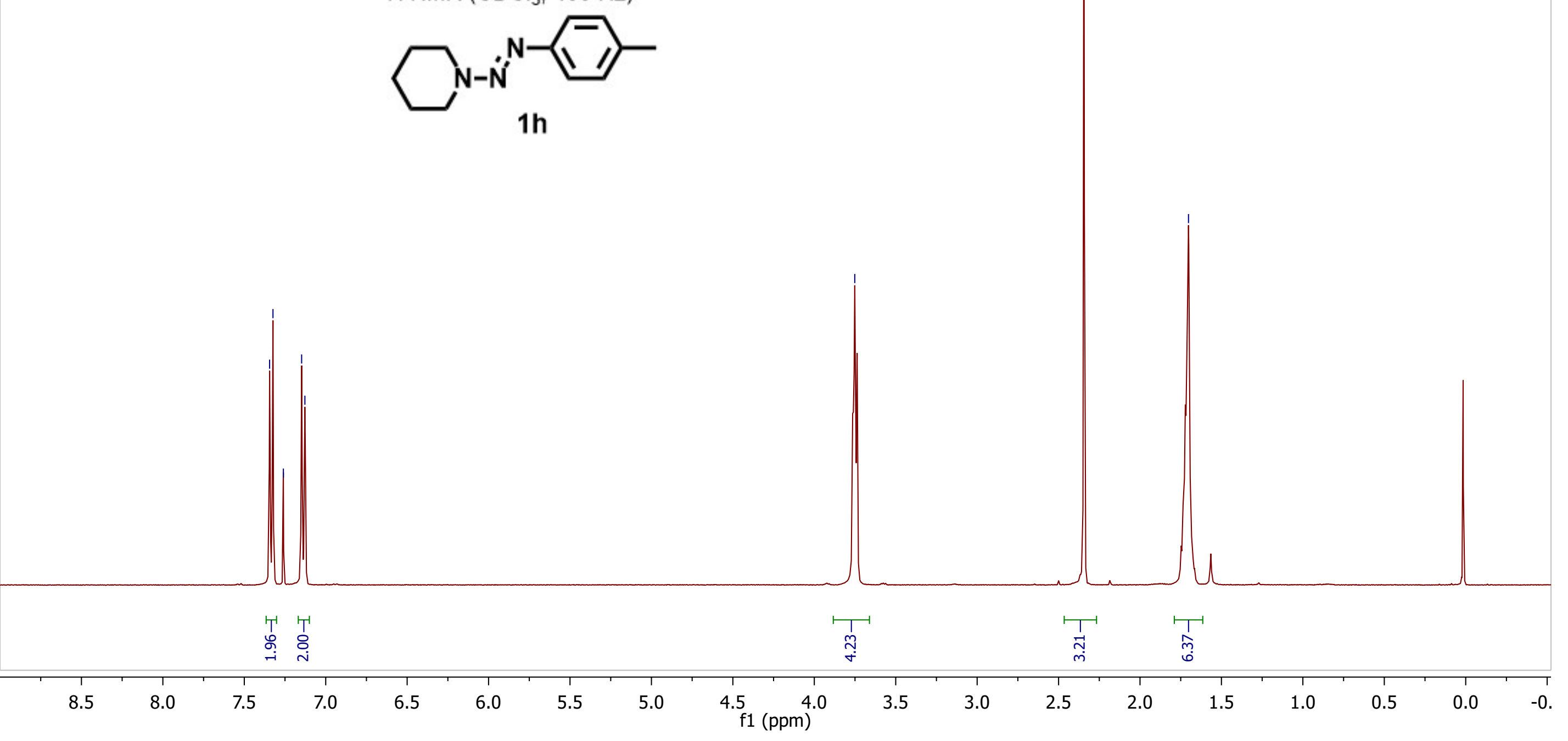


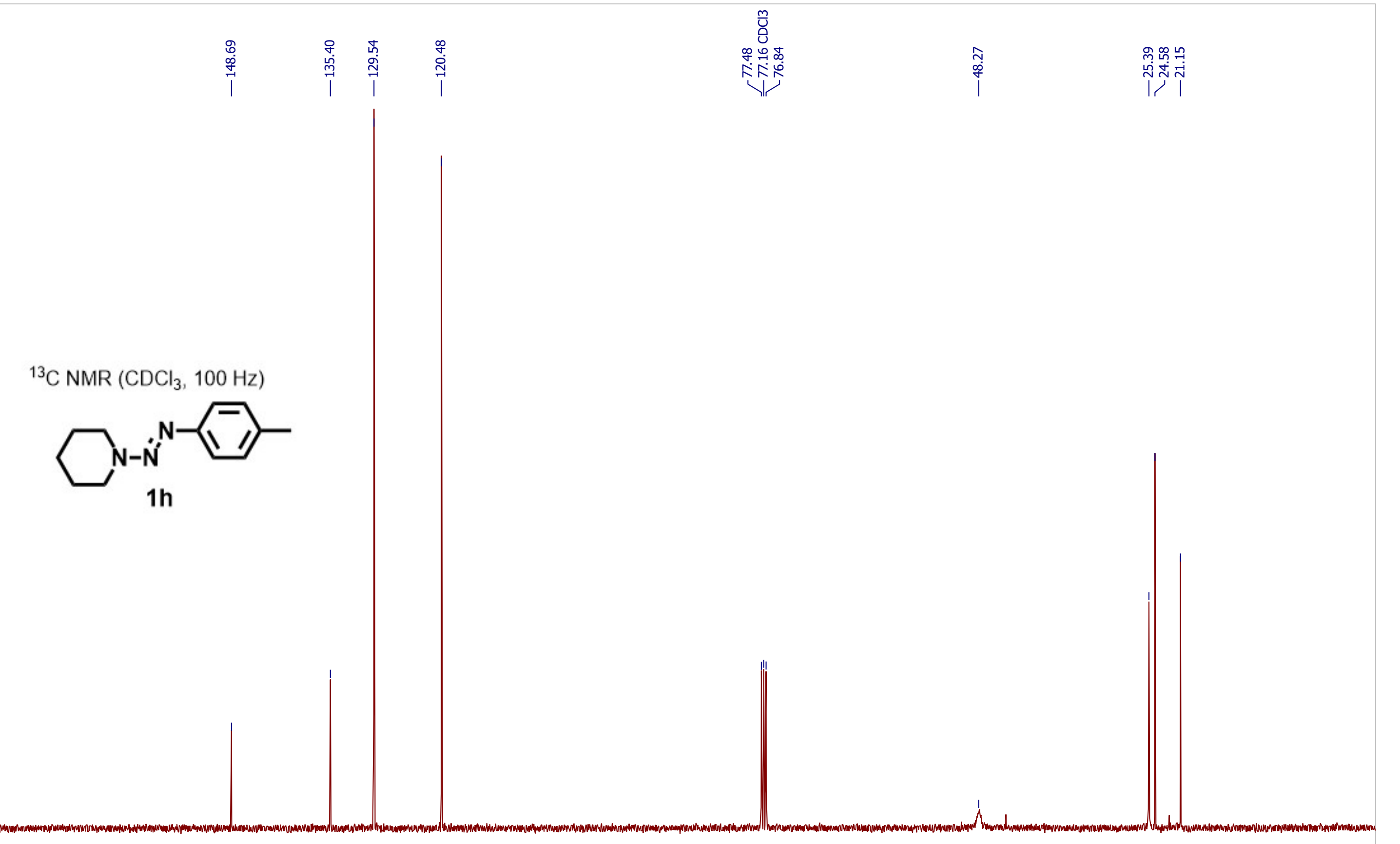

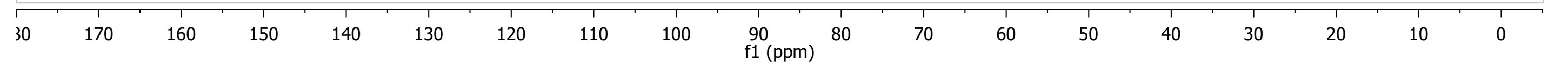


${ }^{1} \mathrm{H} \mathrm{NMR}\left(\mathrm{CDCl}_{3}, 400 \mathrm{~Hz}\right)$<smiles>COc1ccc(N=NN2CCCCC2)cc1</smiles>
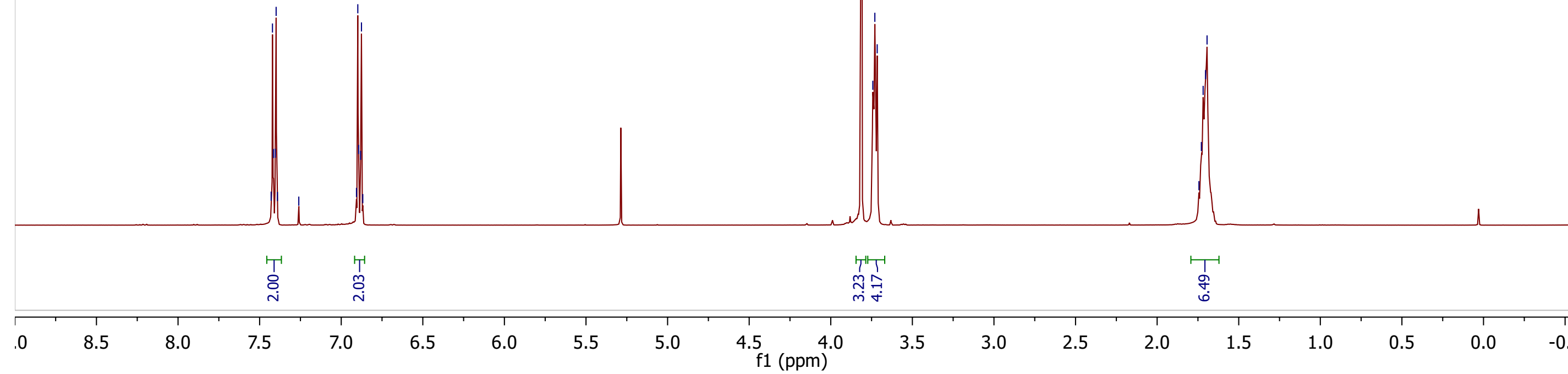


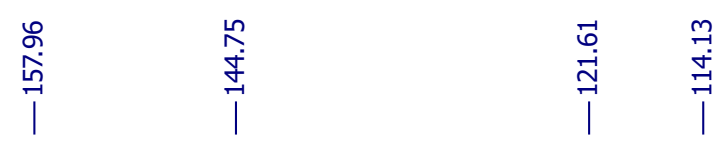

${ }^{13} \mathrm{C} \mathrm{NMR}\left(\mathrm{CDCl}_{3}, 100 \mathrm{~Hz}\right)$

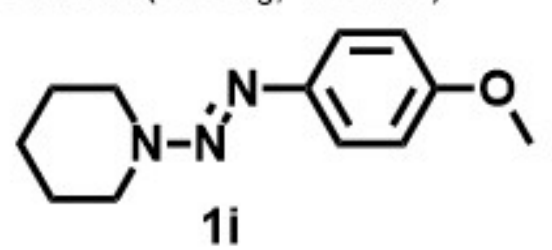

60



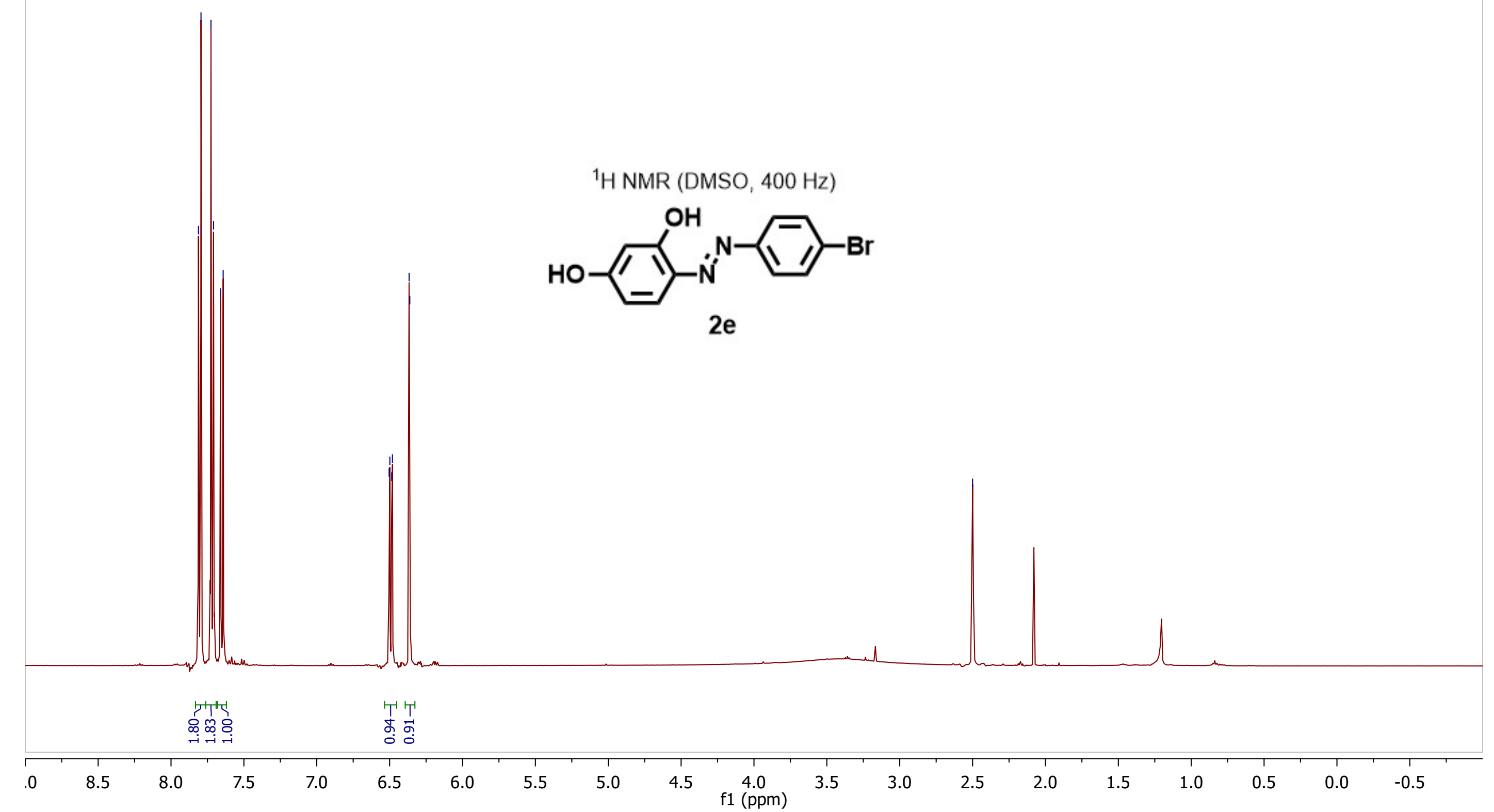


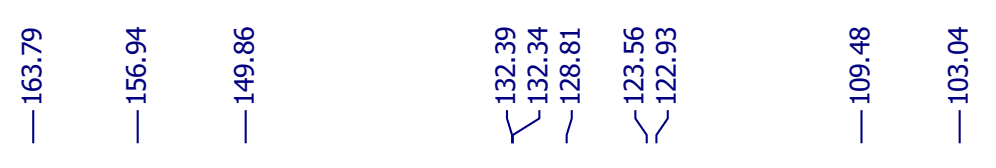

${ }^{13} \mathrm{C}$ NMR (DMSO, $100 \mathrm{~Hz}$ )<smiles>Oc1ccc(N=Nc2ccc(Br)cc2)c(O)c1</smiles>

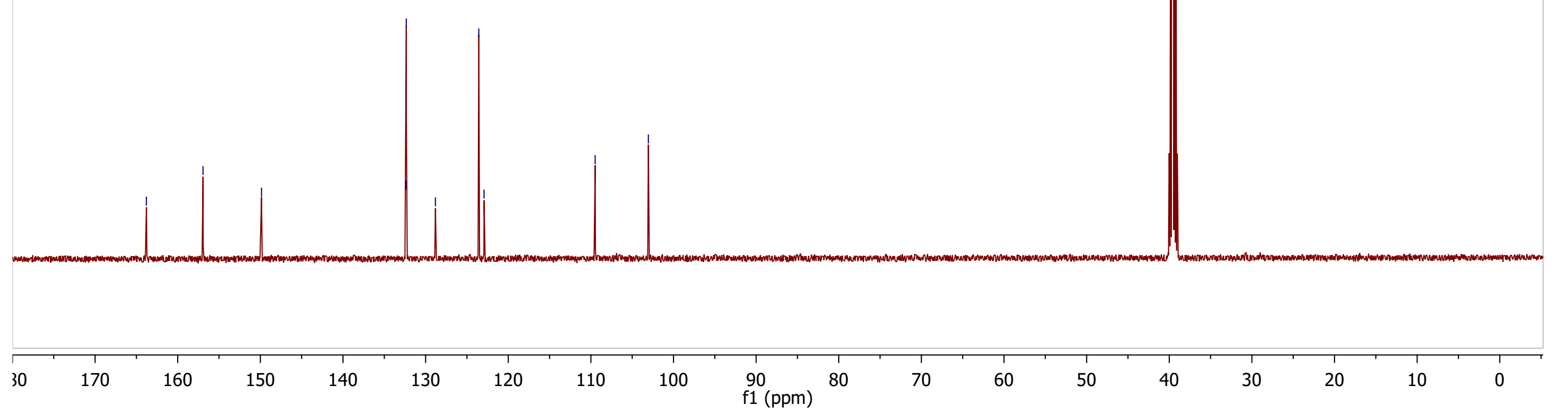


辛垶

|

${ }^{1} \mathrm{H}$ NMR (DMSO, $400 \mathrm{~Hz}$ )
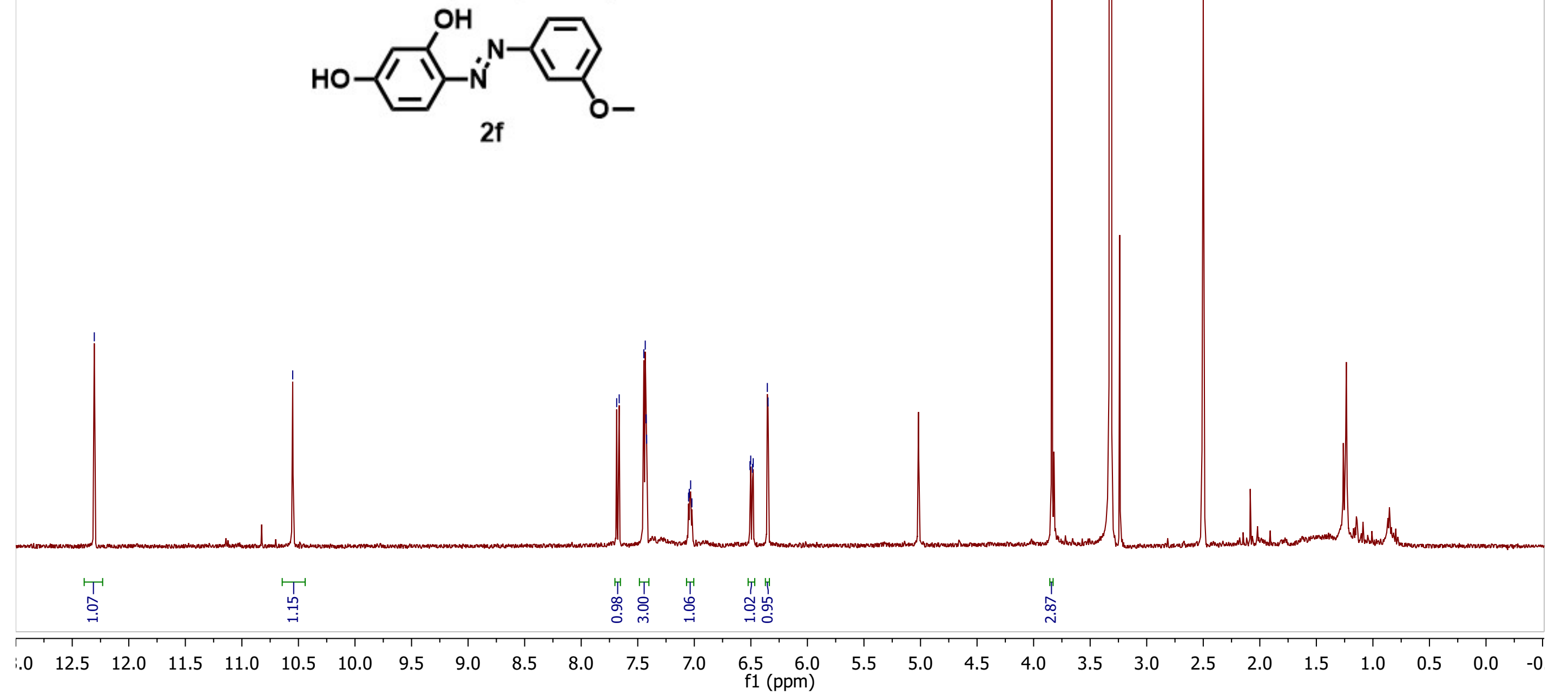


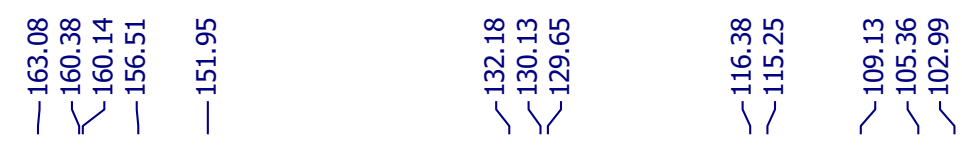

${ }^{13} \mathrm{C}$ NMR (DMSO, $100 \mathrm{~Hz}$ )

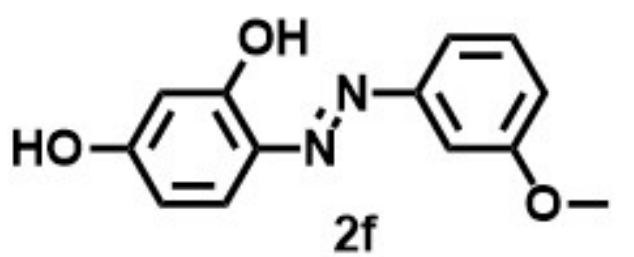




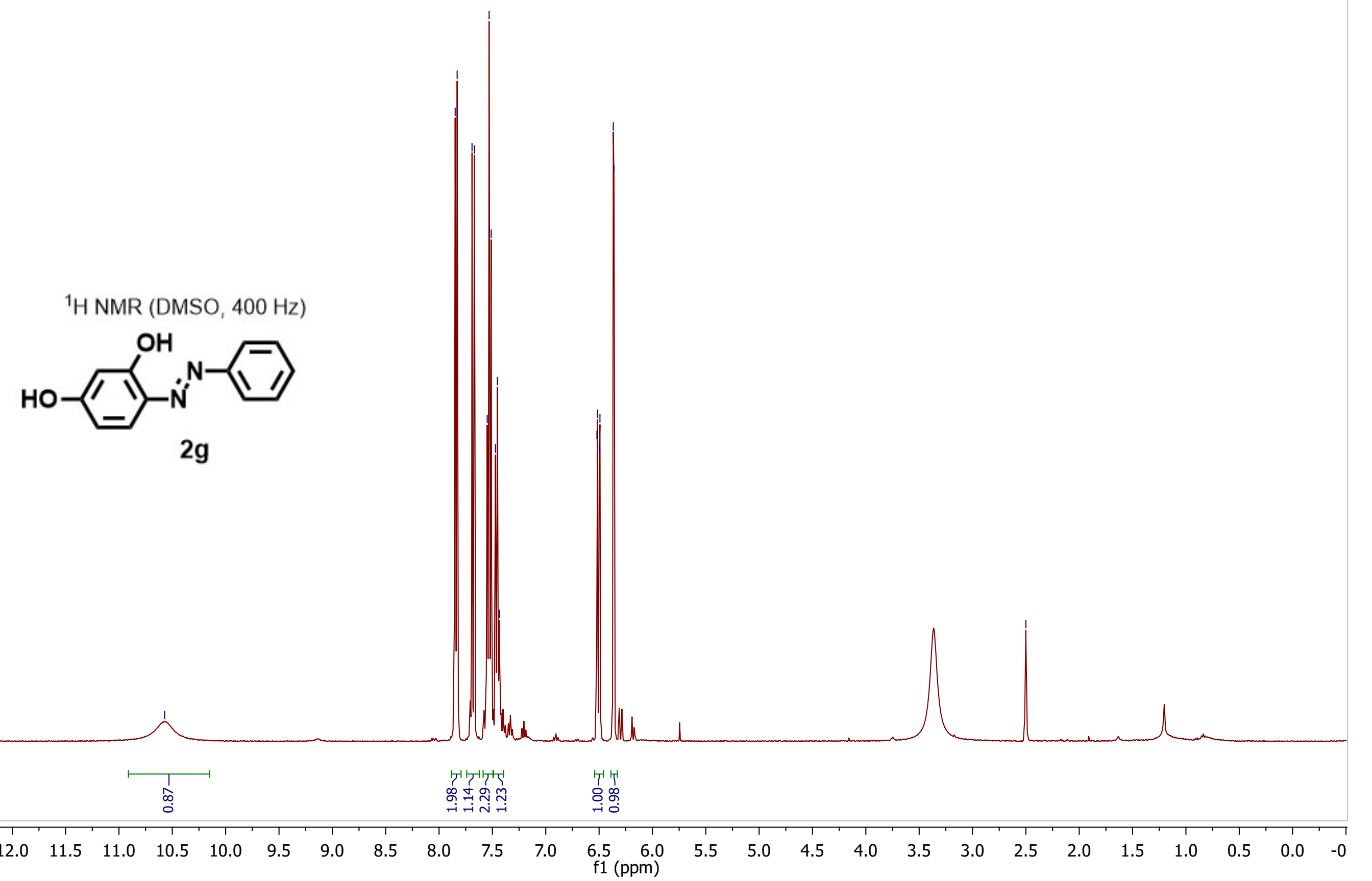




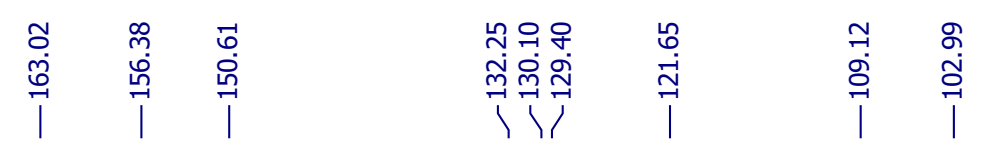

${ }^{13} \mathrm{C}$ NMR (DMSO, $100 \mathrm{~Hz}$ )<smiles>Oc1ccc(N=Nc2ccccc2)c(O)c1</smiles> 
${ }^{13} \mathrm{C}$ NMR (DMSO, $\left.100 \mathrm{~Hz}\right)$<smiles>Cc1ccc(/N=N/c2ccc(O)cc2O)cc1</smiles>

100

90

80

70

$60 \quad 50$


${ }^{1} \mathrm{H} \mathrm{NMR}\left(\mathrm{CDCl}_{3}, 400 \mathrm{~Hz}\right)$

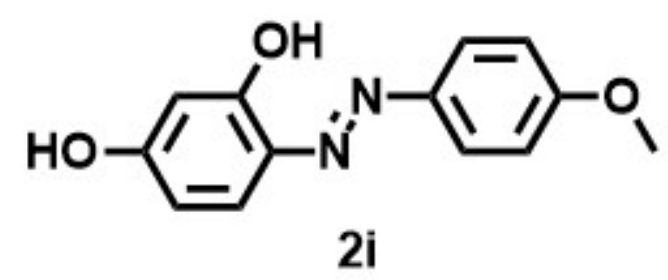

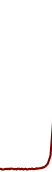
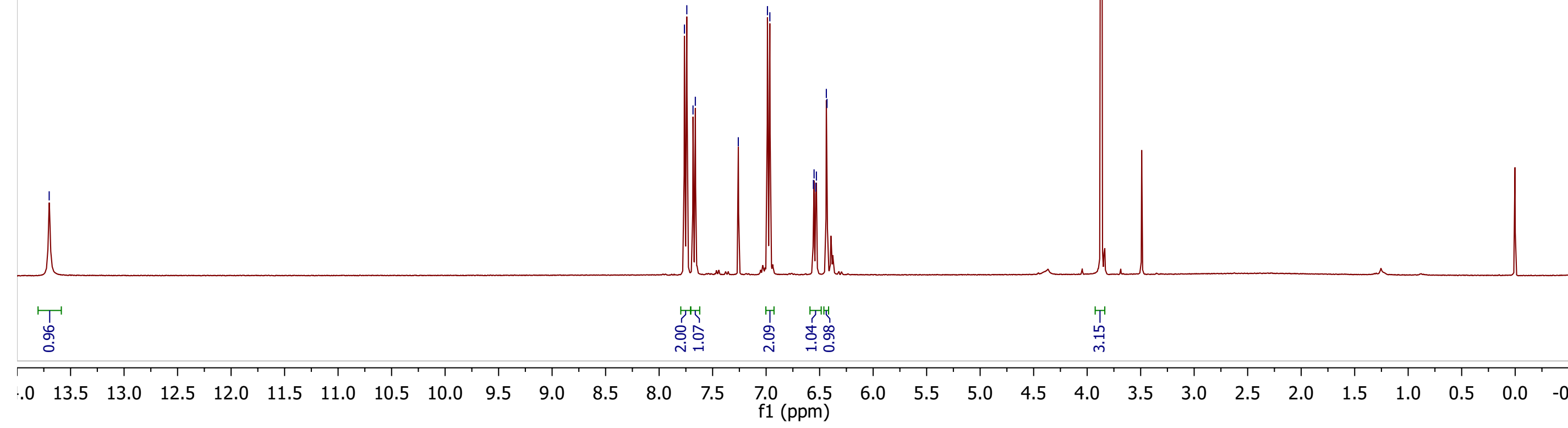


\begin{tabular}{|c|c|c|c|c|c|}
\hline 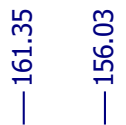 & 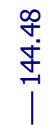 & 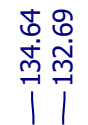 & 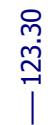 & 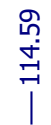 & $\begin{array}{l}\text { m } \\
\infty \\
\text { ò }\end{array}$ \\
\hline
\end{tabular}

${ }^{13} \mathrm{C} \mathrm{NMR}\left(\mathrm{CDCl}_{3}, 100 \mathrm{~Hz}\right)$<smiles>COc1ccc(/N=N/c2ccc(O)cc2O)cc1</smiles>

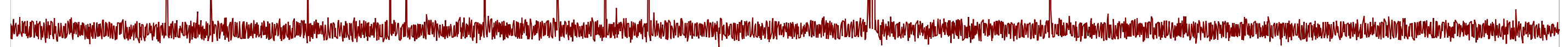

\begin{tabular}{|c|c|c|c|c|c|c|c|c|c|c|c|c|c|c|c|c|c|c|}
\hline 30 & 170 & 160 & 150 & 140 & 130 & 120 & 110 & 100 & $\begin{array}{l}90 \\
\mathrm{f} 1(\mathrm{ppm})\end{array}$ & 80 & 70 & 60 & 50 & 40 & 30 & 20 & 10 & 0 \\
\hline
\end{tabular}




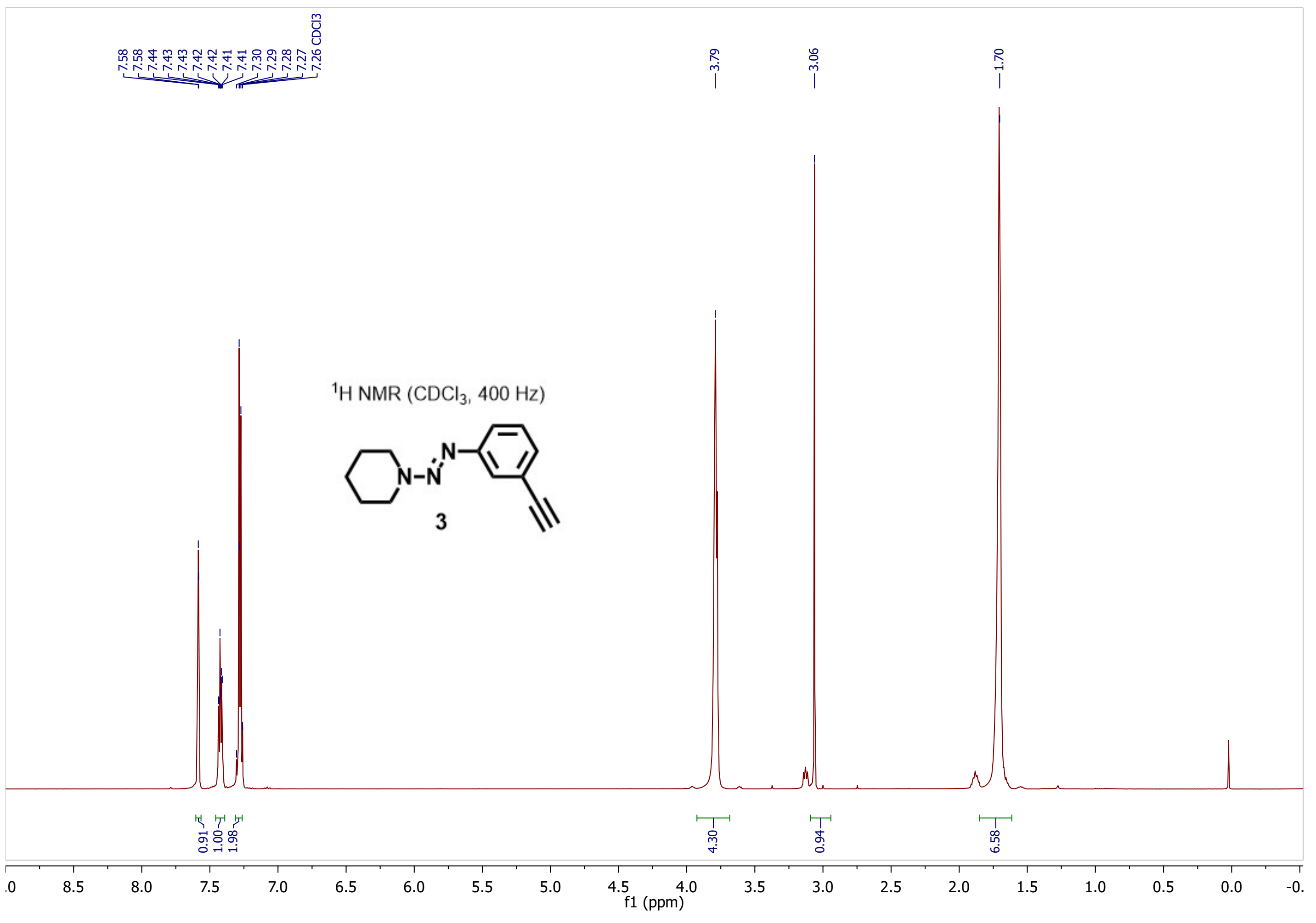




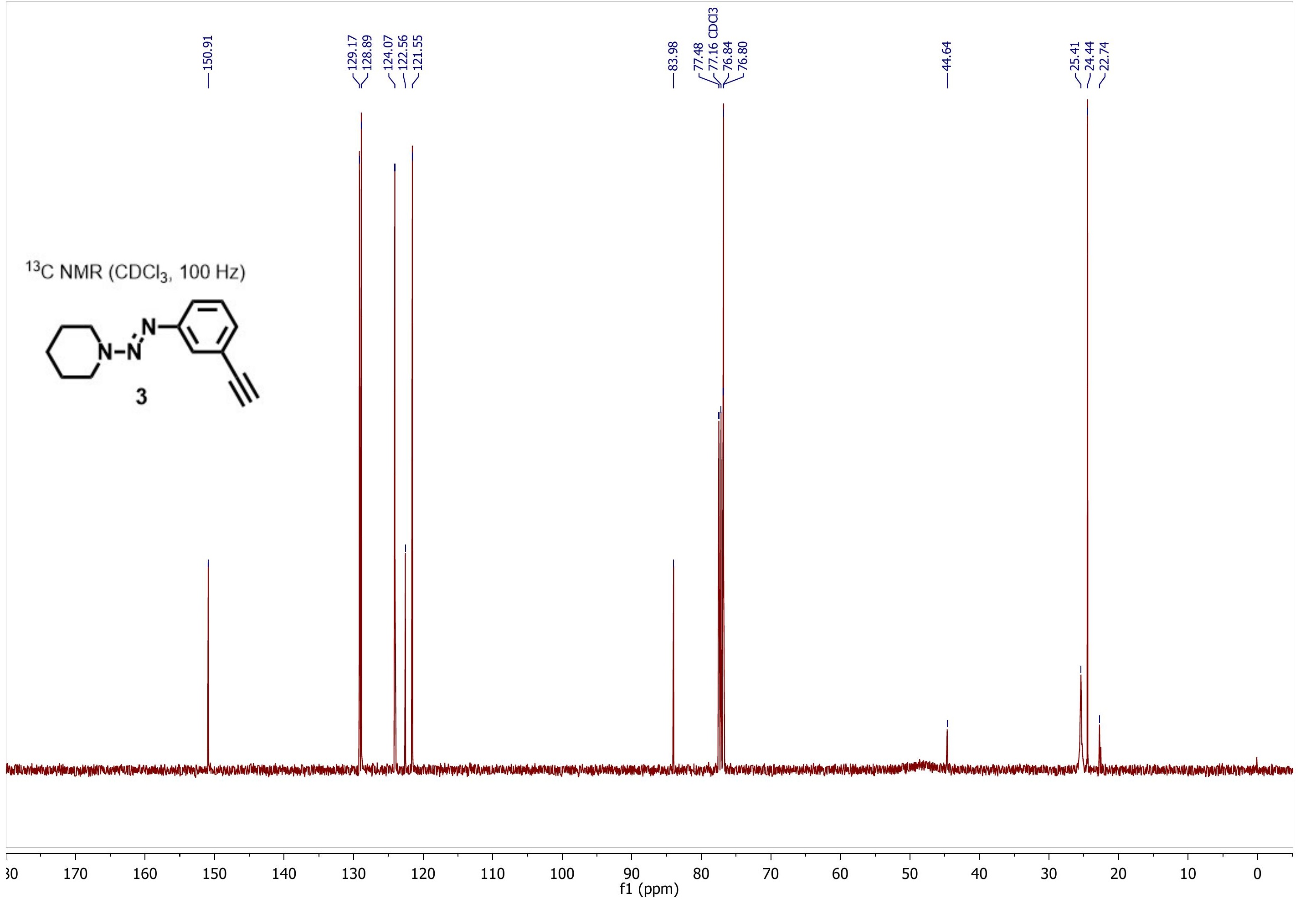



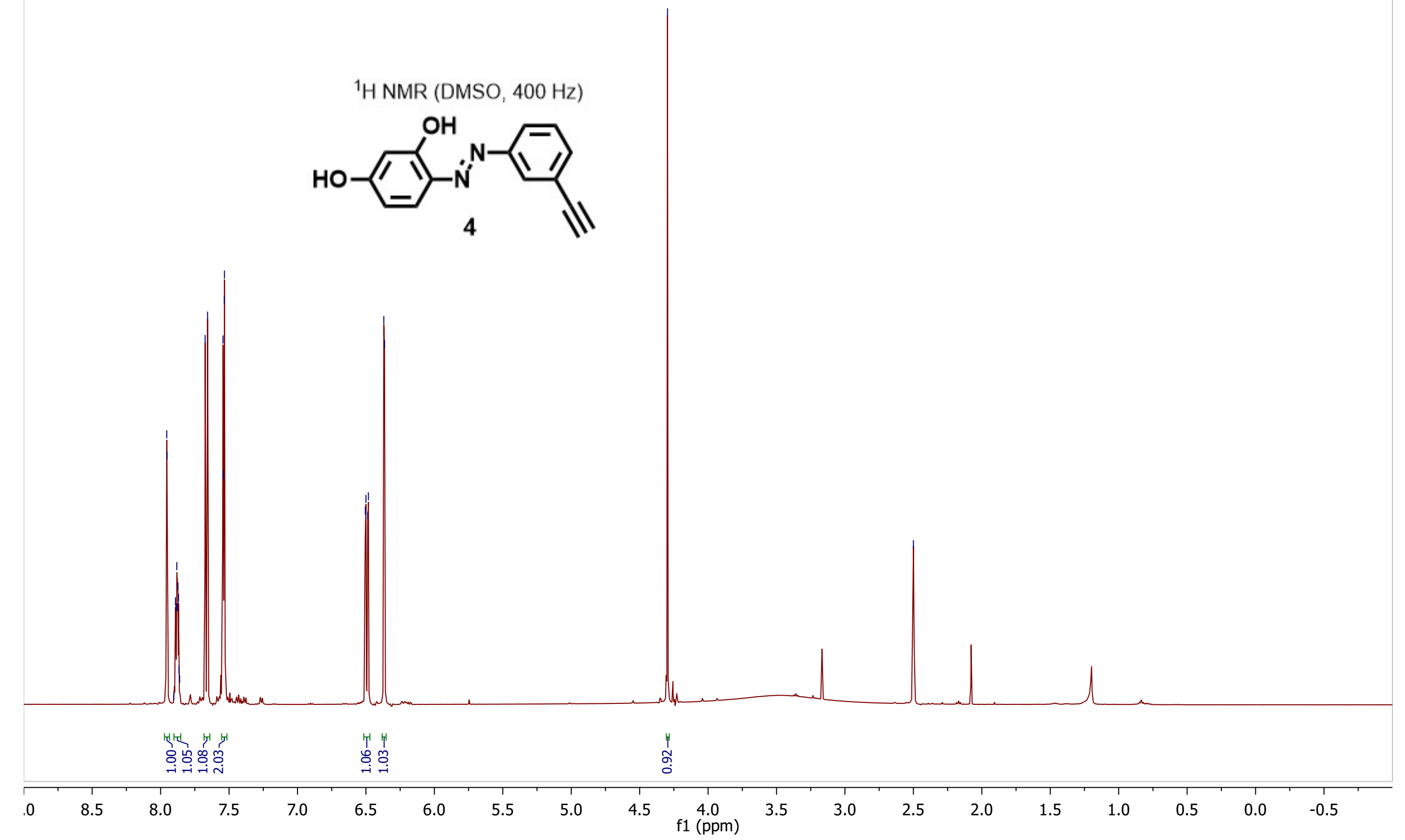


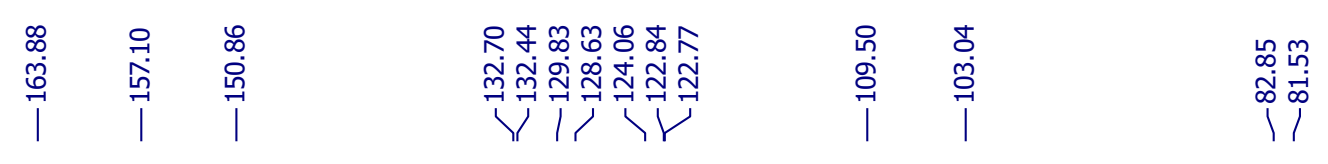

${ }^{13} \mathrm{C}$ NMR (DMSO, $100 \mathrm{~Hz}$ )
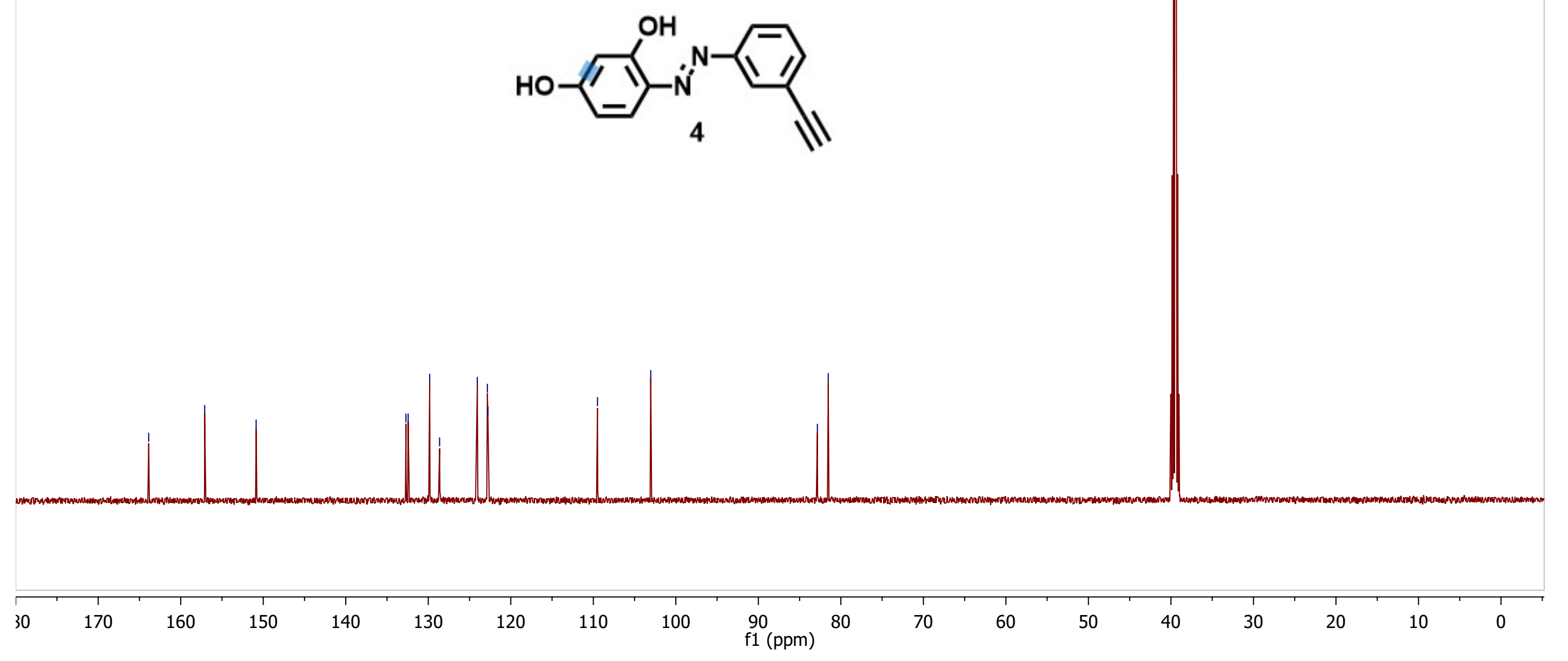
${ }^{1} \mathrm{H} \mathrm{NMR}\left(\mathrm{CDCl}_{3}, 400 \mathrm{~Hz}\right)$
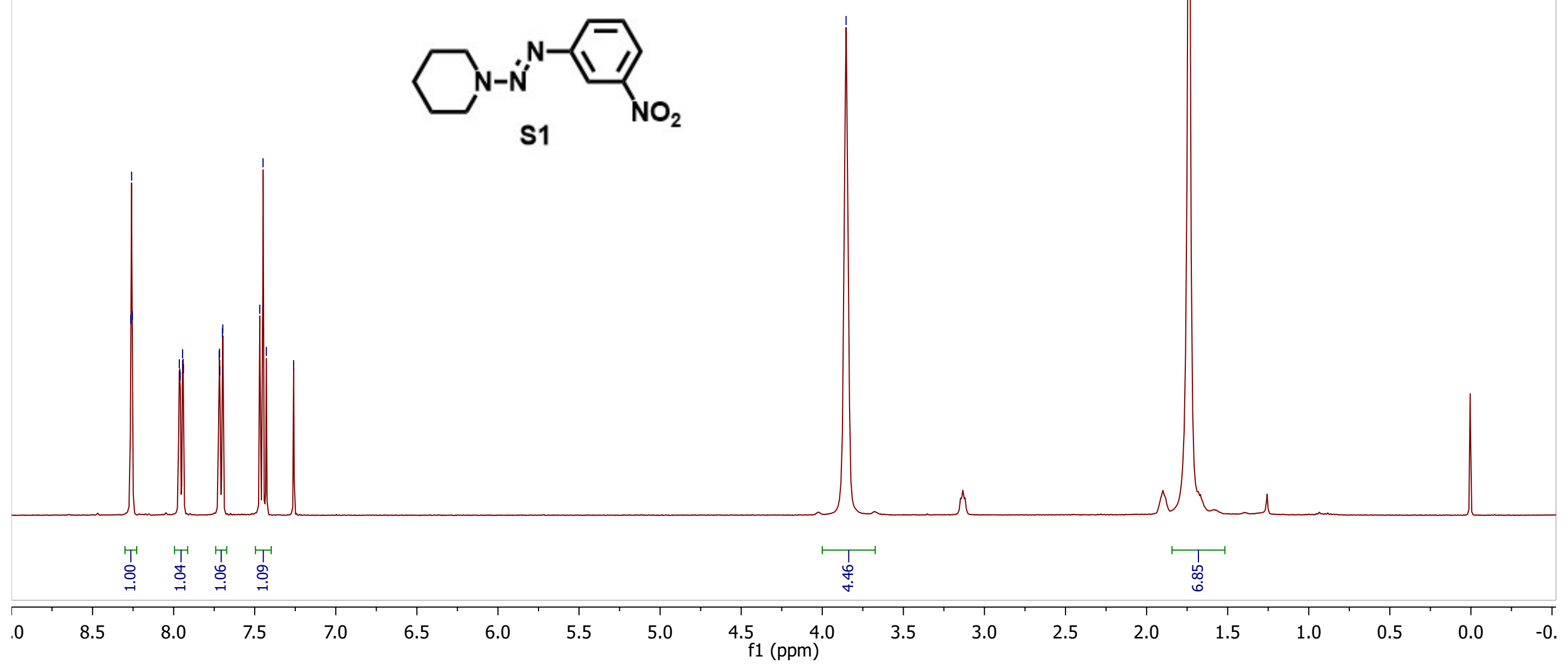


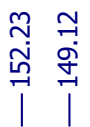
|

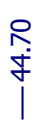

${ }^{13} \mathrm{C} \mathrm{NMR}\left(\mathrm{CDCl}_{3}, 100 \mathrm{~Hz}\right)$<smiles>O=[N+]([O-])c1cccc(/N=N/N2CCCCC2)c1</smiles>

s1

$$
\mathrm{O}_{2}
$$


${ }^{1} \mathrm{H} \mathrm{NMR}\left(\mathrm{CDCl}_{3}, 400 \mathrm{~Hz}\right)$
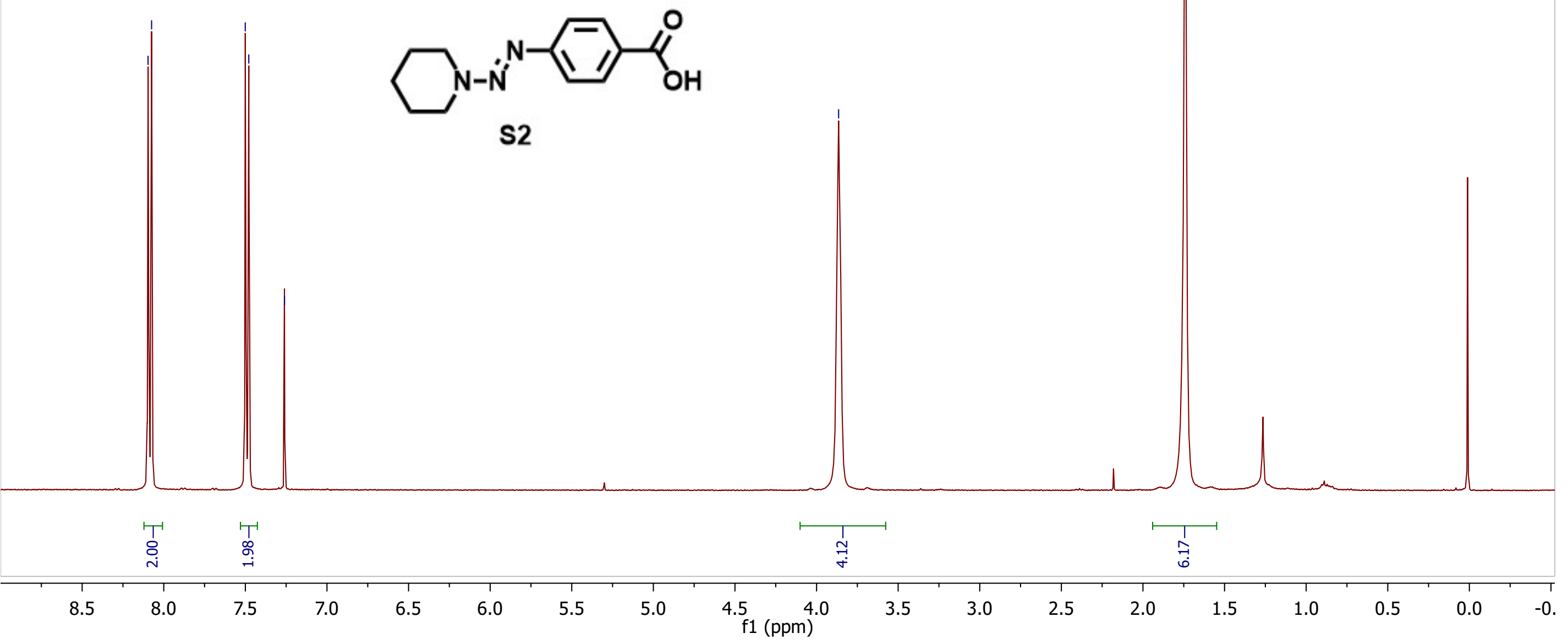
${ }^{13} \mathrm{C} \mathrm{NMR}\left(\mathrm{CDCl}_{3}, 100 \mathrm{~Hz}\right)$<smiles>O=C(O)c1ccc(N=NN2CCCCC2)cc1</smiles>

|

\begin{tabular}{|c|c|c|c|c|c|c|c|c|c|c|c|c|c|c|c|c|c|c|}
\hline 30 & 170 & 160 & 150 & 140 & 130 & 120 & 110 & 100 & $\begin{array}{l}90 \\
\mathrm{f} 1(\mathrm{ppm})\end{array}$ & 80 & 70 & 60 & 50 & 40 & 30 & 20 & 10 & 0 \\
\hline
\end{tabular}




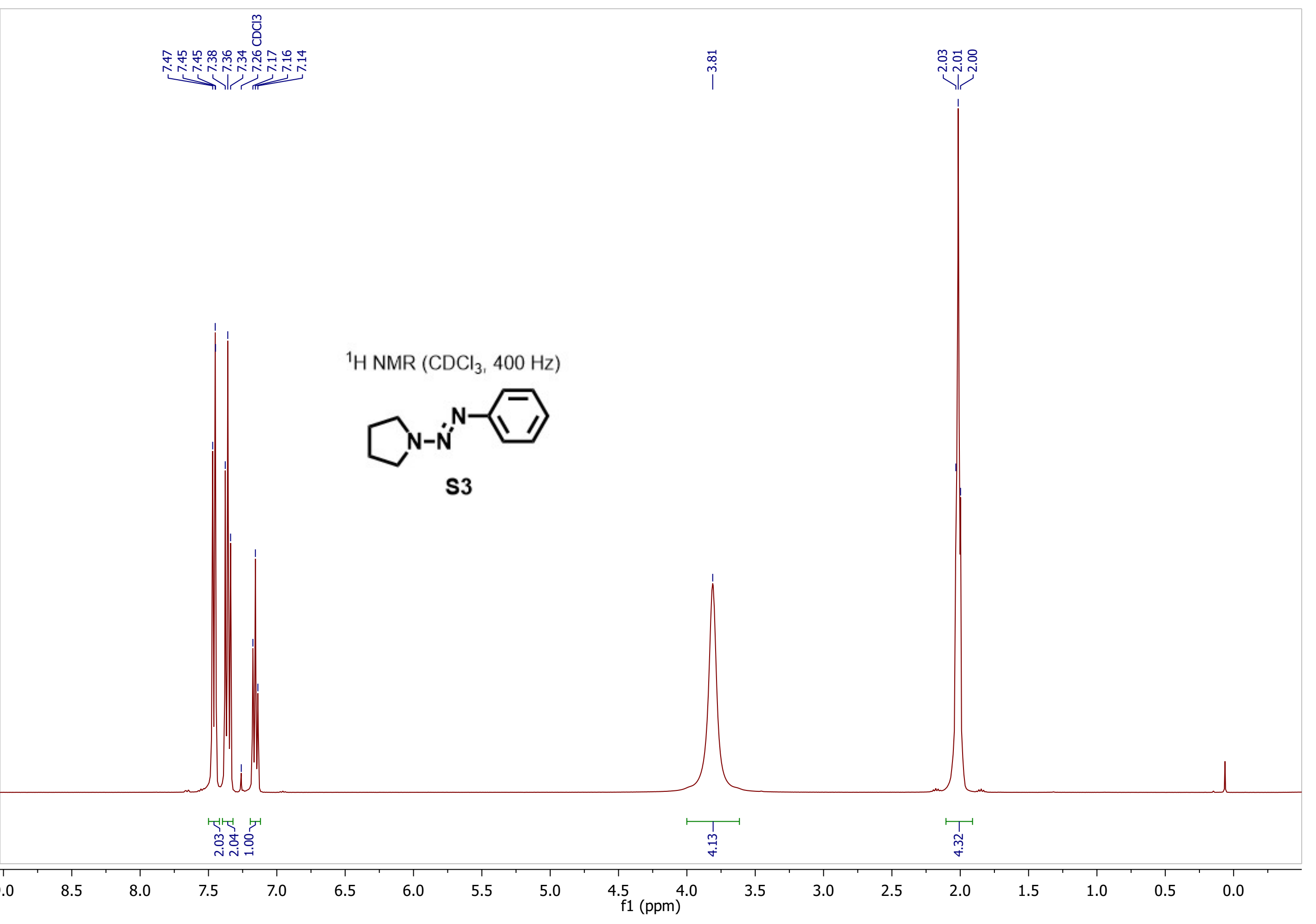




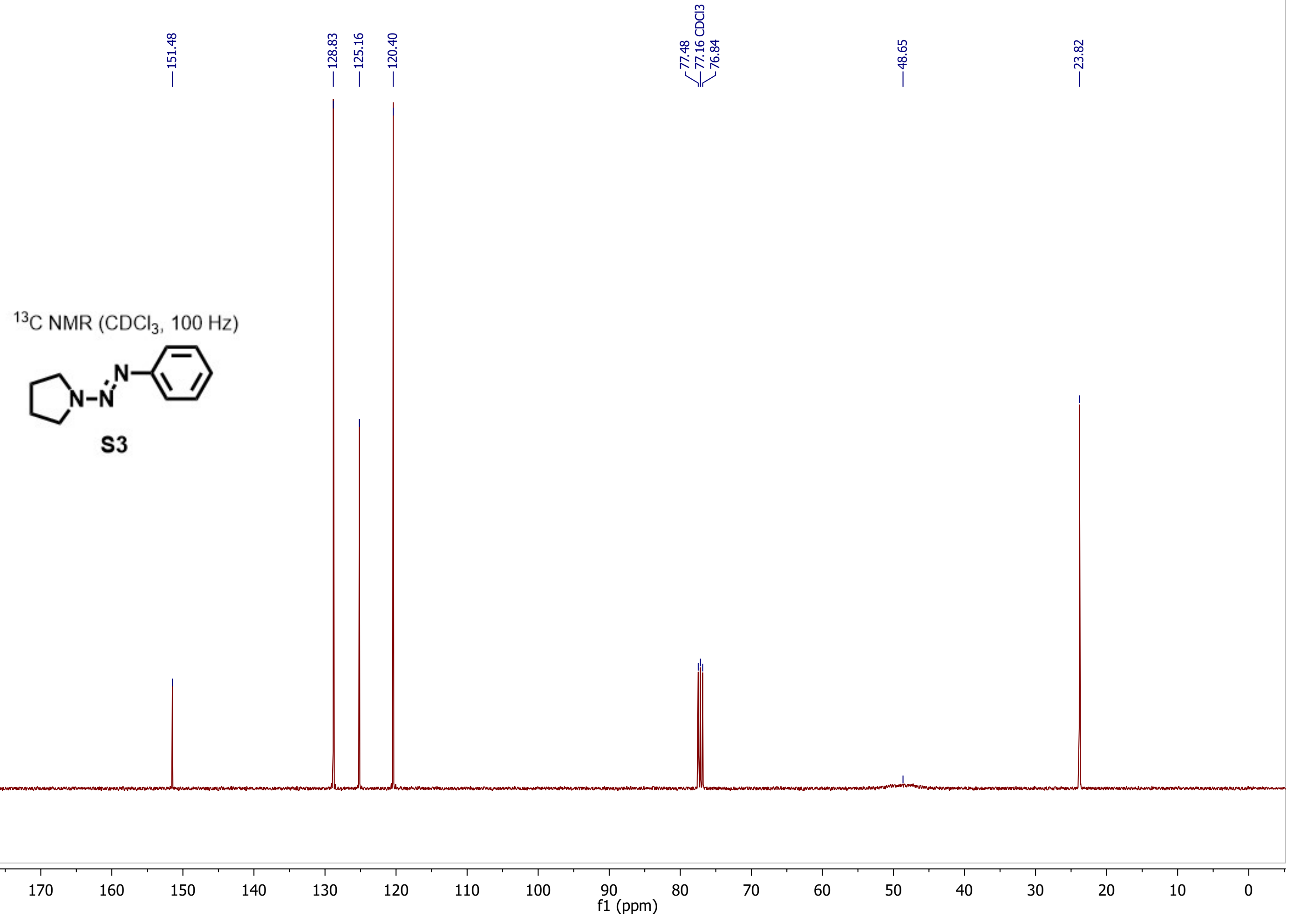


${ }^{1} \mathrm{H} \mathrm{NMR}\left(\mathrm{CDCl}_{3}, 400 \mathrm{~Hz}\right)$
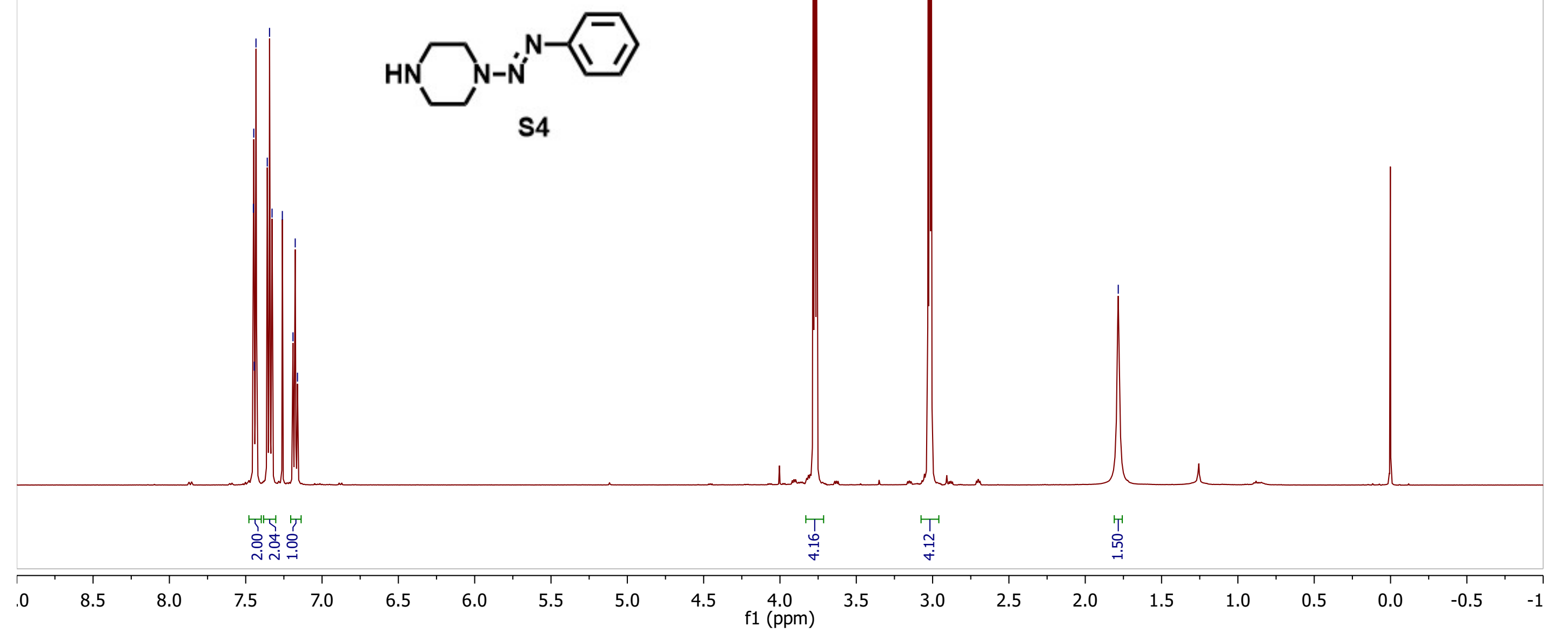


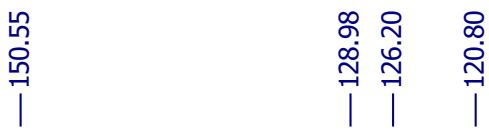

范

궁웃형

솟ㅇำ

๓

+

${ }^{13} \mathrm{C} \mathrm{NMR}\left(\mathrm{CDCl}_{3}, 100 \mathrm{~Hz}\right)$

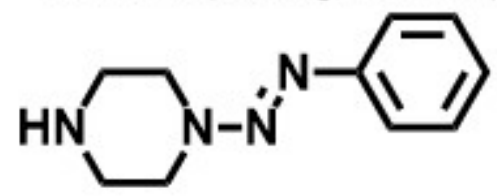

S4

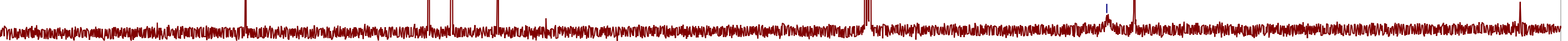


${ }^{1} \mathrm{H} \mathrm{NMR}\left(\mathrm{CDCl}_{3}, 400 \mathrm{~Hz}\right)$
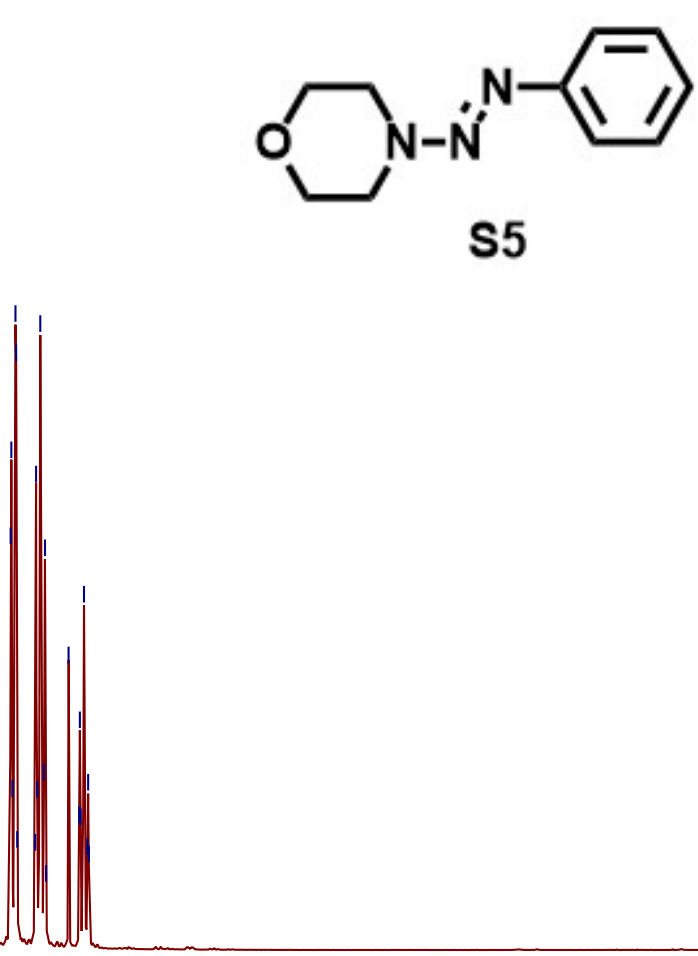

lnt

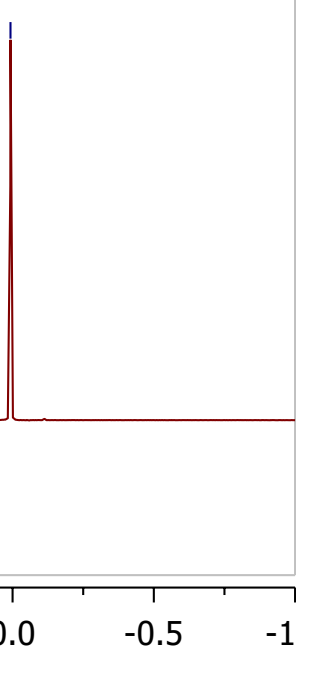




|

${ }^{13} \mathrm{C} \mathrm{NMR}\left(\mathrm{CDCl}_{3}, 100 \mathrm{~Hz}\right)$<smiles>c1ccc(N=NN2CCOCC2)cc1</smiles>

s5 


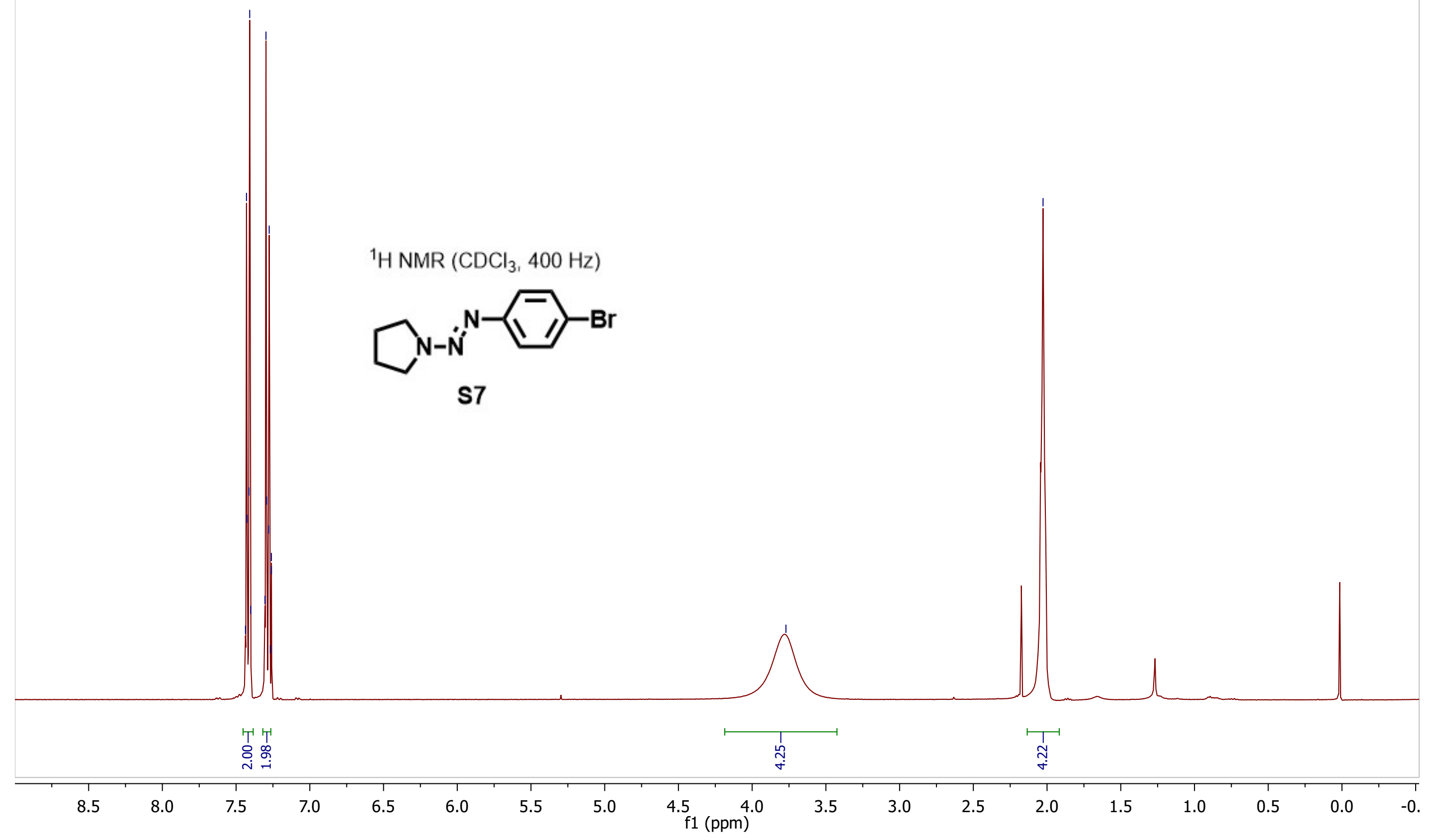




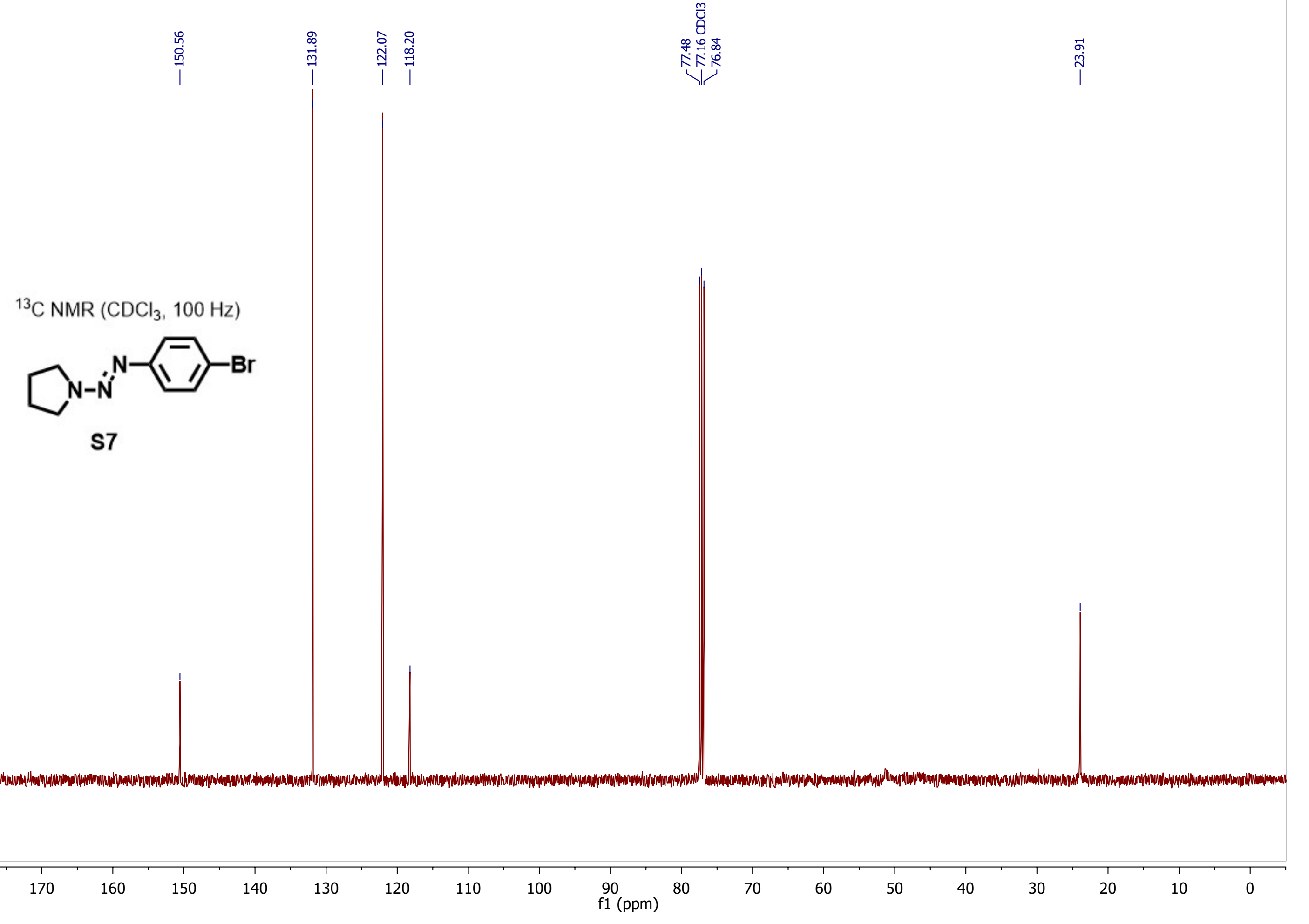



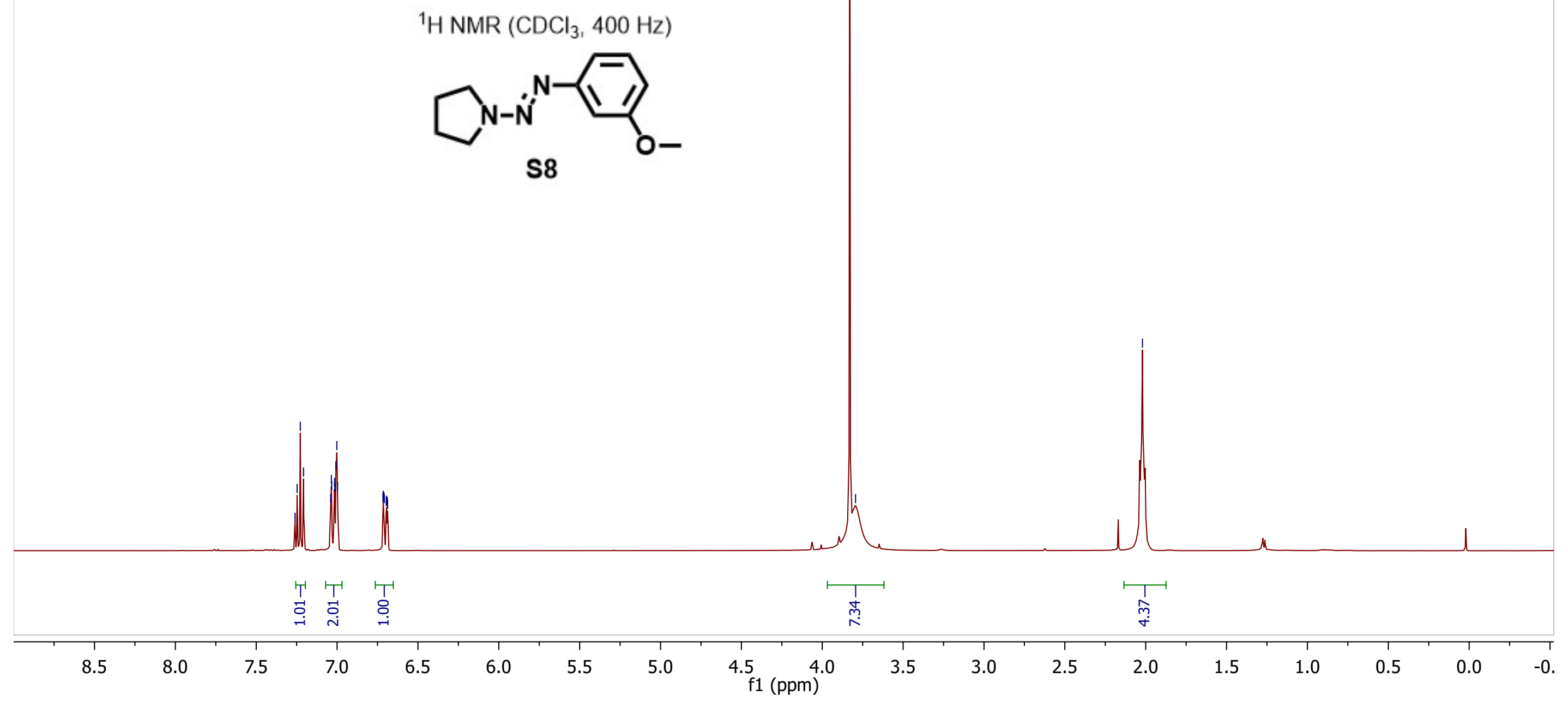


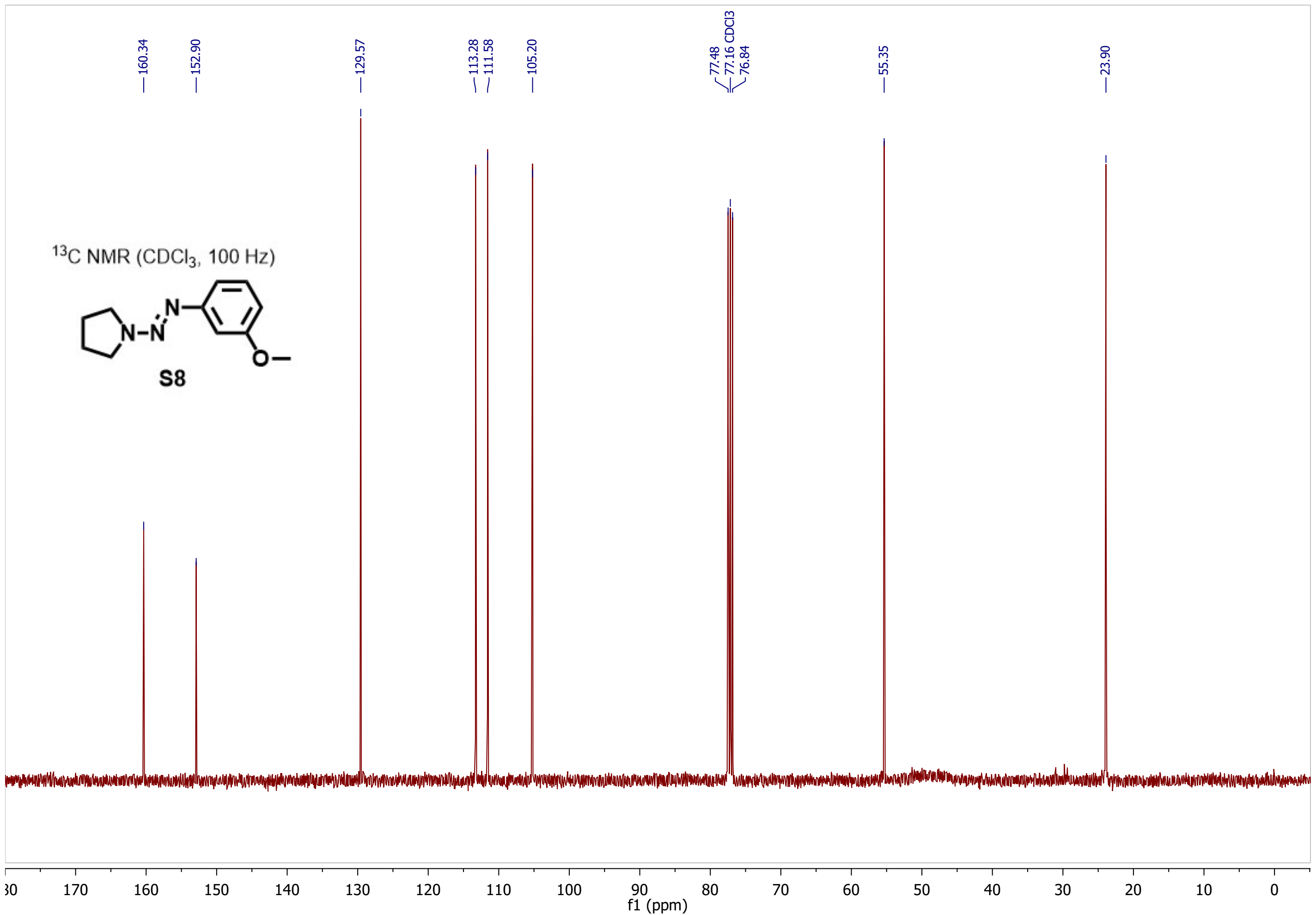




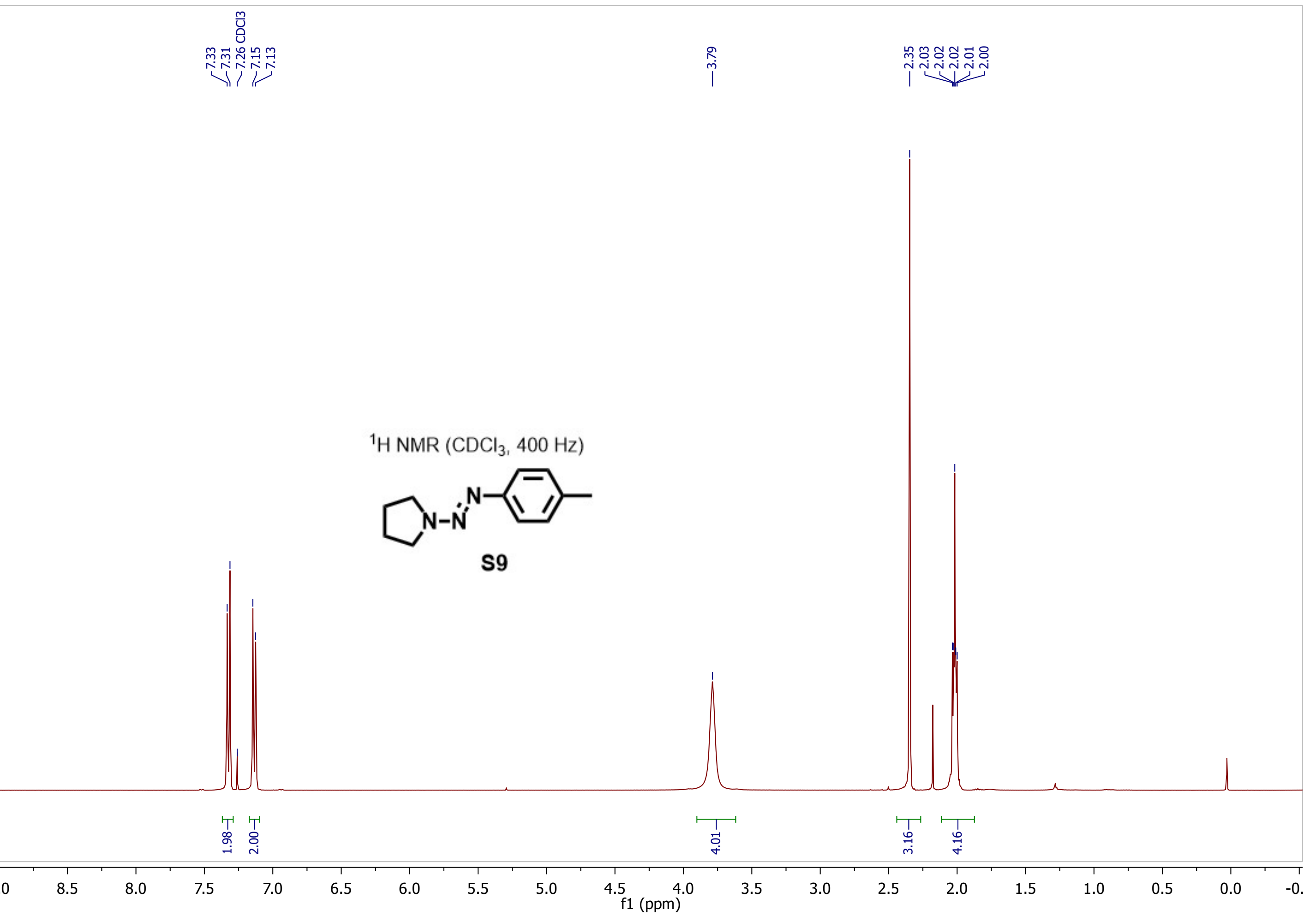


${ }^{13} \mathrm{C} \mathrm{NMR}\left(\mathrm{CDCl}_{3}, 100 \mathrm{~Hz}\right)$<smiles></smiles> 


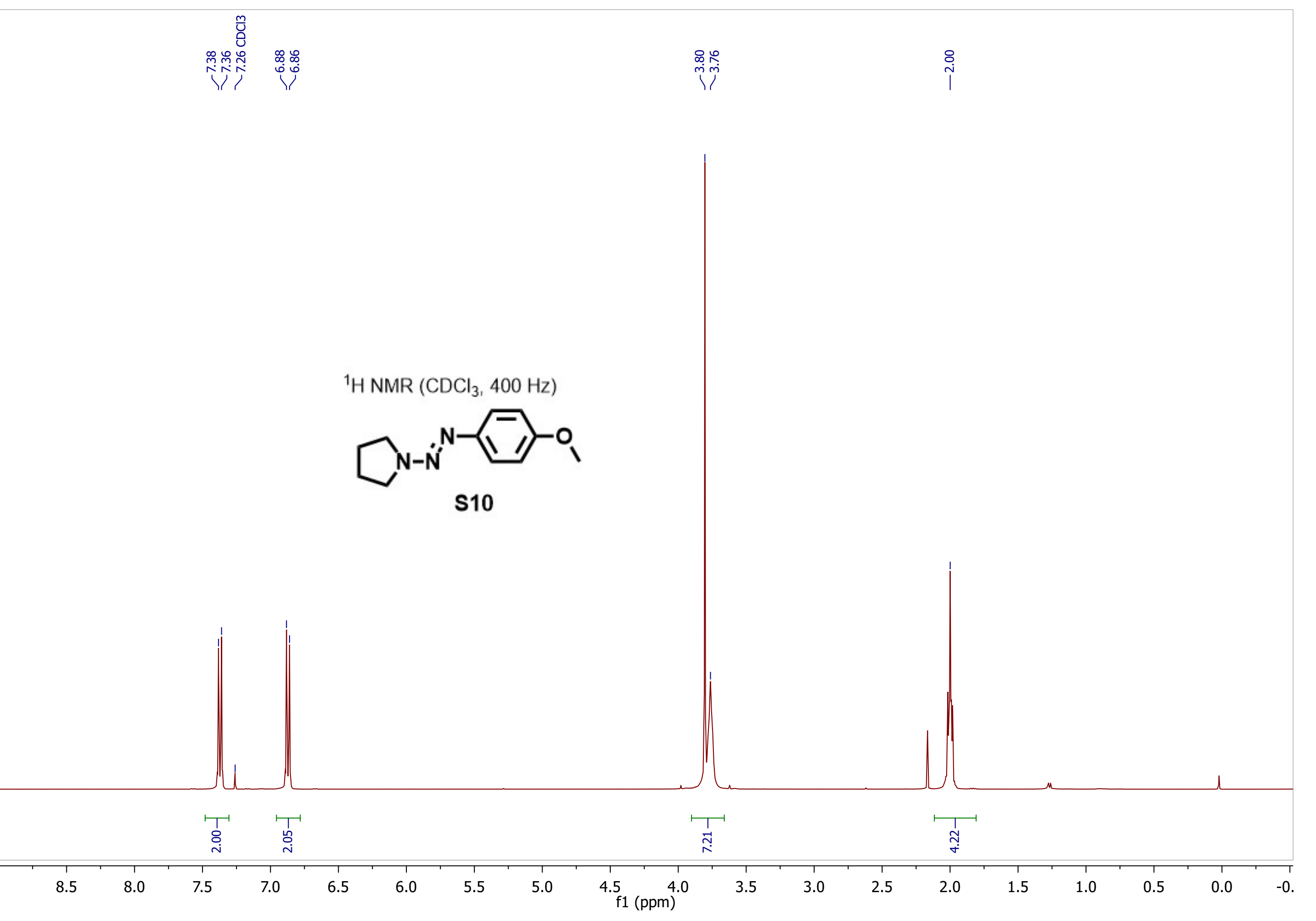




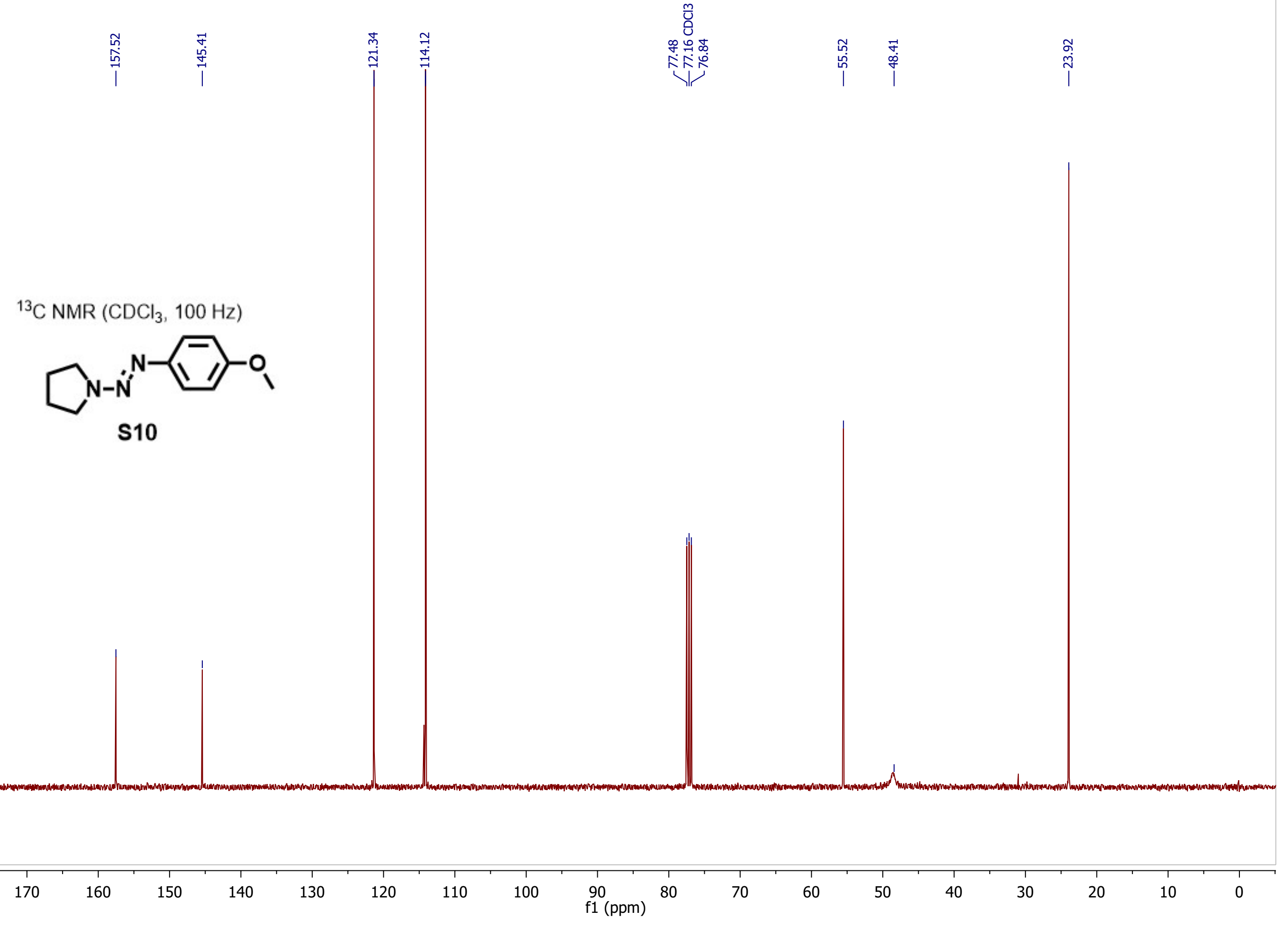

